\title{
Effect of thrombopoietin receptor agonists on coagulation and fibrinolysis in patients with immune thrombocytopenia
}

Thesis for the degree of Philosophiae Doctor (PhD)

by

Lamya Garabet, MD

2021

Centre for Laboratory Medicine

Østfold Hospital Trust

Multidisciplinary Laboratory Medicine and Medical Biochemistry

Akershus University Hospital

Institute of Clinical Medicine

University of Oslo 
(C) Lamya Garabet, 2021

Series of dissertations submitted to the Faculty of Medicine, University of Oslo

ISBN 978-82-8377-876-2

All rights reserved. No part of this publication may be reproduced or transmitted, in any form or by any means, without permission.

Cover: Hanne Baadsgaard Utigard.

Print production: Reprosentralen, University of Oslo. 


\section{Table of content}

ACKNOWLEDGEMENTS

$\begin{array}{ll}\text { ABBREVIATIONS } & 7\end{array}$

THESIS SUMMARY

$\begin{array}{lr}\text { ARTICLES IN THE THESIS } & 11\end{array}$

$\begin{array}{lr}\text { INTRODUCTION } & 13\end{array}$

$\begin{array}{ll}\text { THE HAEMOSTATIC SYSTEM } & 13\end{array}$

THE ROLE OF CELLS IN HAEMOSTASIS/THROMBOSIS $\quad 20$

$\begin{array}{lr}\text { Platelets } & 21 \\ \end{array}$

$\begin{array}{lr}\text { Endothelial cells } & 22\end{array}$

$\begin{array}{lr}\text { Neutrophils } & 22\end{array}$

$\begin{array}{lr}\text { Monocytes } & 24\end{array}$

$\begin{array}{lr}\text { OTHER PLAYERS IN HAEMOSTASIS/THROMBOSIS } & 24\end{array}$

$\begin{array}{lr}\text { Microvesicles } & 24\end{array}$

$\begin{array}{lr}\text { Endothelial adhesion molecules and thrombomodulin } & 27\end{array}$

$\begin{array}{ll}\text { The selectins } & 28\end{array}$

$\begin{array}{lr}\text { Plasminogen activator inhibitor-1 (PAI-1) } & 29\end{array}$

$\begin{array}{lr}\text { ASSESSMENT OF THE COAGULATION PROCESS AND THE PROCOAGULANT PHENOTYPE } & 29\end{array}$

$\begin{array}{lr}\text { IMMUNE THROMBOCYTOPENIA (ITP) } & 30\end{array}$

$\begin{array}{lr}\text { THROMBOSIS IN ITP } & 33\end{array}$

THROMBOPOIETIN RECEPTOR AGONISTS AND THROMBOSIS $\quad 33$

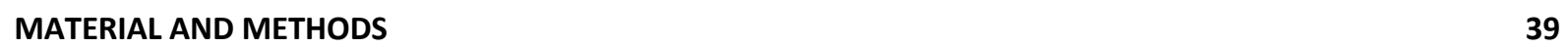

$\begin{array}{lr}\text { STUDY DESIGN AND STUDY POPULATION } & 39\end{array}$

$\begin{array}{lr}\text { BLOOD SAMPLING AND PREPARATION } & 39\end{array}$

$\begin{array}{lr}\text { REGULATORY APPROVALS } & 40\end{array}$

$\begin{array}{lr}\text { ASSAYS USED IN THE STUDY } & 40\end{array}$

$\begin{array}{lr}\text { STATISTICAL ANALYSIS } & 46\end{array}$

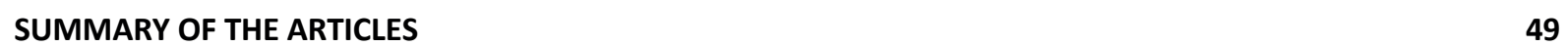

$\begin{array}{ll}\text { DISCUSSION } & 53\end{array}$

$\begin{array}{lr}\text { METHOdOLOGICAL CONSIDERATIONS } & 54\end{array}$

$\begin{array}{lr}\text { STUDY POPULATION } & 54\end{array}$

Timing of blood sampling $\quad 56$

$\begin{array}{lr}\text { Study sample size } & 57\end{array}$

$\begin{array}{lr}\text { Pre-analytical conditions } & 57\end{array}$

$\begin{array}{ll}\text { Choice and limitations of coagulation tests } & 58\end{array}$

$\begin{array}{lr}\text { Statistical methods } & 59\end{array}$

$\begin{array}{lr}\text { DISCUSSION OF THE MAIN FINDINGS } & 60\end{array}$

CONCLUSION AND FUTURE PERSPECTIVES
71

$\begin{array}{ll}\text { CONCLUSIONS } & 71\end{array}$

$\begin{array}{ll}\text { FUTURE PERSPECTIVES } & 73\end{array}$

$\begin{array}{lr}\text { REFERENCES } & 75\end{array}$

\begin{tabular}{l} 
ORIGINAL ARTICLES \\
\hline 2
\end{tabular} 


\section{Acknowledgements}

This work presented in this thesis would not have been accomplished without the unstinting support, advice and encouragement of my supervisors, co-authors, colleagues and family, whom I would like to recognize.

First, I would like to thank my main supervisor, Professor Per Morten Sandset, for introducing me to research and the field of coagulation. His scientific knowledge has impressed me profoundly. He has guided me through this work, ensuring good research quality and continuous progress. I am also very grateful to Professor Christine Jonassen at the Centre of Laboratory Medicine, Østfold Hospital Trust. She has been a supportive, caring and encouraging co-supervisor, giving me scientific advice and comfort when needed.

I want to extend my appreciation to Østfold Hospital Trust for giving me financial support. I would like to express my gratitude to the Department of Research for giving me the opportunity to perform this project, Jonas Bergan, Magnus K. Olsen and Andreas Rekvin for their technical assistance whenever needed, Heidi Hassel Pettersen and Christina Roaldsnes for their help with organizing the data, and Eli Førsund for following up the patients. I would like to express my deepest gratitude to Professor James Bussel at Weill Cornell, New York, and Professor Waleed Ghanima at the Department of Research, Østfold Hospital Trust, both of whom have generously and kindly allowed me to use their valuable blood samples in my research, providing me with knowledge and guiding me through the whole course of this project.

I would like to thank my co-author Carola Henriksson at the Department of Clinical Biochemistry, OUS, for her important contribution in the design of article II and for sharing her knowledge in the field of coagulation. Her thorough and critical revisions of my manuscripts were indispensable. I want to convey my sincere gratitude to all the remaining co-authors of the articles in this thesis: René Holst, for his support in statistical methodology; Maria Luisa Lozano, for always being supportive, giving valuable comments and the analysis of NETs at their laboratory in Spain, together with Constantino Martínez and Rocío González-Conejero; and Ellen Brodin and Hoa Tran, for their valuable help in including patients from Akershus University Hospital (Ahus) in the study.

I am very grateful to Åse-Berit Mathisen at the Centre of Laboratory Medicine for her assistance in collecting the blood samples, doing the necessary arrangements needed to perform the analysis, and recruiting controls and to Heidi Strand for collecting the samples at Ahus. I would like to thank Marit Hellum at the Department of Clinical Biochemistry, OUS, for performing the assays in article II, showing me how to perform the thrombin generation assay with different 
approaches and valuable discussions. I have learned a lot from you. I also want to thank MarieChristine Mowinckel at the Research Institute of Internal Medicine for performing tests in article I and ELISA tests in article III. She has impressed me with her dedication in organizing the samples and being extremely accurate in performing the laboratory analysis. I want to thank the patients and controls for their participation and kind donation of blood samples to this project; and Ellen Tenstad at Science Shaped for her help with some of the figures.

I want to extend my gratitude to my leaders Anne Palacious and Heidi Kjøniksen at Østfold Hospital and Kariann Vangen Frøystein at Ahus, and to all my colleagues at the Department of Multidisciplinary Laboratory Medicine and Medical Biochemistry, Ahus Gunnhild Kravdal, Ingrid Hardang, Eric Dizerens, Linn Austdal, Cindhya Sithiravel and Ragnhild Røysland, as they have been supportive, showing understanding and flexibility. Tor-Arne Hagve, you have impressed me with your scientific knowledge and enthusiasm for research.

My biggest thank you goes to my wonderful family. I am deeply grateful to my mother, Layla, for her unconditional love, kindness, and support and for always being there for me, and to my father Samir, who encouraged scientific endeavours. He passed away before this work was started but I am sure that he would have been proud of me if he were with us. I am grateful to my precious, wonderful sons Josef and André, for their love, care and encouragement. You mean the world to me, and your presence in my life makes the hard work worthwhile. You are both simply my pride and my joy. Finally, to my husband, Waleed, words cannot express my gratitude. I can only say thank you for it all. This is for you! 


\section{Abbreviations}

a

ADP

APA

APC

APTT

AT

CAT

CTI

EDTA

ELISA

ETP

EVs

$\mathrm{F}$

$\mathrm{F}_{1+2}$

FDF

FCM

GP

HK

ICAM-1

IL

ITP

IVIg

MPs

MVs

NETs

PAI

PK

PLs

PNP

PPP

PRP

PS

ROTEM

PT

PSGL-1

TAFI

TEE

$\mathrm{TF}$

TFPI

TGA

Th

TM

TNF-alpha

tPA

TGA

TPO

TPO-RA

ttPeak

uPA
Activated

Adenosine diphosphate

Antiphospholipid antibody

Activated protein $\mathrm{C}$

Activated partial thromboplastin time

Antithrombin

Calibrated automated thrombogram

Corn trypsin inhibitor

Ethylenediamine-tetraacetic acid

Enzyme-linked immunosorbent assay

Endogenous thrombin potential

Extracellular vesicles

Factor

Prothrombin fragments $1+2$

Fibrin degradation products

Flow cytometry

Glycoprotein

High-molecular-weight kininogen

Intercellular adhesion molecule-1

Interleukin

Immune thrombocytopenia

Intravenous immune globulin

Microparticles

Microvesicles

Neutrophil extracellular traps

Plasminogen activator inhibitor

Prekallikrein

Phospholipids

Pooled normal plasma

Platelet-poor plasma

Platelet-rich plasma

Phosphatidylserine

Rotational thromboelastometry

Prothrombin time

P-selectin glycoprotein ligand-1

Thrombin-activatable fibrinolysis inhibitor

Thromboembolic events

Tissue factor

Tissue factor pathway inhibitor

Thrombin generation assay

Thelper

Thrombomodulin

Tumour necrosis factor-alpha

Tissue plasminogen activator

Thrombin generation assay

Thrombopoietin

Thrombopoietin receptor agonist

Time to peak

Urokinase plasminogen activator 
VI

VTE

VWF
Velocity index

Venous thromboembolism

Von Willebrand factor 


\section{Thesis summary}

Immune thrombocytopenia (ITP) is an autoimmune disorder characterized by isolated thrombocytopenia and an increased risk of bleeding. Thrombopoietin receptor agonists (TPORAs), such as romiplostim and eltrombopag, have been licenced for the treatment of ITP for more than 10 years and have been shown to be effective in increasing platelet counts and reducing the risk of bleeding events. However, an important concern regarding the safety of these agents has been an increase in the risk of thromboembolic events, which have been reported in approximately $6 \%$ of ITP patients on long-term treatment with both agents. Furthermore, epidemiological studies have shown that chronic ITP patients not receiving TPORA treatment have a higher thrombotic risk than patients without ITP or matched control subjects from the general population.

We investigated the presence of a procoagulant state in ITP patients and evaluated the influence of TPO-RA treatment on this state by measuring various markers before and sequentially after the initiation of TPO-RA treatment, hoping to find biomarkers that could help to identify patients with a greater risk of thrombosis in ITP patients, particularly after TPO-RA treatment. In article I, we measured markers of coagulation activation and fibrinolysis, as well as soluble P-selectin (sP-selectin) and antiphospholipid antibodies, and we performed a thrombin generation assay. In article II, we investigated the role of procoagulant microvesicles (MVs), the procoagulant effect of phospholipids and tissue factor in the procoagulant state in ITP and their possible involvement in the increased thrombotic risk before and after TPO-RA treatment. In article III, we wanted to evaluate whether endothelial cell activation and neutrophil extracellular trap formation play a role in the procoagulant state and to study the effect of TPORAs on these possible contributing players in the increased thrombotic risk.

We found that ITP patients, despite their low platelet count, have a procoagulant state prior to the initiation of treatment with TPO-RAs, manifested by increased coagulation activation with increased prothrombin fragments $1+2$ and D-dimer, and impaired fibrinolysis due to higher plasminogen activator inhibitor-1 (PAI-1) activity compared with controls. We found that ITP patients showed an activation of endothelial cells and increased neutrophil extracellular trap formation, both of which can contribute to increased thrombotic risk. Moreover, we found that treatment with TPO-RAs was associated with increased soluble P-selectin, probably indicating increased in vivo platelet activation. This treatment was also associated with a further increase in PAI-1 activity, leading to further impairment of fibrinolysis, as well as an increase in phospholipid-dependent thrombin generation, indicating increased phospholipid-dependent 
procoagulant activity of microvesicles. However, we did not show a clear influence of TPORA treatment on the activation of endothelial cells or on neutrophil extracellular trap formation. Our findings may be part of the explanation of the procoagulant state in ITP patients and the increased thrombotic risk in those who are treated with TPO-RAs. 
Articles in the thesis

Article I

Effect of Thrombopoietin Receptor Agonists on Markers of Coagulation and P-selectin in Patients with Immune Thrombocytopenia.

Garabet L, Ghanima W, Monceyron Jonassen C, Skov V, Holst R, Mowinckel MC, Hasselbalch HC, A Kruse TA, Thomassen M, Liebman H, Bussel JB, Sandset PM.

Platelets 2019;30:206-212.

Article II

Increased Microvesicle-associated Thrombin Generation in Patients with Immune Thrombocytopenia after Initiation of Thrombopoietin Receptor Agonists.

Garabet L, Ghanima W, Hellum M, Sandset PM, Bussel JB, Tran H, Henriksson CE.

Platelets 2020;31:322-328.

\section{Article III}

Markers of Endothelial Cell Activation and Neutrophil Extracellular Traps Are Elevated in Immune Thrombocytopenia but Are Not Enhanced by Thrombopoietin Receptor Agonists.

Garabet L, Henriksson CE, Lozano ML, Ghanima W, Bussel JB, Brodin E, María Piedad Fernández-Pérez M, Martínez C, González-Conejero R, Mowinckel MC, Sandset PM.

Thrombosis Research 2020;185:119-124. 


\section{Introduction}

\section{The haemostatic system}

Haemostasis is the physiological process of blood clot formation at the site of vessel injury. The process of haemostasis is carefully regulated, and normal haemostasis is characterized by equilibrium between the procoagulant and anticoagulant components of the coagulation system. However, when a pathological process leads to increased coagulation activation that overwhelms the regulatory mechanisms, excessive quantities of thrombin are formed, which may initiate thrombosis. Many risk factors, such as surgery, trauma, immobilization, pregnancy, the use of oral contraceptives or hormone replacement therapy, and various disease conditions, such as malignancies, myeloproliferative neoplasms, paroxysmal nocturnal haemoglobinuria, antiphospholipid syndrome and hereditary thrombophilia, can interfere with this equilibrium and may thus lead to thrombosis.

For over a century, the pathogenesis of venous thrombosis was centred on Virchow's triad. Rudolf Virchow proposed that venous thrombosis occurs as a result of alterations in blood flow (i.e., stasis), changes in the vessel wall (i.e., the vascular endothelium), and alterations in the constituents of the blood (hypercoagulable state). Arterial thrombi, on the other hand, typically form under conditions of high blood flow and shear stress and are mainly composed of platelet aggregates. Evidence suggests that the formation of arterial thrombi occurs as a consequence of an injured atherosclerotic plaque and involves platelet aggregation and platelet adhesion to the vascular wall [1]. In the early 1970s, Stewart et al. suggested a relationship between thrombosis and inflammation [2], and in recent decades, studies have demonstrated a tight interplay between inflammation and the coagulation system and supported the role of inflammation in the development of both arterial and venous thrombosis [3].

\section{Phases of haemostasis}

Although normal haemostasis comprises a dynamic interaction of different processes, it can be viewed as occurring in phases, starting with the formation of platelet plugs, which are consolidated by fibrin and ultimately form fibrin clots, followed by the termination of the coagulation process by a range of regulatory proteins and finally fibrinolysis and clot removal.

1- Endothelial injury and platelet plug formation

When a vessel wall injury occurs, platelets become activated at the site of vascular injury and form a platelet plug to stop bleeding. Injury to the endothelium leads to the exposure of 
subendothelial components to the blood, resulting in the activation of endothelial cells and the recruitment of platelets and other blood cells, such as neutrophils and monocytes, to the site of injury. Through the exposure of platelets to the extracellular matrix, platelets bind to von Willebrand factor (VWF) immobilized on the exposed collagen in the extracellular matrix via the VWF receptor glycoprotein (GP)Ib-V-IX receptor complex or collagen receptor GPVI and become subsequently activated. Upon activation, platelets change their shape, and the insideout signaling pathways increase the affinity of GPIIb/IIIa to fibrinogen. Activated platelets then secrete a variety of proteins from their alpha and dense granules, including VWF, adenosine diphosphate (ADP) and thromboxane A2, into the circulation, which stimulate neighbouring platelets, causing them to become activated and, in turn, to secrete more thromboxane A2 and ADP (Figure 1). Activated platelets also directly bind to circulating fibrinogen via the fibrinogen receptor GPIIb/IIIa [4]. Fibrinogen can simultaneously bind to two GPIIb/IIIa receptors, one on each platelet, and can therefore function as a bridge between two platelets. This platelet-fibrinogen-platelet interaction is responsible for initiating the process of platelet aggregation [5]. The activation of platelets in the initial platelet plug adherent to the endothelium leads to increased expression of anionic phospholipids on their outer membrane, supporting the assembly of procoagulant complexes [6]. It has also been shown that activated/damaged endothelium at the site of injury also provides binding sites for the assembly of the prothrombinase complex and supports thrombin formation [7].
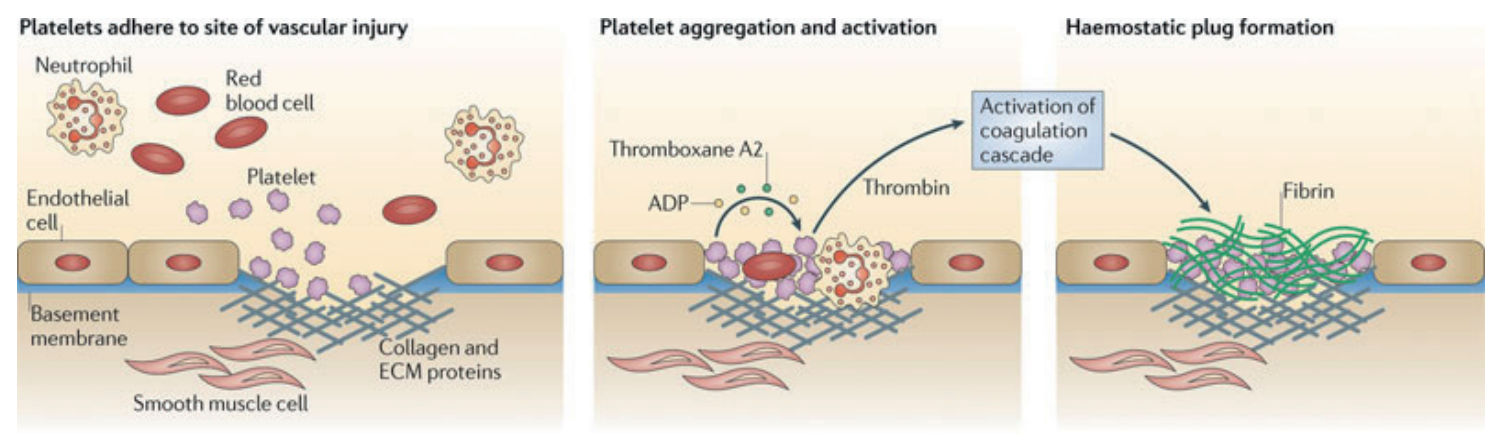

Nature Reviews | Immunology

\section{Figure 1: Platelet plug formation}

Reprinted from: Platelets and the immune continuum. John W. Semple, Joseph E. Italiano and John Freedman. Nat Rev Immunol 2011 Apr;11(4):264-74 with permission from Springer Nature via Copyright Clearance Center. 
2- Activation of the coagulation process and clot formation

The sequential activation of a series of proenzymes (zymogens) to active enzymes leads to significant stepwise response amplifications and results in local generation of fibrin, which reinforces the platelet plug. By convention, zymogen coagulation factors are named by Roman numerals, whereas their respective activated factors (enzymes) are denoted by the suffix $a$. Historically, the activation of different coagulation factors was described as occurring in a "waterfall sequence" or a "cascade", where one factor activates the other in a series of proteolytic reactions, the so-called "waterfall or cascade model" [8,9]. Later, the cascade model was presented as consisting of two separate pathways, an intrinsic and an extrinsic pathway. The extrinsic pathway is initiated when tissue factor (TF) is exposed to circulating blood upon vessel wall damage, whereas the intrinsic pathway is triggered when factor (F) XII (FXII), prekallikrein (PK) and high-molecular-weight kininogen (HK) become activated by contact with a negatively charged surface. Both pathways converge on the activation of FX (common pathway), which leads to the generation of thrombin and the formation of a cross-linked fibrin polymer (Figure 2). Although this classic view of the coagulation cascade explains the interactions between the different coagulation factors and has been useful in the interpretation of in vitro coagulation tests (i.e., prothrombin time (PT) and activated partial thromboplastin time (aPTT)), this view is unable to explain some clinical observations, such as why patients with FXII deficiency do not exhibit bleeding diathesis [10]. Later, it was shown that there is an interaction and cross-activation between the two pathways. Østerud et al. showed that the TF/FVIIa complex of the extrinsic pathway activates FIX of the intrinsic pathway in addition to activating FX (Figure 2) [11]. FXI can also be activated by thrombin on activated platelets in a feedback mechanism [12]. 


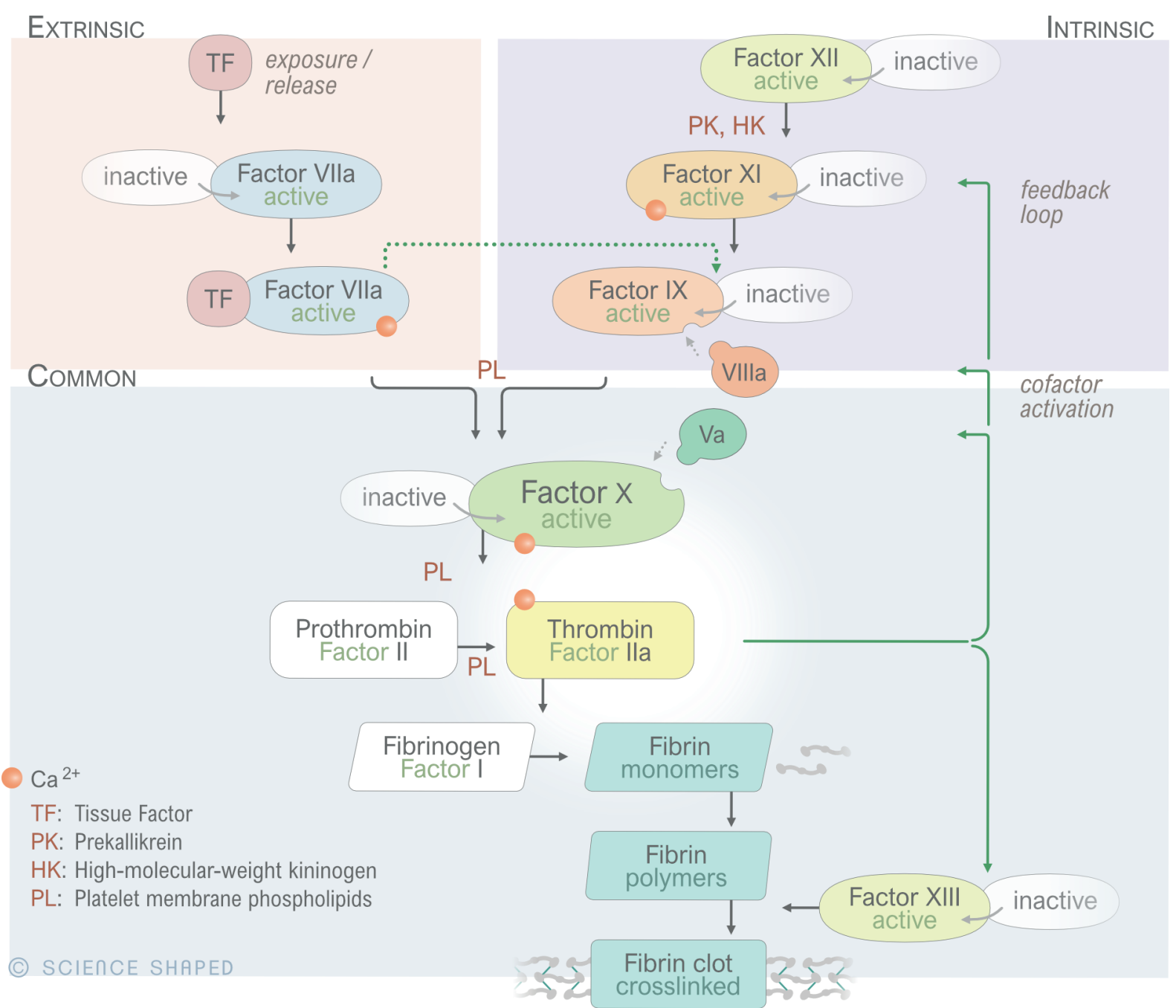

Figure 2: Schematic representation of the coagulation cascade showing the intrinsic, extrinsic and common pathways.

Based upon Graphic 69920 from: Overview of Hemostasis in UptoDate adopted from: Ferguson JD, Banning AP. Spontaneous intramural aortic haematoma: incidence, prognosis and complications. Eur Heart J 1998.

This led to the recognition of the important role of cells in haemostasis. Hoffman and Monroe developed a new model, a cell-based model of coagulation, proposing that coagulation is regulated by the properties of cell surfaces and that coagulation occurs in three overlapping stages: initiation, amplification and propagation [13].

Initiation

The initiation phase of clot formation begins on TF-bearing cells exposed at the site of vascular injury, such as fibroblasts and smooth muscle cells. When the exposed TF binds to FVII (or FVIIa), FVII immediately becomes activated, and the newly formed TF/FVIIa complex then activates both FIX and FX. Activated FX, in association with its activated cofactor FVa, forms 
a prothrombinase complex (FXa/FVa) on TF-bearing cells and converts prothrombin (FII) into thrombin (FIIa) (Figure 3). FXa activity is localized to the cell surface where it is formed, and any FXa that dissociates from the cell surface will be rapidly inactivated by the TF pathway inhibitor (TFPI), and antithrombin (AT) $[14,15]$. On the other hand, FIXa can move through the fluid phase to the nearby platelet surface since it is not inhibited by TFPI and is only weakly inhibited by AT [15]. Furthermore, circulating TF-positive microvesicles derived from activated monocytes/macrophages are capable of binding and fusing with activated platelets and initiating coagulation on these activated platelets [16].

\section{Amplification}

The relatively small amount of the initially generated thrombin will move to the nearby platelets that have adhered to the site of injury and further activate these platelets. Activated platelets release FV and expose phospholipids (PLs) on their surface. Thrombin will also activate FXI, FVIII and FV on the surface of platelets in a positive feedback amplification (Figure 3). Both FVa and FVIIIa can bind to the surface of activated platelets $[15,17]$, facilitate the subsequent binding of FX and FIX to form procoagulant complexes (Figure 3) and drive the formation of more thrombin in the final propagation phase [18].

\section{Propagation}

FXIa then activates FIX, which associates with its activated cofactor FVIIIa to form the intrinsic tenase complex (FIXa/FVIIIa), which will increase the formation of FXa. FXa complexes with its cofactor FVa to form the prothrombinase complex, which leads to a burst of thrombin generation (Figure 3). The generation of more thrombin then converts fibrinogen to fibrin monomers, which undergo polymerization, leading to the formation of a fibrin clot at the site of injury. Thrombin activates FXIII (FXIIIa), which cross-links and stabilizes fibrin polymers (Figure 2). Thrombin activation of FXIII is accelerated by the presence of non-cross-linked fibrin but inhibited by fully cross-linked fibrin. 


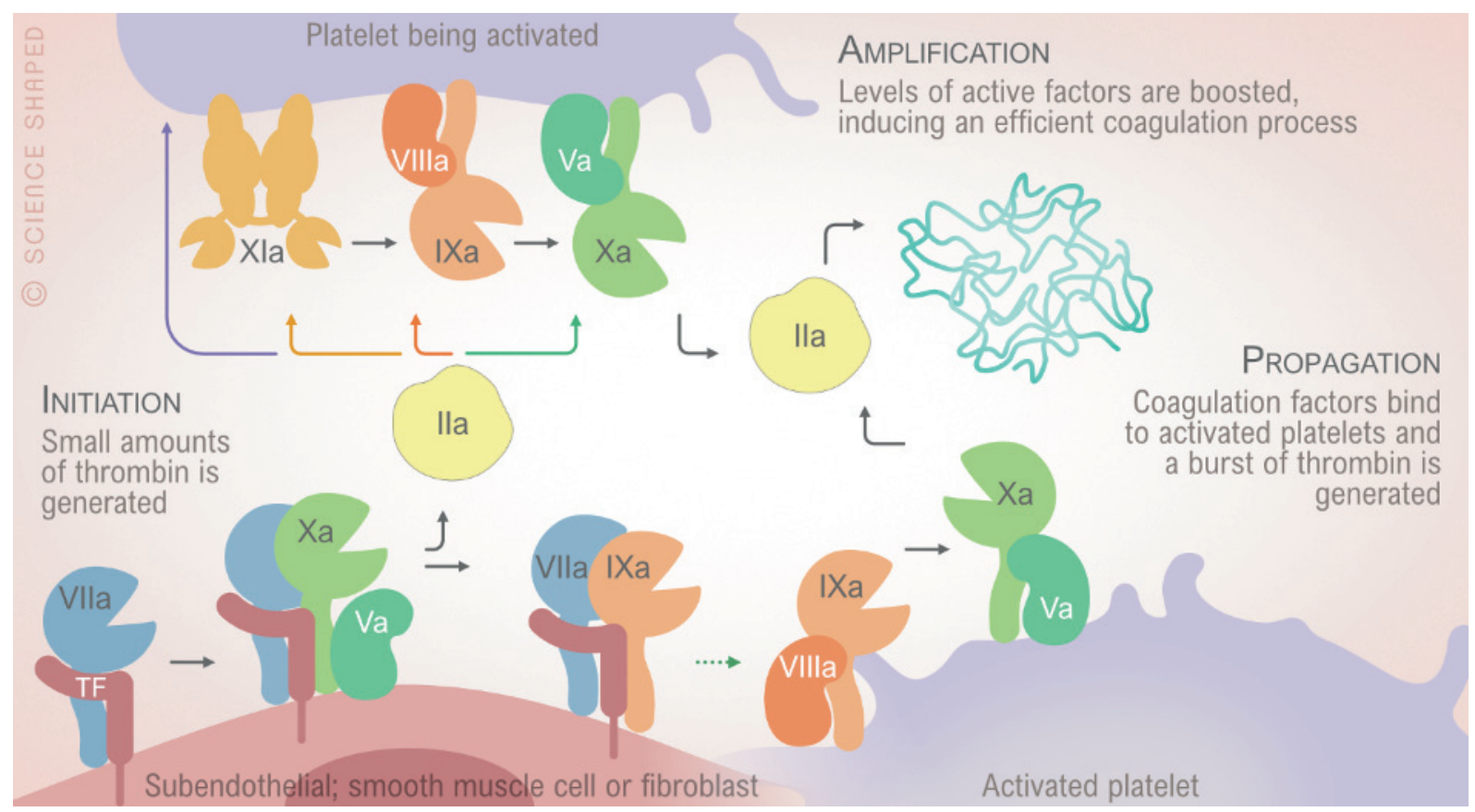

Figure 3: The cell-based model of coagulation, showing the interaction between cell surfaces and coagulation factors essential for the coagulation process.

Adopted with modification from: New Fundamentals in Hemostasis. Versteeg HH, Heemskerk JW, Levi M, and Reitsma PH. Physiol Rev. 2013 Jan;93(1):327-58, with permission from Springer Nature via Copyright Clearance Center.

\section{3- Termination of the coagulation process}

The interactions between activated platelets and the coagulation cascade give rise to a rapid haemostatic response that is localized to the injury site. If this process fails to be sufficiently regulated, it could lead to pathological thrombosis. However, the coagulation process is modulated by physiological inhibitors that dampen and eventually turn off the activity of the activated clotting factors:

- Tissue factor pathway inhibitor: TFPI inhibits both FXa and the TF/FVIIa complex, where in the first step, it directly inhibits FXa, and in the second step, the TFPI/FXa complex inhibits TF/FVIIa by the formation of a quaternary TFPI/FXa/TF/FVIIa complex.

- Contact activation pathway inhibitor: C1 esterase inhibitor inhibits FXIIa, PK, complement $\mathrm{C} 1$ and FXIa.

The regulation of the termination phase of the coagulation process involves two other important regulatory mechanisms: 
- Antithrombin (AT): AT neutralizes thrombin, FXa and FIXa, as well as FXIIa and FXIa, by the formation of irreversible enzyme-antithrombin complexes. This effect of AT is strongly enhanced by endogenous glycosaminoglycans, such as heparin sulfate located on endothelial surfaces and heparin released from intracellular sources, and by exogenous heparins.

- The protein $\mathrm{C} /$ protein $\mathrm{S}$ anticoagulant system: When thrombin is generated, it may also bind to thrombomodulin (TM), a membrane protein on the surface of endothelial cells, and this thrombin-TM binding alters thrombin specificity from a procoagulant (targeting fibrinogen) to an anticoagulant that cleaves and activates protein C. Activated protein $\mathrm{C}$ (APC), in association with its cofactor protein S, cleaves and inactivates FVa and FVIIIa.

\section{4- Removal of the clot by fibrinolysis}

Finally, after clot formation and the healing of vessel damage, surplus fibrin must be removed to restore vessel patency. This process is performed by the fibrinolytic enzyme plasmin. Plasminogen is activated by tissue plasminogen activator (tPA) and urokinase plasminogen activator (uPA) to the active enzyme plasmin $[19,20]$. Plasmin cleaves polymerized fibrin at multiple sites and releases soluble fibrin degradation products (FDPs). Plasmin can also cleave activated FXIII, leading to less cross-linking of fibrin [21].

While tPA is synthesized by endothelial cells, uPA is produced by monocytes and urinary epithelium. Excess plasminogen activators are neutralized by plasminogen activator inhibitor1 (PAI-1) and plasminogen activator inhibitor-2 (PAI-2). PAI-1 is released into the circulation from endothelial cells and platelets [22]. It is the most important and rapidly acting inhibitor of tPA and uPA [23]. PAI-2 is synthesized by white blood cells and the placenta. In pregnancy, the concentration of PAI-2 increases as pregnancy progresses [24]. Another important inhibitor of plasmin is $\alpha 2$-antiplasmin, which is secreted by the liver and is also present within platelets [25]. When plasmin is released into the circulation, it is rapidly inactivated by $\alpha 2$-antiplasmin $[26]$.

Thrombin-activatable fibrinolysis inhibitor (TAFI) is a procarboxypeptidase, a proenzyme that circulates in plasma. When TAFI is activated by the thrombin-TM complex, it acts as a fibrinolysis inhibitor. TAFI removes C-terminal lysine and arginine residues on fibrin, thereby 
decreasing the number of available plasminogen binding sites, slowing plasmin generation and leading to delayed clot lysis [24] (Figure 4).

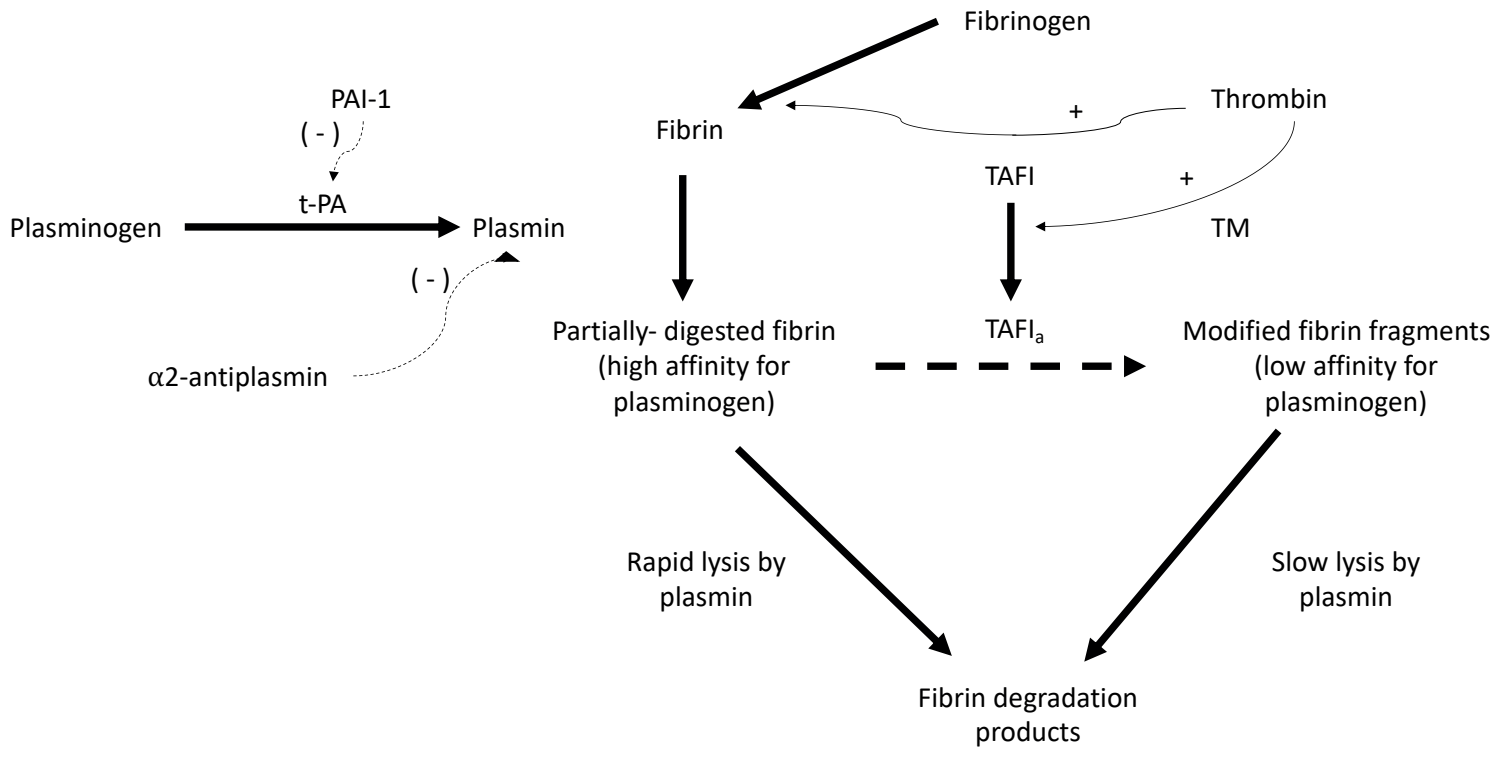

Figure 4: Regulation of fibrinolysis by plasminogen activator inhibitor-1 (PAI-1), $\alpha 2$ antiplasmin and thrombin-activatable fibrinolysis inhibitor (TAFI).

Reprinted from Overview of Hemostasis in UptoDate (Graphic 81428 supplied by William P Fay) with permission from UpToDate.

\section{The role of cells in haemostasis/thrombosis}

A wide range of interactions among coagulation factors, cells and inflammatory mediators have been identified at several stages of the haemostatic process. However, if these interactions are unchecked, they could contribute to a prothrombotic state and subsequent thrombosis. In addition to the recognized roles of platelets and endothelial cells in thrombus formation, neutrophils and monocytes have also been shown to play a role. 


\section{Platelets}

The procoagulant activity of platelets is related to their activation. There are a number of physiological platelet stimuli, including ADP, thromboxane A2, epinephrine, thrombin, and collagen, where collagen and thrombin are the most potent platelet activators. Injury to the vascular endothelium leads to platelet adhesion, activation and ultimately platelet plug formation. The initially generated thrombin, triggered by the exposed TF and the formation of the TF/FVIIa complex at the site of injury, leads to further activation of platelets.

An important aspect of platelet procoagulant activity is that activated platelets expose procoagulant PLs on their surface. These PLs, especially the negatively charged phosphatidylserine (PS), provide a surface for the assembly of procoagulant complexes. These procoagulant complexes on the platelet surface represent the close interplay between platelet activation and the activation of the clotting cascade, which has been referred to as "cell-based" coagulation (Figure 3) [27].

In addition, activated platelets secrete bioactive molecules from their granules. The dense granules release small molecules such as ADP that, together with thromboxane A2, cause positive feedback platelet activation and sustain aggregation, and calcium that is necessary for the function of most coagulation factors. The $\alpha$-granules retain important proteins for the haemostatic function of platelets, including FV, VWF, fibrinogen, platelet-derived growth factor, platelet factor 4 (PF-4, CXCL-4), and P-selectin. Fibrinogen and VWF help to propagate platelet activation and aggregation at the site of injury. Upon activation, P-selectin translocates from $\alpha$-granules to the cell surface of adherent platelets and recruits monocytes and neutrophils, inducing an inflammatory response [28]. This process is mediated by the interaction between platelet P-selectin expressed on their surface and P-selectin glycoprotein ligand 1 (PSGL-1) on leukocytes. PSGL-1 is also expressed on platelets and can mediate platelet-endothelial interactions [29]. Platelets also contain abundant chemokines and cytokines, particularly PF-4, which has been shown to drive neutrophil adhesion [30] and monocyte recruitment to the endothelium [31]. Platelets are important sources of coagulation factor V, XI, XIII and prothrombin. The $\alpha$-granules also contain anticoagulant regulatory proteins such as TFPI and protein $\mathrm{S}$, as well as the fibrinolysis initiator plasmin and its precursor plasminogen, which are essential to sustain haemostatic balance [32].

Furthermore, inorganic polyphosphates, a linear highly anionic polymer of orthophosphates, are stored in platelet dense granules and released upon platelet activation [33]. The long-chain polyphosphates (present in microorganisms) are highly procoagulant and possibly represent the 
negatively charged surface that triggers blood coagulation via the intrinsic pathway. Mediumchained polyphosphates (secreted from activated platelets) can accelerate FV activation, abrogate the anticoagulant function of TFPI, enhance fibrin polymerization, and accelerate FXI activation by thrombin [34].

\section{Endothelial cells}

Endothelial cells constitute the lining of the blood and lymphatic vessels and interact with both surrounding cells and flowing blood. The endothelium mediates vasomotor tone, regulates cellular trafficking, contributes to the local balance between pro- and anti-inflammatory mediators as well as procoagulant and anticoagulant activity, contributes to the generation of new blood vessels, participates in innate and acquired immunity and interacts with circulating blood cells $[35,36]$.

Quiescent endothelial cells display a thromboresistant, anti-adhesive and vasodilatory phenotype, whereas activated endothelial cells have procoagulant, pro-adhesive, and vasoconstricting properties. Injury to the endothelium leads to the exposure of circulating blood cells to components in the subendothelium (such as collagen, fibrinogen, and VWF), leading to the activation of platelets at the site of injury and the formation of platelet plugs. Vascular injury also leads to endothelial cell activation and increases the expression of adhesive molecules, which may further promote the recruitment of platelets and leukocytes and provide binding sites for coagulation factors as endothelial cells undergo apoptosis [37]. In addition, inflammatory mediators may interact with and activate endothelial cells, leading to a loss of the normal thromboresistant phenotype.

\section{Neutrophils}

Neutrophils are the most abundant innate immune cells that are attracted and recruited to sites of infection and inflammation by a variety of inflammatory mediators generated at these sites. Neutrophils are also recruited to the vessel wall at the site of injury and incorporated into the growing clot [38]. In recent years, there has been a tremendous advance in understanding the role of neutrophils in clearing pathogens, immune regulation and disease pathology, in particular by the formation of NETs. These extracellular, web-like structures composed of cytosolic and granule proteins assembled on a scaffold of decondensed chromatin are released to capture and kill microbes [39]. However, it has been shown that NETs are involved in the pathogenesis of various diseases, such as autoimmune diseases, atherosclerosis and cancer [40]. 
NET release occurs primarily through programmed cell death, a process termed NETosis (Figure 5) [41]. An alternative mechanism for NET release is non-lytic NETosis, which can occur independently of cell death [42]. The mechanisms that clear NETs are less well understood and might involve macrophage scavenging [40]. NETs play an important role in thrombosis through different mechanisms. They can lead to platelet recruitment through their binding to VWF, promoting platelet activation and thrombin generation [43], providing a surface for the activation of FXII [44], and stabilizing thrombi by binding to VWF and fibrinogen [45]. Furthermore, NETs can directly induce endothelial cell death [46].

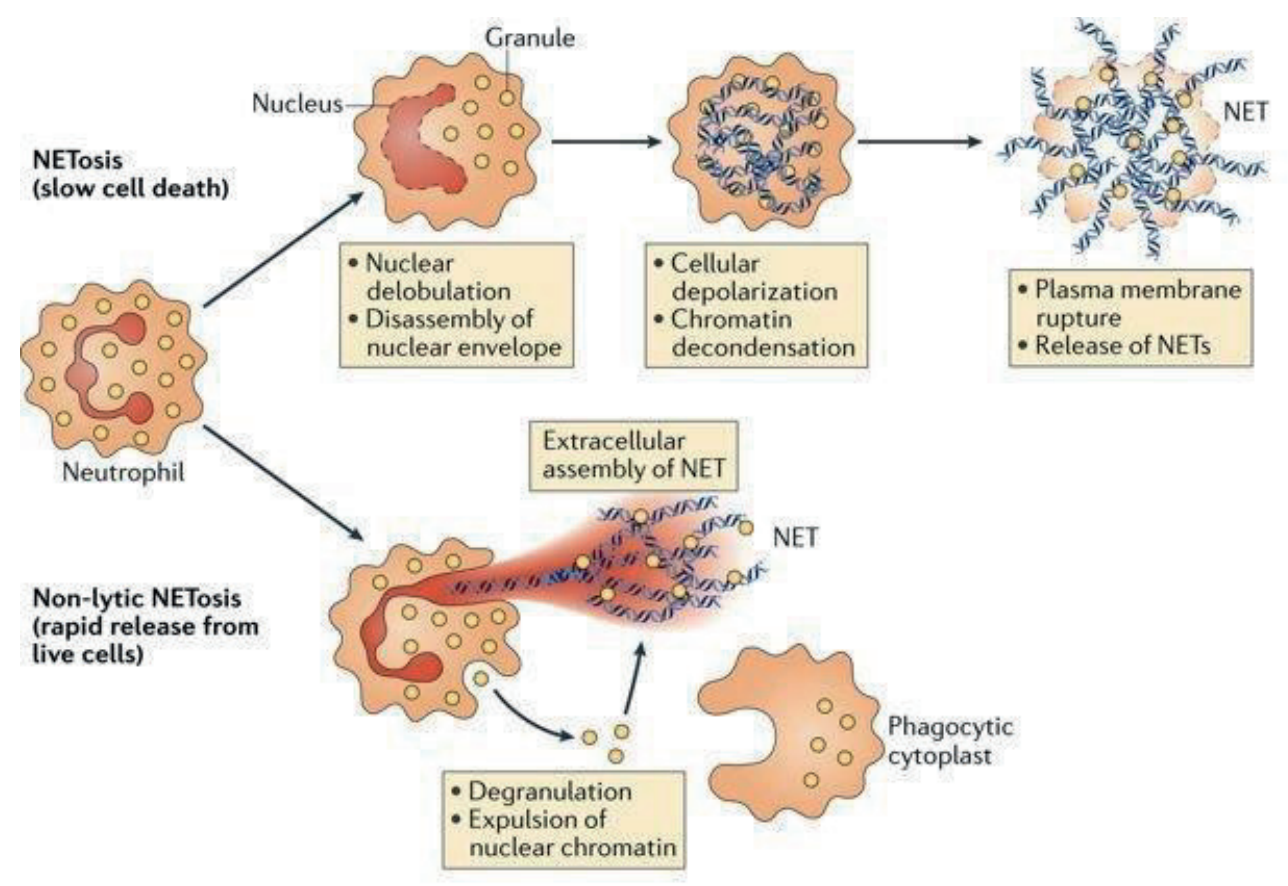

Nature Reviews | Immunology

Figure 5: Neutrophil extracellular trap formation pathways.

Reprinted from: Neutrophil extracellular traps in immunity and disease. Papayannopoulos V. Nat Rev Immunol. 2018 Feb;18(2):134-147, with permission from Springer Nature via Copyright Clearance Center. 


\section{Monocytes}

Monocytes, together with neutrophils, are recruited to the vessel wall and incorporated into the growing clot. Activated monocytes are able to express TF on their surfaces or on the surface of monocyte-derived microvesicles, which contributes to both physiological haemostasis and pathological thrombosis [47].

\section{Other players in haemostasis/thrombosis}

\section{Microvesicles}

Extracellular vesicles (EVs) are a heterogeneous population of small membrane-enclosed structures that originate from the endosomal system or are released from the cell plasma membrane in response to specific stimuli or apoptosis. These vesicles can transfer cellular components such as nucleic acids and cytosolic proteins between cells. EVs are involved in physiological processes, such as intercellular communication, and pathological processes, such as coagulation, inflammation and tumorigenesis [48]. EVs have been divided into three major populations:

1) Exosomes, which are preformed vesicles (50-100 $\mathrm{nm}$ in diameter) generated via exocytosis of multivesicular bodies.

2) Microvesicles (MVs) (100-1000 $\mathrm{nm}$ in diameter), also called microparticles (MPs), which are released from the cell membrane and induced by cell activation or apoptosis.

3) Apoptotic bodies, which are larger (1-5 $\mu \mathrm{m}$ in diameter) and are produced during the latter stages of cell apoptosis [49] (Figure 6).

These different subgroups of EVs overlap in size, and current purification methods do not fully discriminate among these groups. The terms MPs and MVs have been interchangeably used; in this thesis, the term MVs will be used. In healthy individuals, blood contains MVs that are derived from different types of cells, including platelets, red blood cells, monocytes and endothelial cells; however, platelet-derived MVs have been shown to be the most abundant type [50]. In addition, tumour cells release MVs into the circulation [51]. Recent data have shown that a significant portion of blood-borne MVs originating from platelets may actually be derived from megakaryocytes (MKs) in the bone marrow [52]. MVs have an intact membrane that expresses cell surface proteins, and they have important cytoplasmic components derived from their cell of origin. The specific MV subsets can be identified by flow cytometry according to 
their cell of origin using antibodies to common antigens of the parent cell, often in combination with annexin V, a marker for PS [53].

MVs have a relatively short half-life in the circulation, and the spleen is the major site for their clearance [51]. They play a role in both physiological and pathological processes, such as cell survival, intercellular communication, inflammation and immune response, and the enhancement of blood coagulation [54]. Both platelet-derived MVs and red cell-derived MVs are shown to be increased in patients with immune thrombocytopenia (ITP) [55, 56].

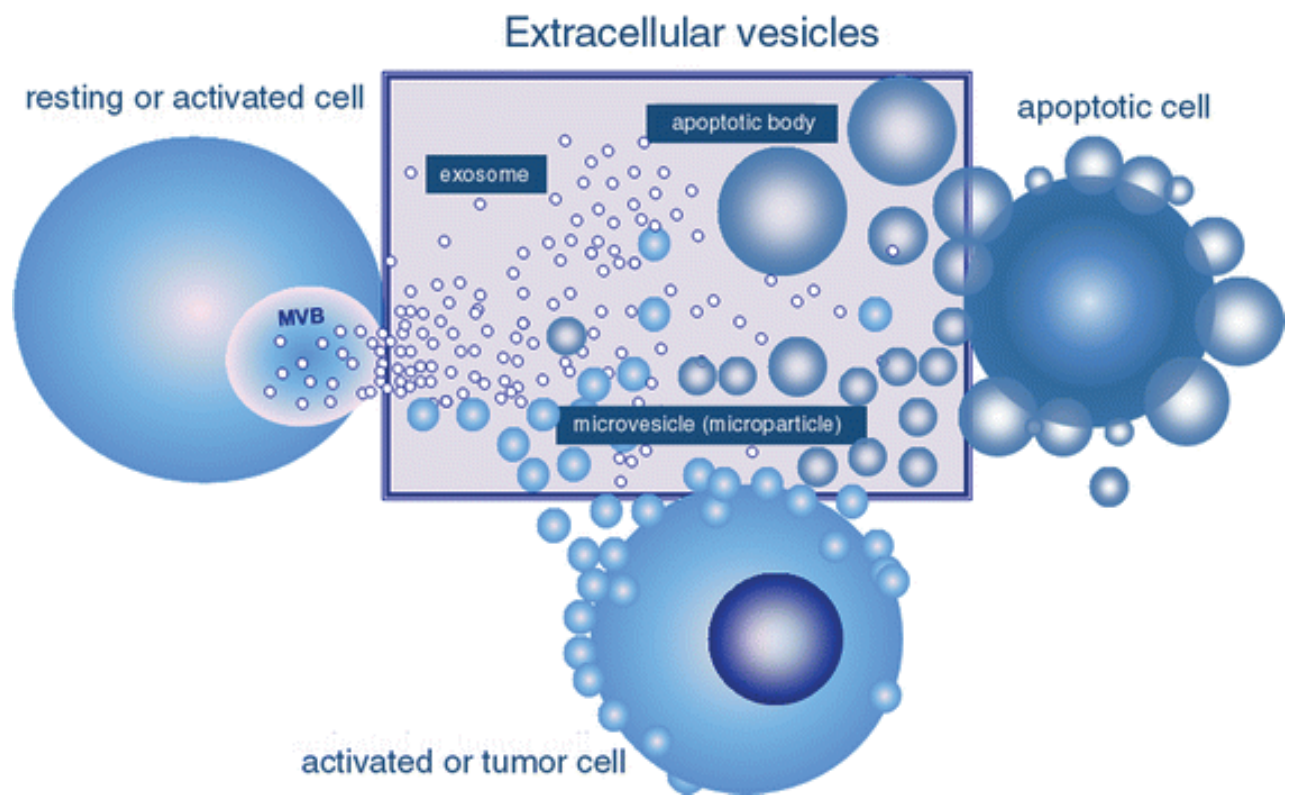

Figure 6: Schematic representation of the extracellular vesicles.

Reprinted from: Membrane vesicles, current state-of-the-art: emerging role of extracellular vesicles. György B, Szabó TG, Pásztói M. et al. Cell. Mol. Life Sci. 2011 Aug; 68(16): 2667-2688. This article has been distributed under a Creative Commons licence (Attribution-Noncommercial) and needs no additional permission to reuse for non-commercial/educational purposes. MVB: Multivesicular bodies.

The procoagulant properties of MVs

The potential procoagulant properties of MVs are linked to the exposure of anionic PS [57] and the presence of TF on their surface membrane [58]. MVs that express both PS and TF have higher total procoagulant activity than those expressing TF or PS alone [59]. In resting cells, PS is sequestered to the inner leaflet of the cell membrane; however, upon activation or other pathological conditions, PS flops on the outer leaflet of the plasma membrane, and MVs are 
released. Although the definition of an MV generally includes the externalization of PS, new evidence supports the notion that PS is not exposed on the surface of all MVs. The expression of PS on MVs is dependent on the cell of origin and the stimulus or the mechanism by which they were generated [60]. However, it is unclear whether the lack of PS exposure is true or whether PS expression is below the detection threshold of conventional techniques, particularly on smaller MV subsets [61].

MV-associated PS provides a catalytic surface for the assembly of coagulation factors that initiate and maintain coagulation [51]. PS-exposing platelet MVs and red cell MVs generated ex vivo have been shown to initiate and support thrombin generation through the intrinsic pathway in an FXII-dependent manner [62]. Furthermore, red cell MVs in sickle cell disease [63] and in banked units for transfusion [64] have been shown to promote coagulation through the intrinsic pathway in an FXI-dependent manner. MV-associated TF is thought to be functionally active and may thus contribute to the procoagulant nature of MVs. TF binds to FVII(a), and the resulting TF/FVIIa complex activates both FIX and FX to initiate blood coagulation as described previously. It has been shown that monocyte-derived and tumour-derived MVs may express TF on their surface; however, it is debated whether platelet MVs or endothelial MVs express biologically active TF $[65,66]$. In a mouse model, it has been demonstrated that TFpositive MVs can bind to activated platelets through the interaction of MV PSGL-1 and platelet P-selectin at the site of thrombus formation and participate in clot propagation [66]. It has been estimated that platelet MVs generated ex vivo have 50- to 100-fold higher procoagulant activity than the same area on an activated platelet [67], which may help account for the potential thrombogenicity of platelet MVs.

In addition to their procoagulant functions, MVs are able to regulate coagulation through anticoagulant or fibrinolytic mechanisms. MVs may harbour functionally active TFPI on their membrane [68] and support APC- and protein-S-mediated regulation of coagulation [69, 70], both of which are normal anticoagulant pathways. It has also been shown that MVs may support plasmin generation [71], a regulatory mechanism to degrade fibrin. Therefore, it is likely that the balance between the pro- and anticoagulant properties of these MVs ultimately determines their effect on haemostasis and thrombosis.

\section{Analysis of MVs}

Numerous methods have been used for the analysis of MVs, including enzyme-linked immunosorbent assays (ELISAs), atomic force microscopy, and electron microscopy; however, 
flow cytometry (FCM) is the most commonly used method for the detection and analysis of MVs [53]. FCM provides quantitative as well as qualitative information through the immunophenotyping of MVs and thus helps to identify their cellular origin [72]. One challenge with FCM is the limited ability to detect the smallest MVs $(<200 \mathrm{~nm})$, which account for approximately $50 \%$ of the thrombin-generating capacity of MVs [53], which may explain the lack of correlation between FCM and functional assays for MVs. Furthermore, the high-speed centrifugation that is used to isolate MVs may result in the aggregation of MVs and thus a change in their size, leading to an altered number of measured MVs by size-based gating [53]. In addition, the centrifugation protocol may influence the assay, as increased numbers of contaminating platelets prior to plasma freezing will lead to a greater number of MVs from damaged platelets, and these MVs will be detected by FCM when MVs are measured in frozen biobanked samples [73]. Functional assays are used to assess the procoagulant activity of the MV population when MVs are isolated from plasma using either capture techniques or ultracentrifugation and are investigated for their ability to support coagulation using either clotbased or chromogenic endpoint assays. The advantages of these assays are their simplicity and high sensitivity [53]. However, functional assays do not provide information on the cellular source of the MVs or their number or size. TF-dependent activity assays are based on the ability of TF present on MVs to activate FX upon the addition of FVIIa and FX. The amount of FXa is measured by its ability to split a specific FXa substrate. PS-dependent activity assays are based on the ability of captured PS-positive MVs in the presence of FV, FX and prothrombin to form the prothrombinase complex that cleaves prothrombin to thrombin. A chromogenic substrate for thrombin is then added to assess the levels of thrombin. Furthermore, thrombin generation assays can be modified to measure PS-dependent MV-associated procoagulant activity in plasma and on isolated MVs [74].

Endothelial adhesion molecules and thrombomodulin

Intercellular adhesion molecule-1 (ICAM-1) and vascular cell adhesion molecule-1 (VCAM1) belong to the immunoglobulin superfamily of molecules that are expressed on endothelial cells. They interact with integrins on leukocytes and are involved in leukocyte-endothelial cell adhesion and transmigration. ICAM-1 is constitutively expressed at low levels on endothelial cells, and its expression is upregulated upon stimulation with various inflammatory mediators. ADP-activated platelets increase the surface expression of ICAM-1 on endothelial cells [75].

VCAM-1 is synthesized by and expressed on endothelial cells following stimulation with inflammatory mediators. VCAM-1 is not expressed on resting endothelial cells. 
Thrombomodulin is an endothelial cell membrane protein that can bind to thrombin, leading to the activation of protein $\mathrm{C}$. Thrombomodulin is expressed by vascular endothelial cells and released in the circulation when vascular endothelial cell injury occurs. Soluble thrombomodulin reflects the extent of vascular endothelial cell damage.

\section{The selectins}

Selectins are transmembrane glycoproteins that can be expressed on leukocytes, platelets and endothelial cells [76]. Three selectins exist and are named for the cell type in which they were originally identified: E-selectin (endothelium), P-selectin (platelet), and L-selectin (leukocyte). All three selectins share similar structural features and an N-terminal carbohydrate recognition domain that is crucial for ligand binding. This is reflected in their function as adhesion molecules supporting interactions of platelets or endothelial cells with leukocytes during thrombosis and inflammation [77].

E-selectin (CD62E) is synthesized de novo and expressed on endothelial cells and leukocytes after stimulation by various inflammatory mediators, such as interleukin-1 (IL-1), endotoxin, and tumour necrosis factor-alpha (TNF-alpha) [78]. L-selectin (CD62L) is expressed only on leukocytes, and it mediates leukocyte recruitment to the endothelium. P-selectin (also called $\mathrm{CD} 62 \mathrm{P}$ ) is involved in early leukocyte recruitment during the inflammatory response [76]. It is constitutively expressed and stored in the $\alpha$-granules of platelets and in the secretory granules (Weibel-Palade bodies) within endothelial cells [79]. The expression of P-selectin on the surface of endothelial cells following vascular injury and/or inflammation supports leukocyte tethering and rolling, a step required for the firm adhesion/activation and transmigration of leukocytes [80].

Following platelet stimulation, P-selectin becomes expressed on the platelet surface, where it is rapidly shed. This shedding from platelets is thought to be a main source of the soluble form found in plasma following thrombotic events $[81,82]$. However, part of the soluble P-selectin found in plasma might also be of endothelial origin [83]. When the endothelium is stimulated by inflammatory mediators, the secretory granules fuse with the plasma membrane and increase the surface expression of P-selectin, which is recycled back into the cell. PSGL-1 is expressed on most leukocytes and can interact with all three selectins under inflammatory conditions [84]. The crucial role played by platelet-expressed P-selectin in thrombus formation has led to highlighting the interconnections between inflammation and thrombosis at the site of vascular 
injury [85]. Thrombin stimulates P-selectin translocation and expression on the surface of activated platelets. The P-selectin expressed on the surface of activated platelets will be incorporated in the growing thrombus and support the recruitment of circulating leukocytes to the site of injury and mediate the binding of platelets to monocytes and neutrophils. Another important consequence of the expression of P-selectin on the platelet surface is that it supports the binding of circulating TF-bearing procoagulant microparticles. Analyses of thrombi, utilizing confocal and widefield intravital microscopy, have revealed that these microparticles bind to P-selectin exposed on adhering platelets via PSGL-1 and contribute to thrombus growth and fibrin formation in injured arteries [86, 87].

Plasminogen activator inhibitor-1 (PAI-1)

PAI-1 is a serine protease inhibitor and is present in plasma in trace concentrations. As discussed before, PAI-1 is the primary inhibitor of both t-PA and u-PA. It plays an important role in the regulatory mechanism maintaining a well-balanced activity of the fibrinolytic system [88]. PAI-1 is secreted by multiple cell types, mainly the vascular endothelium and platelets [89-91]. The release of PAI-1 by activated platelets may contribute to the relative resistance of platelet-rich arterial thrombi to thrombolysis. PAI-1 is upregulated by a large number of proinflammatory cytokines [92]. Studies have associated elevated plasma PAI-1 levels with thrombosis, both venous and arterial [93, 94], as well as with the risk of septic shock and multiple organ system failure [95]. Particular interest has been paid to the potential role of PAI1 in the pathogenesis of coronary heart disease and myocardial infarction [96].

\section{Assessment of the coagulation process and the procoagulant phenotype}

The assessment of coagulation using standard laboratory clotting tests, such as PT/INR and aPTT, is not sensitive enough to detect a hypercoagulable state. These two assays are based on assessing the time to the formation of fibrin as the endpoint, thus primarily measuring the initiation and not the amplification and propagation phase of clot formation. As previously discussed, it is now established that coagulation does not occur as a consequence of linear sequential enzyme activation pathways but rather via a network of simultaneous interactions with the regulation and modulation of these interactions during the thrombin generation process itself [97].

Global haemostatic assays, such as the thrombin generation assay (TGA) and thromboelastography (TEG), measure the whole process of thrombin generation, from the 
initiation of clot formation to the termination of clot formation, reflecting a more complete picture of coagulation; however, they still have limitations [98]. TGA measures the initiation phase of coagulation, where the first trace of thrombin is formed; the amplification/propagation phase, where the bulk of thrombin is generated via feedback loops on FV, FVIII and FXI; and the termination phase, where thrombin formation is shut down by the anticoagulant pathways and all thrombin activity is inhibited $[98,99]$.

TEG and rotational thromboelastometry (ROTEM) provide information on the dynamics of clot development, stabilization and dissolution. They are used as monitors in complex major surgery to guide the use of blood component therapy. An activator (TF) is used to standardize and speed up the initiation of the clotting process. In addition to providing information on thrombus generation, TEG and ROTEM can provide information on the rate of thrombus lysis.

Prothrombin fragment $1+2\left(\mathrm{~F}_{1+2}\right)$, which is released when activated FX cleaves prothrombin to thrombin, reflects in vivo thrombin generation. In addition, D-dimer, which is generated when cross-linked fibrin polymers are degraded by plasmin, reflects both thrombin generation (past or ongoing) and ongoing fibrinolytic activity.

\section{Immune thrombocytopenia (ITP)}

Primary immune thrombocytopenia (ITP) is an autoimmune disorder characterized by isolated thrombocytopenia (platelet count $<100 \cdot 10^{9} / \mathrm{L}$ ) in the absence of an underlying disease [100]. By contrast, secondary ITP is triggered by infections (e.g., hepatitis C virus, HIV, Epstein-Barr virus, and Helicobacter pylori), autoimmune diseases (systemic lupus erythematosus, rheumatoid arthritis, antiphospholipid syndrome), lymphoid malignancies (chronic lymphatic leukaemia, lymphoma) and medications (gold, quinine) [100]. Therefore, the diagnosis of ITP involves a battery of investigations to exclude other conditions/diseases that mimic primary ITP or cause secondary ITP.

ITP can be observed in both children and adults, with both sexes being affected. In adults, approximately $80 \%$ of diagnosed patients have primary ITP, whereas the remaining $20 \%$ have secondary ITP [101]. Primary ITP has a prevalence of 9-11 per 100,000 adults and an incidence of approximately 2-6/100,000 adults per year [102, 103]. ITP has two peaks: one between 20 and 30 years of age with a female predominance and a larger peak after 60 years of age with approximately equal sex distribution. At least one-fourth of ITP patients are asymptomatic at the time of diagnosis, with low platelet counts discovered incidentally in blood tests. The 
symptoms of ITP are predominantly mild, and patients usually present with petechiae, purpura, mucosal bleeding and epistaxis [104]. Serious haemorrhages usually occur in patients with platelet counts less than $10-20 \cdot 10^{9} / \mathrm{L}[105,106]$. However, despite low platelet counts, serious bleeding is uncommon, and fatal intracranial haemorrhages are rare and occur in approximately $0.2 \%$ of cases [107]. Generally, bleeding diathesis is very heterogeneous and therefore difficult to predict clinically. It is still unclear why patients with similar platelet counts can present with different clinical bleeding manifestations [108]. In addition, patients with ITP frequently complain of fatigue and often have reduced quality of life [109].

ITP can be clinically classified into 3 phases: newly diagnosed ITP, occurring during the first 3 months after diagnosis; persistent ITP, which refers to ITP ongoing between 3 and 12 months; and chronic ITP, in which the disease persists beyond 12 months [100]. The majority of adult ITP patients will progress to chronic ITP $[103,110]$.

\section{Pathophysiology of ITP}

The pathophysiology of ITP is complex and involves interactions of multiple cell types. B cells and plasma cells are abnormally regulated and produce autoantibodies against platelets and MKs; this mechanism is central in the pathogenesis of ITP. Anti-platelet antibodies primarily bind to platelet GPIIbIIIa and GPIb receptors, inducing their impairment and/or degradation in the spleen and liver [111]. Anti-platelet antibodies can also cause complement-mediated or desialylation-induced platelet destruction [112]. In addition, it has been shown that some patients with ITP have autoantibodies that inhibit MK maturation [113]. However, anti-platelet antibodies are not detectible in $30-40 \%$ of ITP patients $[112,114,115]$. It is not obvious why some ITP patients lack these anti-platelet antibodies; whether this absence of anti-platelet antibodies is because the methods used to detect these antibodies are not robust enough; or whether these patients have other mechanisms involved, such as a purely $\mathrm{T}$ cell-mediated mechanism [115].

In addition, various $\mathrm{T}$ cell abnormalities have been reported in ITP patients, including unbalanced $\mathrm{CD}^{+} \mathrm{T}$ helper (Th) cell subsets with elevated Th17 and Th1 profiles [116] and a lower frequency of circulating $\mathrm{T}$ regulatory cells (Tregs) that are crucial for immune suppression [117]. Lower Tregs together with impaired B regulatory cells (Bregs) [118], which promote peripheral tolerance, contribute to autoreactive plasma cell survival, supporting autoantibody production. Furthermore, cytotoxic $\mathrm{CD}^{+} \mathrm{T}$ cells are also activated, inducing 
platelet lysis [119], and accumulate in the bone marrow, inhibiting megakaryopoiesis [112, 120]. Therefore, $\mathrm{T}$ cell abnormalities may also play a major role in the pathogenesis of ITP.

\section{Treatment of ITP}

The goals of treatment are to stop current bleeding and reduce the risk of future bleeding [121]. There are various therapies available targeting various aspects of ITP pathophysiology. If the patient has active serious bleeding, urgent treatment with platelet transfusions, glucocorticoids, and intravenous immune globulin (IVIg) is indicated [121]. In asymptomatic patients or those with mild mucocutaneous bleeding, the decision to treat should be guided by the risk of future bleeding and patient preferences [121]. A platelet count of less than $20-30 \cdot 10^{9} / \mathrm{L}$ is frequently used as a criterion for treatment $[121,122]$. Glucocorticoids are uniformly used as first-line treatment; however, prolonged use should be avoided because of adverse effects [121, 122]. In ITP patients who fail to achieve remission or in those who relapse after tapering glucocorticoids, other treatment strategies are recommended, including stimulating platelet production with thrombopoietin receptor agonists (TPO-RAs) or decreasing the immune response through the use of immunomodulatory agents, such as anti-CD20 antibodies (e.g., rituximab), mycophenolate mofetil, azathioprine, dapsone, and danazol. Rituximab and TPORAs are currently the most widely used treatment options in patients in whom corticosteroid treatment fails or in those who become dependent on corticosteroids [112, 122]. Splenectomy has been the standard second-line therapy for decades; however, its use has decreased dramatically during the last decade [123]. Splenectomy is associated with long-lasting remissions in 60 to $70 \%$ of patients [124]. However, due to potential complications such as infections, thrombosis, and post-operative complications [125], and because of the availability of other effective medical therapies, the use of splenectomy is currently limited to patients who do not achieve a response to or do not tolerate standard medical therapies and in whom at least a year has passed since diagnosis [121]. Rituximab is administered intravenously by 2 to 4 infusions and induces a response in $60 \%$ of treated patients. However, half of the responding patients will gradually lose response, resulting in 5-year sustained response rates of $20-30 \%$ [126-128]. TPO-RAs are administered either orally or subcutaneously and provide a durable response rate of approximately $65 \%$, yet maintenance therapy is required to sustain the effect. However, recent data indicate that up to approximately $30 \%$ of patients could discontinue TPORAs without losing response $[129,130]$. 


\section{Thrombosis in ITP}

Following the initial TPO-RA trials that showed the occurrence of thromboembolic events in ITP patients, both in the TPO-RA-treated arm and in the comparison arm [131-133], large epidemiological studies were conducted to investigate the inherent risk of venous and/or arterial thrombosis in ITP. In a review by Rodeghiero [134], the results of five large epidemiological studies that compared thrombosis in chronic ITP patients not receiving TPO-RA treatment with controls, who were either patients without ITP registered in clinical practice or matched subjects from the general population, were analysed [135-139]. These studies showed a consistently higher risk of venous thrombosis (approximately twice that of the control population) in ITP patients.

The annualized incidence rate of venous thrombosis in ITP patients in these different studies varied between 0.41 and 0.67 , compared with corresponding ranges in control populations, which varied between 0.20 and 0.42 . In these population-based studies, the increased risk was more evident in patients older than 50 - 60 years. However, no higher risk of venous thrombosis in splenectomized patients was shown in these studies, except in the Scandinavian populationbased study by Nørgaard et al. [137]. For arterial thrombosis, there was a trend of increased risk in patients with chronic ITP, but only in the study by Enger et al. did the risk achieve statistical significance [138]. A more recent study that included 6591 ITP patients also showed an increased risk of developing cardiovascular disease, including ischaemic heart disease and stroke, compared to matched controls [140].

Various factors have been shown to be associated with an increased risk of thromboembolism in ITP, including age above 60 years, the presence of other risk factors for thrombosis, a history of arterial or venous thrombosis, steroid use, splenectomy and the presence of antiphospholipid antibodies [141-144].

\section{Thrombopoietin receptor agonists and thrombosis}

Romiplostim and eltrombopag are two TPO-RAs that were approved for the treatment of ITP in 2009, whereas a third small-molecule TPO-RA, avatrombopag, was recently approved for the treatment of chronic ITP in the USA [145]. TPO-RAs act by binding to the thrombopoietin receptor c-MPL and activating intracellular signaling pathways (the JAK-STAT and MAP kinase pathways) to stimulate megakaryocyte differentiation, proliferation and platelet production, which results in elevated platelet counts (Figure 7). Eltrombopag and avatrombopag 
bind to the thrombopoietin receptor at the transmembrane domain, unlike thrombopoietin and romiplostim.

In randomized, placebo-controlled clinical trials, romiplostim and eltrombopag demonstrated unequivocal superiority over placebo or the standard of care in elevating platelet counts in ITP patients [146]. In these studies, a durable response was seen in $60 \%$ of TPO-RA-treated ITP patients [131, 147-149]. TPO-RAs have also been shown to decrease the risk of bleeding events, reduce the proportion of patients needing rescue medication, and reduce the need for concomitant ITP medications [146]. Although these agents have shown acceptable safety profiles [150, 151], concerns have been raised regarding the possible increase in thromboembolic risk based on the observed thromboembolic events (TEEs) in some of the phase II and III randomized controlled trials for both agents [132, 133]. However, a metaanalysis that included all RCTs performed on the three thrombopoietic agents showed no significant increase in the rate of thromboembolism in the TPO-RA arms compared to the comparator arms (placebo or standard of care) [151]. Thromboembolism was also reported in the open-label extension studies of eltrombopag and romiplostim. In a report on the safety and efficacy of long-term treatment with romiplostim in chronic ITP, where the mean duration of treatment was 110 weeks, TEEs occurred in $6.5 \%$ of patients [152], and a pooled analysis of 13 trials of romiplostim showed that $6 \%$ of patients had a TEE [153]. A report on the safety of long-term treatment of ITP with eltrombopag (median duration 2.37 years) showed that the rate of TEEs was 6\% [154]. Of note, in an RCT comparing avatrombopag to placebo, three out of 32 patients treated with avatrombopag experienced TEE episodes during 24 weeks of treatment compared to none in the placebo arms, with another patient developing jugular venous thrombosis during the open-label extension study [155].

In all studies, thrombotic events occurred independent of platelet counts, whether low, normal, or high. TEEs occurred more often in older patients and mostly in those with at least one thrombosis risk factor (such as hypertension, smoking, obesity, family history) [150]. Moreover, no clear relationship was found with the dose of the TPO-RA used or the duration of exposure [134]. Of note, venous thrombosis has been reported in several paediatric ITP patients on TPO-RAs; however, some of the patients had additional risk factors for thrombosis, such as splenectomy, immobilization after fracture, and the use of steroids or oral contraceptives [156, 157].

To summarize, although the meta-analyses do not show an increased risk of TEE associated with TPO-RAs, the incidence of TEE in long-term open-label studies and in the paediatric 
population raises suspicion regarding a possible increase in the risk of venous and arterial thrombosis associated with the use of TPO-RAs.

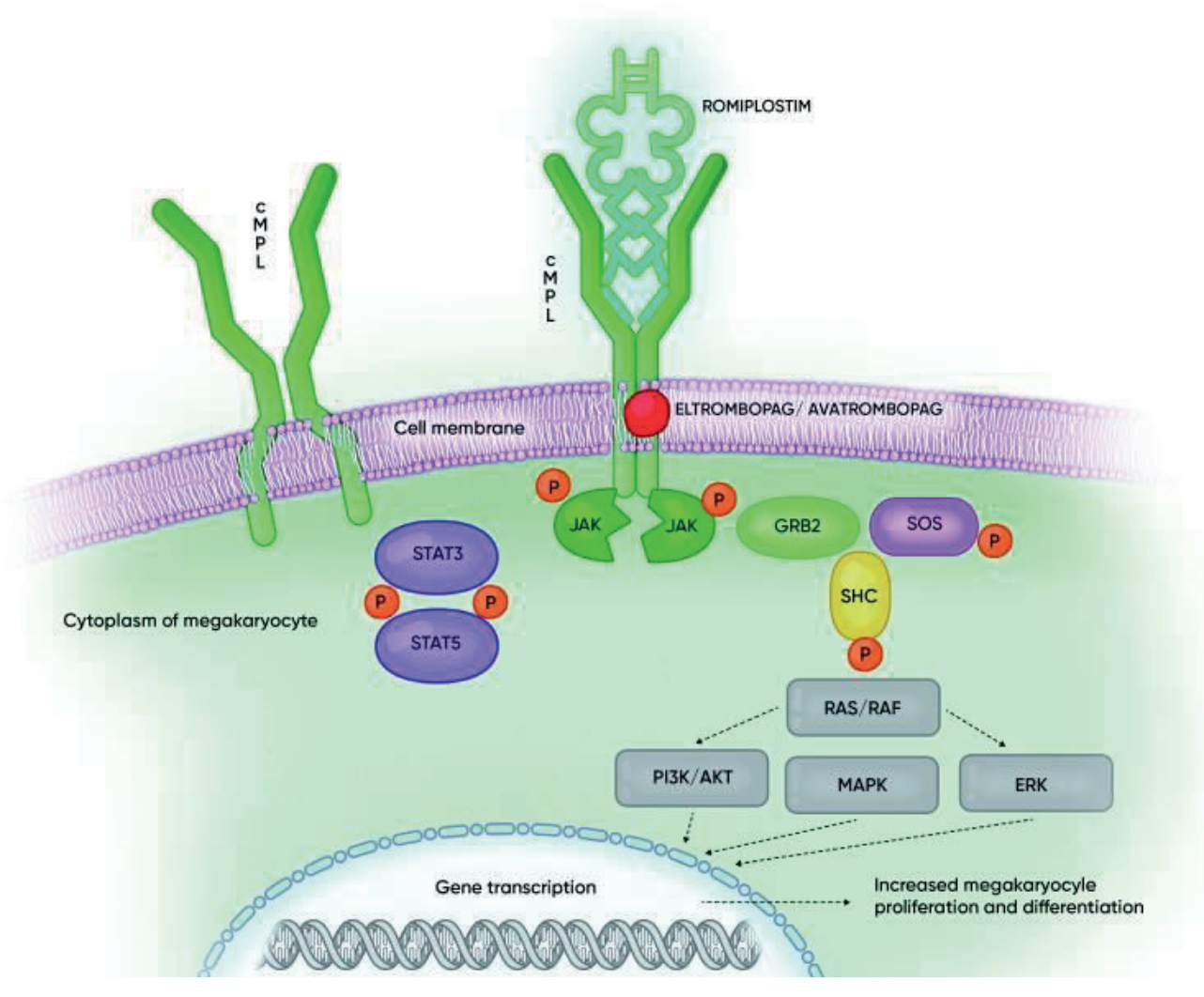

Figure 7: Activation of the thrombopoietin (TPO) receptor (c-MPL) by thrombopoietin receptor agonists (TPO-RAs).

Reprinted from: Thrombopoietin receptor agonists: ten years later. Waleed Ghanima et al. Haematologica 2019 Jun; 104(6): 1112-1123 with permission from Haematologica.

GRB2: growth factor receptor-binding protein 2; JAK: Janus kinase; MAPK: mitogen-activated protein kinase; P: phosphorylation; RAF: rapidly accelerated fibrosarcoma kinase; RAS: rat sarcoma GTPase; SHC: Src homology collagen; STAT: signal transducer and activator of transcription; PI3K: phosphatidylinositol 3-kinase; ERK: extracellular-signal-regulated kinase. 


\section{Thesis aims}

The overall objectives of this thesis were to investigate the presence of a procoagulant state in ITP patients compared with healthy controls and to evaluate the influence of treatment with TPO-RAs on the haemostatic state in ITP patients, especially whether this treatment enhances the coagulation process, leading to a more hypercoagulable state and thus greater thrombotic risk. We performed various laboratory analyses before and sequentially after initiating treatment with TPO-RAs to explore the potential underlying mechanisms that might contribute to a hypercoagulable state in ITP patients, assess the effect of TPO-RA treatment on these mechanisms, and to identify possible biomarkers for increased risk of thrombosis.

The specific aims of the thesis were:

I. To study markers of coagulation activation and fibrinolysis (prothrombin fragment $1+2$, Ddimer and PAI-1 activity), measuring thrombin generation, sP-selectin, gene expression of Pselectin and PAI-1, and the presence of anti-phospholipid antibodies in ITP patients prior to the initiation of treatment with TPO-RAs and two, six and twelve weeks after treatment, as well as in ITP patients who had been on long-term TPO-RA treatment (more than one year), to evaluate the short- and long-term effect of treatment on these markers.

II. To assess the procoagulant properties of MVs, both PS- and TF-dependent procoagulant activity, in the plasma of ITP patients and their possible contribution to the procoagulant state and increased thrombotic risk, and to study the capacity of isolated MVs and plasma to generate thrombin in a phospholipid-dependent manner, both before and two weeks and six weeks after the initiation of treatment with TPO-RAs, to evaluate the effect of this treatment on the procoagulant activity of MVs.

III. To study markers of endothelial cell activation/injury and markers of NET formation in patients with ITP before and two weeks and six weeks after the initiation of TPO-RA treatment to explore whether these mechanisms are involved in the procoagulant state in ITP patients and to study the effect of TPO-RA treatment on these markers. 


\section{Material and methods}

\section{Study design and study population}

The study comprised two cohorts of ITP patients and controls. Patients with primary ITP were prospectively recruited from four study centres in Norway and one study centre in the United States. Inclusion criteria were as follows: 1- a diagnosis of primary ITP; 2 - age $\geq 8$ years for patients included in the United States (however all patients included from United States in the study were adults) and $\geq 18$-year-old for Norwegian patients; and 3- planned treatment with a TPO-RA either romiplostim or eltrombopag (cohort 1, total 39 patients) or patients with ITP who had been on romiplostim or eltrombopag treatment for more than one year (cohort 2, total 18 patients). Hospital employees (35 subjects) without a history of ITP and who were not on anticoagulant treatment were recruited in Norway as controls in an attempt to match for age and sex as much as possible.

Medical history, including previous venous or arterial thrombosis, comorbidity and concomitant medications, was acquired from all patients. TPO-RA treatment was initiated in patients in cohort 1 for clinical reasons, and consent was obtained to draw blood for the study and to acquire clinical information and blood test results. Samples were drawn at the first visit before the initiation of treatment and then at three time points (two weeks, six weeks and twelve weeks) after the initiation of TPO-RA treatment.

Only in article I were samples acquired from all four time points in cohort 1 as well as samples acquired from patients in cohort 2 included. In articles II and III, only three sequential samples in cohort 1, i.e., before the initiation of TPO-RA and two weeks and six weeks on treatment, were included.

\section{Blood sampling and preparation}

Blood samples were collected prior to the initiation of TPO-RA treatment (day -15 to day 0 ) and at approximately two weeks, six weeks and twelve weeks after the initiation of TPO-RA treatment for patients in cohort 1. For patients in cohort 2 and for the controls, blood samples were collected only once. Venous blood samples were collected in 1) vacuum tubes containing $3.2 \%$ sodium citrate $(0.109 \mathrm{~mol} / \mathrm{L}), 2)$ vacuum tubes containing ethylenediamine-tetraacetic acid (EDTA), 3) serum tubes from Becton-Dickinson (Plymouth, UK) and Greiner Bio-One (Kremsmünster, Austria), and 4) PAXgene Blood RNA Tubes from Qiagen (Franklin Lakes, NJ, USA) using a standard procedure. Citrated blood tubes were centrifuged within 1 hour at 
$2000 \mathrm{~g}$ at room temperature for 20 minutes to prepare platelet-poor plasma (PPP), and aliquots were stored at $-80{ }^{\circ} \mathrm{C}$ until analysis. Serum tubes were left to stand for at least 30 minutes and then centrifuged at $2000 \mathrm{~g}$ for 10 minutes, and aliquots were stored at $-80{ }^{\circ} \mathrm{C}$ until analysis. Two EDTA whole-blood tubes were acquired from each patient. The first was used the same day to measure platelet count on automated haematology instruments at local laboratories in each centre, and the second EDTA tube was immediately centrifuged at $2000 \mathrm{~g}$ for $15 \mathrm{~min}$. Aliquots of EDTA plasma were stored at $-80{ }^{\circ} \mathrm{C}$ until analysis.

\section{Regulatory approvals}

The study was approved by the South-Eastern Norway Regional Committee for Medical and Health Research Ethics (approval number 2011/1747a) and by the Institutional Review Board at Weill Medical College of Cornell University. Informed consent was obtained from all patients or their parents and controls.

\section{Assays used in the study}

An overview of the assays used in this study to evaluate the coagulation status of ITP patients and assays assessing other possible contributing players in the hypercoagulable state both before and after treatment with TPO-RAs is provided below. A more detailed discussion regarding the diagnostic value and limitations of the assays will be reviewed under "Methodological consideration".

\section{Thrombin generation assay}

Measuring the capacity to generate thrombin reflects the hyper-/hypocoagulability of the blood. A calibrated automated thrombogram (CAT) provides a reproducible method to measure thrombin generation, and the thrombin generation curve represents the overall function of the blood coagulation system [98]. The commonly measured parameters when analysing thrombin generation include the lag time, time to peak thrombin generation, peak height, endogenous thrombin potential (ETP) (the area under the curve), and velocity index [99].

In the CAT method, the addition of TF, PLs and calcium to citrated plasma results in coagulation activation and subsequent generation of thrombin. Thrombin cleaves the fluorescent substrate that is added to the reaction, releasing a fluorophore whose fluorescence intensity is recorded and automatically converted by software into thrombin generation 
concentrations (nM). The software also calculates thrombogram parameters (Figure 8), such as endogenous thrombin potential (ETP), from the area under the curve and the peak thrombin concentration. The fluorescence intensity is converted to thrombin concentration (nM) using a reference curve prepared by measuring the conversion rate of the substrate with a known concentration of thrombin with a series of specified parameters. The thrombin generation curve reflects and integrates all pro- and anticoagulant reactions that regulate the formation and inhibition of thrombin; therefore, it represents a global test of plasma coagulability.

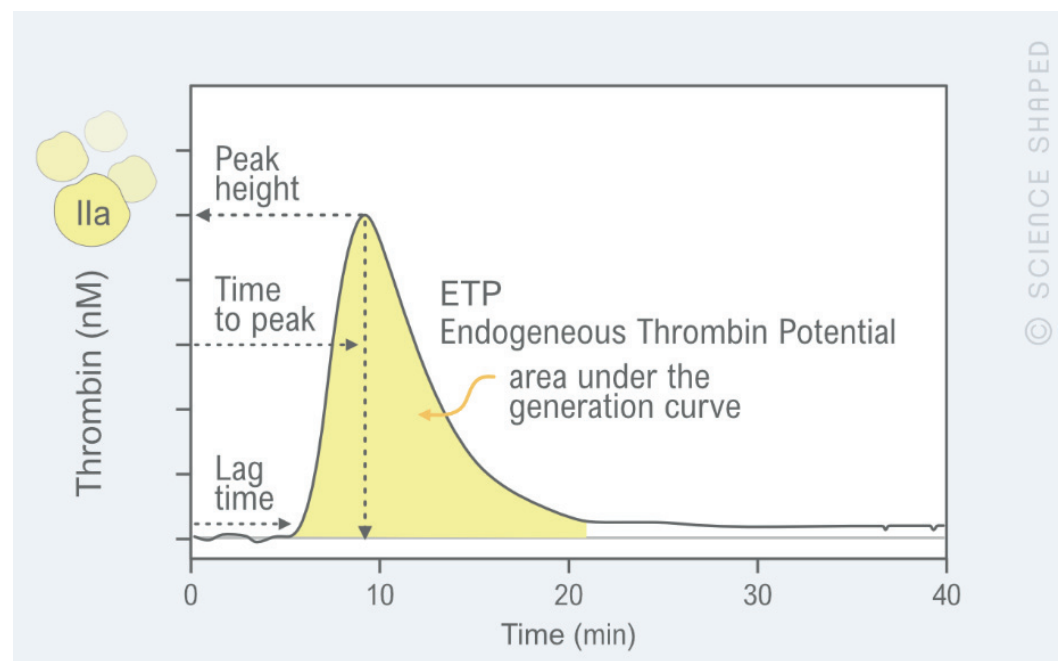

Figure 8: Typical thrombogram with relevant parameters.

Adopted with modification from: Thrombin generation assay and its application in the clinical laboratory. Tripodi A. Clinical Chemistry, 2016, 62(5):699-707 with permission from the American Association for Clinical Chemistry via Oxford University Press and Copyright Clearance Center.

The parameters of the thrombogram are as follows:

Lag time: is the time in minutes ( $\mathrm{min}$ ) that follows the addition of the trigger until the initiation of thrombin generation and is equivalent to the clotting time in a traditional coagulation test.

Peak height: represents the highest thrombin concentration (nmol) that can be generated.

Time to peak (ttPeak): is the time it takes to reach the peak and represents the velocity of thrombin generation. A short ttpeak may represent hypercoagulability.

Velocity index (VI): is defined as [peak height/(ttPeak - lag time)].

ETP: is calculated from the area under the curve (nmol thrombin $\mathrm{x} \mathrm{min)} \mathrm{and} \mathrm{represents} \mathrm{the} \mathrm{total}$ amount of thrombin generated in the sample. 
Thrombin generation is largely influenced by the pre-analytical conditions, including sample collection, centrifugation and storage. In addition, the results of thrombin generation depend on the type of reagent used regarding the concentration of the trigger, whether there is a high or low concentration of TF and a high or low concentration of PLs, and whether the assay was performed with or without the addition of thrombomodulin or APC [158]. A short lag time, high peak, short ttPeak, high VI and high ETP reflect hypercoagulability, while a long lag time, low peak, long ttPeak, low VI and low ETP reflect hypocoagulability [99].

In article I, we performed the CAT assay using a reagent containing $5 \mathrm{pM}$ TF and a relatively high concentration of PLs $(4 \mu \mathrm{M})$, which makes the CAT assay less sensitive to PLs present in the plasma. In this article, the results of parameters of the thrombogram, both for patients and controls, were normalized against those for pooled normal plasma (PNP) measured in the same run and given as a percentage, which was routine in the laboratory where this test was performed.

In article II, we performed thrombin generation in a more phospholipid-dependent manner (phospholipid-dependent thrombin generation in plasma), as we believed that patients with ITP have more PLs in their plasma. Here, we used a CAT reagent that contained the same amount of TF ( $5 \mathrm{pM})$ as in the reagent in article I but had no or a very small amount of PLs, thus making the generation of thrombin much more sensitive to the presence of PLs in the plasma. In article II, the results of the parameters of the thrombogram were given without any normalization against PNP as in article I. In addition, we performed a CAT assay to measure thrombin generation associated with MVs without any trigger (MV-associated thrombin generation). The assay was performed using MVs isolated from the plasma of ITP patients by ultracentrifugation added to PNP in which anti-TFPI was added to enhance the generation of thrombin. With this approach, we measured the contribution of both TF and PS on the MVs to the generation of thrombin.

MV procoagulant activity assays

The procoagulant properties of the MVs are linked to the exposure of PS and/or the presence of TF on their surface membrane. In article II, the procoagulant activity of MVs in patient plasma was measured using two commercially available assays: 
MV-associated PS activity

The PS-dependent procoagulant activity of MVs was measured by the Zymuphen MP Activity assay (Hyphen BioMed, Neuville-sur-Oise, France). In this assay, PS-positive MVs are captured on an ELISA plate coated with annexin V, a specific PS capture protein to which PSpositive MVs in plasma will bind with high affinity in the presence of calcium. The ability of annexin-bound PS-positive MVs to generate thrombin was measured after the addition of prothrombin, FVa and FXa to form the prothrombinase complex that cleaves prothrombin to thrombin. The ability of this complex to convert prothrombin to thrombin is dependent on the concentration of MVs exposing PS. A chromogenic substrate for thrombin is then added to assess the levels of generated thrombin. The chromogenic substrate upon splitting by thrombin will release free para-nitroaniline (pNA), which can be measured at a wavelength of $405 \mathrm{~nm}$. The values are expressed as PS equivalents $(\mathrm{nM})$ and read from a standard curve based on data from liposomes.

\section{MV-associated TF activity}

The Zymuphen MP-TF assay (Hyphen BioMed) was used to measure MV-associated TF activity. The assay is a commercially available chromogenic, FXa-generating assay. Briefly, ELISA plate coated with antibodies against TF, which bind to the extracellular domain of TF without interfering with its activity. TF-bearing MVs in plasma will be captured on the coated plate, and then FVIIa, FX and calcium will be added to the plate. The TF/FVIIa complex will form and activate FX to FXa. The amount of FXa is measured by its ability to split a specific FXa substrate, which results in the release of free pNA, which can be measured at $405 \mathrm{~nm}$. The results are expressed as TF equivalents $(\mathrm{pg} / \mathrm{mL})$ and read from a standard curve based on data from recombinant TF and synthetic phospholipids.

P-selectin, ICAM-1, VCAM-1, E-selectin, thrombomodulin

Soluble P-selectin (sP-selectin), intercellular adhesion molecule-1 (ICAM-1), vascular cell adhesion molecule-1 (VCAM-1), and thrombomodulin were measured in plasma samples, while E-selectin was measured in serum using commercial enzyme-linked immunosorbent assay (ELISA) kits (Quantikine ELISA kits from R\&D Systems, Minneapolis, MN, USA) according to the manufacturer's instructions. In short, plasma/serum samples were added to an 
ELISA plate pre-coated with a monoclonal antibody specific for ICAM-1, VCAM-1, thrombomodulin, P-selectin or E-selectin. After washing away any unbound substances, enzyme-linked polyclonal antibodies specific for ICAM-1, VCAM-1, thrombomodulin, Pselectin or E-selectin were added. Finally, a substrate solution was added to the wells, and colour developed in proportion to the amount of ICAM-1, VCAM-1, thrombomodulin, Pselectin or E-selectin bound. The intensity of the developed colour was measured.

Plasminogen activator inhibitor-1 activity

In article I, PAI-1 activity was measured with the commercial ZYMUTEST PAI-1 Activity kit (Hyphen BioMed). Briefly, microwells coated with recombinant tPA will bind to PAI-1 when present in plasma. Only active PAI-1 will bind to the immobilized tPA. A peroxidase-labelled monoclonal anti-PAI-1 antibody was added. When a peroxidase substrate is added in the presence of hydrogen peroxide, a colour will develop that is proportional to PAI-1 activity $(\mathrm{ng} / \mathrm{mL})$ in the tested sample.

Prothrombin fragment $1+2$ and D-dimer

Prothrombin fragment $1+2\left(\mathrm{~F}_{1+2}\right)$ was assayed with a commercial ELISA kit (Enzygnost $\mathrm{F} 1+2$ monoclonal) from Siemens (Marburg, Germany), and D-dimer was measured with a commercial ELISA kit (Asserachrom D-Dimer) from Diagnostica Stago (Asnieres sur Seine, France) according to the manufacturer's instructions.

mRNA expression of P-selectin and PAI-1

The sequential expression of genes encoding P-selectin (SELP) and PAI-1 (SERPINE1) was quantified as part of a transcriptome profiling study performed on whole blood specimens collected in PAXgene Blood RNA Tubes from 4 ITP patients in cohort 1 prior to and 6-12 weeks after the initiation of treatment. The Paxgene Blood RNA Kit from Qiagen was applied to extract RNA. The quantity of RNA was determined using a NanoDrop spectrophotometer ND-8000 (NanoDrop Technologies, Wilmington, DE, USA), and RNA integrity was assessed using an Agilent 2100 Bioanalyzer (Agilent Technologies, Palo Alto, CA, USA). Purified total RNA was converted to biotin-labelled amplified RNA (aRNA) using the MessageAmp ${ }^{\mathrm{TM}}$ III RNA amplification kit according to the manufacturer's instructions (Ambion, Austin, TX). 
Labelled aRNA was fragmented as described in the Affymetrix manual (Affymetrix, Santa Clara, CA) and hybridized to Affymetrix HG-U133 Plus 2.0 chips. These tests were performed at Zealand University Hospital, Roskilde, Denmark.

Anti-cardiolipin antibodies, anti- $\beta 2$ glycoprotein I, and lupus anticoagulant

Antiphospholipid antibodies (APAs) are often detected in patients with ITP. To assess the presence of such antibodies in our patient populations, anti- $\beta 2$ glycoprotein I (anti- $\beta 2 \mathrm{GPI}$ ) and anticardiolipin (aCL) immunoglobulin $\operatorname{IgM}$ and $\operatorname{IgG}$ were analysed using commercially available semiquantitative ELISA kits (QUANTA Lite $\beta 2$ GPI ELISA kit IgM and IgG and QUANTA Lite ACA IgM and IgG ELISA kits, respectively) from Inova Diagnostics (San Diego, CA, USA). The cut-off values for a positive test were defined by values higher than or

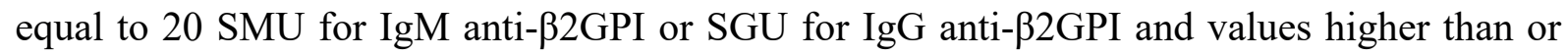
equal to $40 \mathrm{MPL}$ or GPL for aCL. Lupus anticoagulant (LA) detection was performed on an ACL TOP coagulometer (Instrumentation Laboratory, Milan, Italy) using reagents from the Instrumentation Laboratory. Screening tests were performed with silica clotting time (SCT) and dilute Russell's viper venom time (dRVVT) accompanied by confirmatory tests. The results of the SCT and dRVVT screen and confirm were converted to ratios via the clotting times of PNP, and the normalized ratios were then calculated (screen ratio/confirm ratio). The presence of LA was considered if the normalized ratio for SCT or dRVVT was greater than the local cut-off value $(>1.25)$.

Markers of NET formation: citrullinated histone 3-DNA and cell-free DNA

NETs can promote thrombosis through platelet activation/aggregation or by enhancing thrombin generation via factor FXII activation. To evaluate NET formation, we measured citrullinated histone H3 (H3Cit) complexed to DNA (H3Cit-DNA), which is considered a specific marker of NET formation. We also measured cell-free (cf) DNA, although this marker is less specific for NET formation since free DNA can also be released in other forms of lytic cell death [159].

Markers of NET formation were quantified at Hospital JM Morales Meseguer, Murcia, Spain. H3Cit-DNA was quantified in EDTA plasma using a sandwich ELISA according to the method proposed by other authors [160]. Briefly, EDTA plasma was added to microwell plates coated 
with a specific anti-H3Cit antibody that binds to the H3Cit-DNA complex in plasma. Then, a secondary antibody, anti-DNA peroxidase (POD) antibody, was added. After washing, a peroxidase substrate was then added to the wells, a colour will then develop, and the optical density (OD) can be measured at wavelength of $405 \mathrm{~nm}$.

The cfDNA was quantified by using cell-impermeant SYTOX dye (Thermo Fisher), which emits fluorescence after binding to the free DNA. Diluted EDTA plasma in Tris-buffered saline (TBS) was mixed 1:1 with $1 \mu \mathrm{M}$ SYTOX dye in a 96-well plate and incubated for 15 minutes in the dark. The fluorescence was measured (excitation $488 \mathrm{~nm}$, emission $528 \mathrm{~nm}$ ) in a plate reader (Biotek Sinergy Ht), and the autofluorescence was subtracted. The DNA concentration in the samples was calculated by extrapolating to a standard line of known concentrations of salmon sperm DNA (Sigma-Aldrich, Madrid, Spain).

\section{Statistical analysis}

In article I, we used cohort 1 with the four sequential samples to investigate the potential variation over time of the various parameters of the thrombin generation curve, $\mathrm{F}_{1+2}$, D-dimer, PAI-1, platelet count and sP-selectin. In addition to time, age and sex, the analyses assessed the potential effects of the state of treatment (pre-treatment or on treatment with TPO-RA) and the type of TPO-RA. Platelet count was used as an additional explanatory variable for sP-selectin due to an assumed causal impact of platelet counts on sP-selectin. With four measurements per patient, these data were analysed by a random effects model. Data transformations for normality distribution were found by the use of Box-Cox analyses for each outcome variable. Insignificant effects were removed from the models one at a time until all effects showed significance. The 'Ime4' package of the $\mathrm{R}$ program was used for this analysis. The statistician co-author performed these analyses.

PAI-1 results below the quantification level $(<0.9 \mathrm{ng} / \mathrm{mL})$ were considered missing despite these values being known to be below this level. We used multiple imputation to retrieve information about the distribution of PAI-1 below this value.

Comparisons between pre-treatment values in cohort 1 or on-treatment values in cohort 2 and controls were carried out using Mann-Whitney tests, except for analyses of differences in PAI1, where the chi-square test was used. 
For the analysis of mRNA expression of P-selectin and PAI-1, the 'affy' package of the R program was used for background correction, normalization, and expression index calculation using robust multi-array average (RMA) [161]. Differences in gene expression in ITP patients before and after treatment with TPO-RAs were calculated using the regularized t-test limma for paired data [162]. A 2-tailed p-value of less than 0.05 was considered significant in this hypothesis-generating study.

In article II, comparisons of data between ITP patients (before or during treatment with TPORAs) and healthy controls were carried out using the Kruskal-Wallis test with Dunn's multiple comparisons test. To compare data from ITP patients before and after the initiation of treatment with TPO-RAs, the Friedman test with Dunn's multiple comparisons test was used. The correlation between different variables was assessed with Spearman's rank-order correlation test. Statistical analyses were performed using GraphPad Prism, and $\mathrm{p}<0.05$ was considered statistically significant.

In article III, as in article II, comparisons between ITP patients (before or during treatment with TPO-RAs) and healthy controls were carried out using the Kruskal-Wallis test with Dunn's multiple comparisons test. To compare data from ITP patients before and after the initiation of treatment with TPO-RAs, the Friedman test with Dunn's multiple comparisons test was used for the non-parametric data (ICAM-1, VCAM-1, H3Cit-DNA and cfDNA) as in article II; however, one-way ANOVA with Dunn's multiple comparisons was used for the parametric data (thrombomodulin and E-selectin). Statistical analyses were performed using GraphPad Prism, and $\mathrm{p}<0.05$ was considered statistically significant. 


\section{Summary of the articles}

\section{Article I (Effect of Thrombopoietin Receptor Agonists on Markers of Coagulation and P-selectin in Patients with Immune Thrombocytopenia).}

In article I, we aimed to assess the procoagulant profile in a group of ITP patients (cohort 1) before starting TPO-RA treatment and then evaluate this profile in these patients after two weeks, six weeks and twelve weeks of TPO-RA treatment. The procoagulant profile was also evaluated in another group of ITP patients (cohort 2) who had been on TPO-RA treatment for more than one year. We measured the following markers of coagulation activation: prothrombin fragment $1+2\left(\mathrm{~F}_{1+2}\right)$ and D-dimer. We also performed a thrombin generation assay (CAT) before and sequentially after initiating treatment with TPO-RAs using a reagent with a relatively high concentration of PLs. In addition, we measured sP-selectin, which is considered a marker of platelet activation (and endothelial cell activation), and PAI-1 activity, an inhibitor of tPA and therefore an important regulator of fibrinolysis. To confirm our findings of increased sP-selectin and PAI-1 in TPO-RA-treated patients, we performed sequential expression of genes coding for P-selectin (SELP) and PAI-1 (SERPINE1) in 4 patients before and 6-12 weeks after the initiation of treatment. In addition, we measured APAs, including anti- $\beta 2 \mathrm{GPI}$ and $\mathrm{aCL}$ (IgM and $\operatorname{IgG})$, as well as LA.

We did not find significant differences in the parameters of thrombin generation between ITP patients prior to the initiation of treatment with TPO-RAs and controls, nor did we find significant changes in thrombin generation parameters after the initiation of treatment with TPO-RAs. The levels of $\mathrm{F}_{1+2}$ and D-dimer were higher in ITP patients prior to the initiation of treatment with TPO-RAs than in controls. Treatment with TPO-RAs was not associated with a further increase in these markers. However, the levels of these markers were higher in ITP patients who had been on TPO-RA treatment for more than one year than in controls. We also found that the levels of PAI-1 activity were higher in ITP patients prior to the initiation of treatment with TPO-RAs than in controls. The levels increased after the initiation of treatment with TPO-RAs compared with pre-treatment levels. PAI-1 activity was also higher in ITP patients who had been on TPO-RA treatment for more than one year than in controls. Pretreatment levels of sP-selectin did not differ from controls; however, sP-selectin levels increased significantly after the initiation of treatment with TPO-RAs. The levels of sP selectin were also significantly higher in those who had been on TPO-RA treatment for more than one year than in controls. We also found that the expression of the P-selectin gene (SELP) was significantly upregulated, with a 1.6-fold change in the 4 patients after treatment, i.e., in line 
with the increased levels of sP-selectin. Although PAI-1 activity increased significantly after initiating TPO-RA treatment, there was no statistically significant increase in the expression of the gene encoding PAI-1 (SERPINE1) after this treatment. In addition, we found that $23 \%$ of ITP patients included in this study had at least one positive test for APAs.

In this study, we showed that ITP patients had higher levels of $\mathrm{F}_{1+2}$, D-dimer and PAI-1 activity and that TPO-RA treatment was associated with an increase in sP-selectin and a further increase in PAI activity.

\section{Article II (Increased Microvesicle-associated Thrombin Generation in Patients with Immune Thrombocytopenia after Initiation of Thrombopoietin Receptor Agonists).}

Because of the potential role of MVs as biomarkers of thrombotic events [163], we assessed their procoagulant activity in ITP patients and evaluated the effect of treatment with TPO-RAs on this procoagulant activity. We measured MV-associated TF activity and MV-associated PS activity in plasma before and after the initiation of TPO-RA treatment. In addition, we measured the capacity of MVs to generate thrombin by performing CAT assays with two distinct approaches that differed from the CAT assay performed in article I: the first by using MVs isolated from the plasma of ITP patients (MV-associated thrombin generation) and the second by using a reagent with no/only a minimal amount of PLs, which makes the measured generated thrombin in the plasma dependent on amount of PLs in the patient's plasma (phospholipiddependent thrombin generation in plasma) as described in the methods.

We found no significant differences in the MV-associated PS activity measured by the Zymuphen kit or in the parameters of phospholipid-dependent thrombin generation in plasma before treatment with TPO-RAs compared with controls. After two and six weeks of TPO-RA treatment, ITP patients had higher MV-associated PS activity and phospholipid-dependent thrombin generation in plasma than controls. Although some of the parameters of phospholipiddependent thrombin generation in plasma in ITP patients tended to increase after the initiation of TPO-RAs compared with pre-treatment levels, the difference did not attain statistical significance. No significant differences in the parameters of MV-associated thrombin generation were found between ITP patients before treatment and controls; however, this assay showed an increase in patients two weeks after the initiation of TPO-RA compared with pretreatment levels as well as with the levels in controls. MV-associated TF activity in plasma from ITP patients before TPO-RA treatment did not differ significantly from the activity found 
in healthy controls. MV-associated TF activity in ITP patients did not show a significant increase after the initiation of TPO-RA treatment.

This study showed that the treatment of ITP patients with TPO-RAs was associated with increased phospholipid-dependent procoagulant activity of MVs leading to more thrombin generation.

Article III (Markers of Endothelial Cell Activation and Neutrophil Extracellular Traps Are Elevated in Immune Thrombocytopenia but Are not Enhanced by Thrombopoietin Receptor Agonists).

In this article, we aimed to evaluate whether patients with ITP have increased endothelial cell activation/injury and NET formation and to study the effect of treatment with TPO-RAs on these potential contributors to the procoagulant state in these patients. We measured markers of endothelial cell activation/injury (ICAM-1, VCAM-1, E-selectin and thrombomodulin) and markers of NET formation (H3Cit-DNA and cfDNA) before the initiation of TPO-RA treatment and two weeks and six weeks after treatment initiation.

We found that ITP patients, both before and after the initiation of TPO-RA treatment, had elevated plasma levels of markers of endothelial cell activation/injury, ICAM-1 and thrombomodulin, compared with the levels in healthy controls; however, no significant differences in the levels of VCAM-1 and E-selectin between ITP patients and controls were found. In addition, we showed that ITP patients had elevated levels of the NET formation marker H3Cit-DNA compared with controls; however, the levels of cfDNA were not elevated in ITP patients. Treatment with TPO-RAs was not associated with an increase in either endothelial activation markers or markers of NET formation.

Thus, this study showed that endothelial cell activation and NET formation were increased in ITP patients prior to initiating TPO-RA treatment, suggesting that these two mechanisms may contribute to the increased thrombotic propensity in ITP patients. Treatment with TPO-RAs was not associated with significant changes in markers of endothelial cell activation or NET formation. 


\section{Discussion}

The increased risk of thromboembolic events in ITP patients in general and in TPO-RA-treated ITP patients in particular triggered our interest in studying the possible underlying mechanisms. The occurrence of thrombosis despite the presence of thrombocytopenia represents both a pathophysiological enigma and a clinical dilemma. Why do patients with thrombocytopenia, who are expected to have a reduced haemostatic capacity with increased bleeding risk, develop both arterial and venous thrombosis? Do ITP patients develop compensatory mechanisms to reduce bleeding risk caused by thrombocytopenia? There is no doubt that thromboembolism in ITP represents a clinical challenge since the anticoagulants and/or platelet inhibitors required for the treatment of thromboembolism further increase the risk of bleeding.

Several studies have investigated the presence of a hypercoagulable state in ITP patients and the possible factors that may contribute to this hypercoagulable state. Nevertheless, the underlying mechanisms involved in the development of arterial and venous thrombosis in ITP patients in general and in those treated with TPO-RAs remain poorly understood.

Reports have shown that many patients with ITP have APAs; however, there are conflicting data regarding the association between the presence of APAs (aCL and/or anti- $\beta 2$ GPI antibodies and/or LA) and thrombosis in ITP patients. In a large retrospective multicentre study evaluating thrombotic risk in ITP by Ruggeri et al. [144], a sub-cohort of 560 patients positive for LA/APA at diagnosis was evaluated, showing no apparent association between LA/APA and thrombosis. However, other studies in ITP patients have found an association between APAs and thrombosis. The study by Kim et al. [164] on 165 ITP patients identified LA as an independent risk factor for thrombosis. A meta-analysis of a total of 1574 primary ITP patients found that LA positivity and, to a lesser extent, aCL antibodies were associated with an enhanced risk of thrombosis [143]. It has also been shown that ITP patients have increased levels of circulating procoagulant red-cell- and platelet-derived MVs [55, 56], as well as an increase in some coagulation factors, such as FVIII, FIX and FXI [56]. In addition, reticulated/immature platelets have been found to be increased in ITP patients [165], and TPORAs may enhance thrombotic risk as they increase the platelet count in a relatively short time by stimulating the production of young and more active platelets. Limited in vitro studies on the effect of these agents on the function of platelets did not show consistent alterations in platelet function directly linked to hyperactivity [166, 167].

Our approach to understanding the mechanisms underlying thrombosis in ITP patients in general and in those treated with TPO-RAs in particular was to explore the presence of a 
hypercoagulable state in ITP patients before the initiation of TPO-RA treatment and to study whether treatment with TPO-RAs enhances this hypercoagulability and thus contributes to increased thrombotic risk.

General methodological issues for all articles in this study, as well as the main results of each article, are discussed below.

\section{Methodological considerations}

\section{Study population}

We included 39 patients with primary ITP who had clinical indications for the initiation of treatment with TPO-RA and 18 patients who had already been on TPO-RA treatment for more than a year. Thus, we established two cohorts of patients:

- The first cohort consisted of patients starting with TPO-RAs (romiplostim or eltrombopag) who were followed up for twelve weeks, regardless of whether they responded to treatment, to determine the short-term effect of TPO-RAs on markers of coagulation activation and other potential markers that are known to promote or enhance thrombosis.

- The second cohort consisted of ITP patients who had been on a TPO-RA for more than one year to determine the long-term effect of TPO-RAs on coagulation activation and other investigated markers.

In addition, we recruited age- and sex-matched healthy controls to compare the studied parameters in ITP patients before and during TPO-RA treatment with those in controls to determine whether ITP patients (non-TPO-RA-treated/TPO-RA-treated) have a procoagulant profile.

The study had wide inclusion criteria, and only patients with secondary ITP were excluded. Whereas this may increase the generalizability of the results, it may also have an impact on the study results; therefore, some caution is merited when interpreting the results, the reasons for which are outlined below.

First, although the two TPO-RAs, romiplostim and eltrombopag, share the same main intracellular signaling pathway (Figure 7), they differ in their stimulation of some other pathways [141, 150], and how the effect of the activation of these pathways might have affected our studied parameters is unknown. Another problem is the difference in the dose titration time between the two medications. While eltrombopag requires two weeks to reach the maximum 
dose, romiplostim may take up to ten weeks to reach the maximum dose. We did not perform subgroup analyses according to the type of TPO-RA due to the small sample size, although in the first article, we included the effect of the type of TPO-RA in the mixed-effect model without showing an effect.

Second, all patients had failed to respond to or had relapsed after an initial response to first-line therapies and very often to one or more second-line therapies, including rituximab and splenectomy. However, the inclusion of our patients spanned many years, starting from 2011 to 2018. During this period, the approved label for TPO-RA changed few times. Initially, romiplostim and eltrombopag were approved and reimbursed only for refractory patients (those who failed splenectomy or in whom splenectomy was contraindicated); thus, most of the patients included in the beginning of the study were splenectomized and had more prolonged and refractory disease. The label was later changed to chronic ITP patients who had failed to respond to at least one other treatment (e.g., corticosteroids, immunoglobulins) [150], thus allowing earlier use of TPO-RAs and almost no splenectomized patients, resulting in heterogeneity in our studied population. We do not know whether these changes in the indications to use TPO-RAs might have affected our results, and subgroup analysis was not performed because of the small sample size. However, in article II, we outlined the two splenectomized patients and the two non-responders in the figure for phospholipid-dependent thrombin generation in plasma without performing statistical analysis.

Third, due to the anticipated difficulty in recruiting a sufficient number of ITP patients in need of starting TPO-RA treatment only in Norway, patients were also recruited from a hospital in the USA (New York Presbyterian Hospital, Weill Cornell). Including patients from two continents may have resulted in a more heterogeneous study population with different ethnic backgrounds and baseline characteristics, and other possible environmental factors, which could have affected the results. We did not perform statistical adjustments since information on ethnic background was not acquired in the study.

Fourth, many of the patients were on other medications, in particular steroids (with some adjustment of the dose during the study mainly after achieving response), and a few were on other immunosuppressive medications, e.g., cyclosporine and mycophenolate mofetil, as well as few patients who had received treatment with IVIg prior to blood sampling. We cannot exclude that these comedications may have impacted the results of at least some of the laboratory analyses. However, having serial measurements for each patient before the initiation of and during TPO-RA treatment may have contributed to minimizing the influence of stable 
concomitant drugs on the effect of treatment with TPO-RAs on the different markers that were tested in this study, as each patient served as his or her own control.

Furthermore, we did not include a cohort of patients on other types of medications, such as rituximab, or a cohort of only splenectomized patients. The inclusion of a third cohort would have been of significant clinical value to evaluate whether the effect is related to a specific therapy or the disease itself on the procoagulant profile, particularly in patients who are in remission after splenectomy or rituximab.

Fifth, the controls were not perfectly matched with patients. We recruited our controls from hospital employees in Norway only, knowing that the difference in ethnicity and background morbidity could have impacted the results. In addition, our controls included only one subject over 70 years of age, creating an imperfect match.

\section{Timing of blood sampling}

We collected blood samples before the initiation and two, six, and twelve weeks after the initiation of TPO-RA treatment. This timing was chosen since we were interested in studying the short-term treatment effects on the haemostatic markers, and we anticipated that by twelve weeks, most patients would have achieved a treatment response. In addition, we wanted to study the long-term effect of these medications and whether changes occurring early after initiating this treatment would persist for a longer time; therefore, we also collected blood samples from patients with ITP who had been treated with TPO-RAs for more than one year. Although unlikely, the timing of blood sampling could theoretically have influenced our results if changes in the studied markers occurred transiently in the periods between blood sampling. In addition, the response to TPO-RA treatment varies from patient to patient, meaning that not all patients had increased platelet counts in response to treatment at the different points of blood sampling. In the study by Alvarez-Roman et al. [165], blood samples were collected after achieving a response to TPO-RA treatment with a pre-defined platelet count before acquiring blood samples. Consequently, blood samples were collected at different lengths of follow-up after treatment initiation since the time to achieving response varied from patient to patient. Therefore, one could again have missed changes in the haemostatic markers occurring after the initiation of treatment and until achieving the pre-defined platelet response. 
Study sample size

Another important factor to consider in this study is the small sample size, especially for article II and article III. Although we included patients with ITP from four study centres in Norway and one centre in the USA, we were able to include only a total of 57 patients in the study. This is due to the low prevalence of ITP in the population, in addition to the fact that only a small percentage of ITP patients fail other types of treatment and need to start with TPO-RA. The power of a study depends on, among other factors, the sample size. A small sample size may have reduced the probability of the study to detect statistically significant differences between the groups, and there is a real possibility that some of the non-significant differences observed in articles II and III would have reached statistical significance if the sample size had been larger.

Furthermore, there were some missing samples during the follow-up period, as sampling was not performed for various reasons. In addition, some samples were not taken precisely as scheduled two, six and twelve weeks after the initiation of TPO-RA treatment. In article I, missing samples were dealt with by using multiple imputations of the missing values; however, only one sample was missing in articles II and III. In addition, a few patients were excluded from some of the analyses in article I because of concomitant use of anticoagulant medication that might have interfered with some of the clot-based analyses, e.g., thrombin generation and LA.

Despite the considerations mentioned above, our findings, although based on a relatively small number of ITP patients, are strengthened by the availability of repeated measurements for each patient. In addition, some of our results are consistent with findings by other groups; therefore, together, these results provide indications regarding the presence of a hypercoagulable state in ITP patients and the possible enhancing effect of TPO-RA treatment on this state.

\section{Pre-analytical conditions}

Variation in the pre-analytical conditions caused by the inclusion of patients from different sites, and different laboratory personnel drawing and processing the samples may have had an impact on the results. Although all centres operated with the same sampling protocol, having different operators and environmental conditions might have resulted in some variations in the results between the centres. However, these factors will have a similar effect on all the samples for each patient; therefore, the impact on the results would have been minimal. 
Choice and limitations of coagulation tests

Thrombin generations: phospholipid-dependent or not?

The CAT assay, originally developed by Hemker et al., is used to measure thrombin generation in a variety of clinical settings and provides a reproducible method that can be incorporated into clinical laboratory practice [168]. The assay uses a trigger, such as TF, to initiate coagulation. In PPP, procoagulant PLs (in general approximately $4 \mu \mathrm{M}$ ) are normally added to amplify the effects of TF [158]. In platelet-rich plasma (PRP), platelets take the role of PLs as amplifying surfaces [158]. Altman et al. showed that agents that increase platelet reactivity accelerate thrombin generation in PRP [169]. Thrombin generation is dependent upon the amount of added TF and PLs [158]. Therefore, the use of different reagents affects the results of thrombin generation depending on the concentrations of the trigger, TF, and PLs.

To measure thrombin generation in article I and phospholipid-dependent thrombin generation in plasma in article II, we performed CAT assay in PPP. However, in article I, we used the PPP reagent, which contains a relatively high concentration of PLs $(4 \mu \mathrm{M})$, which makes the CAT assay less sensitive to PLs present in the patients' plasma. In this study, we found no significant difference between ITP patients and controls, nor did we find significant changes in thrombin generation after the initiation of TPO-RA treatment.

In the phospholipid-dependent thrombin generation in plasma in article II, we used similar plasma samples as in article I (PPP), but we used a more PL-sensitive reagent, the PRP reagent, which has no or a very small amount of PLs. We found no differences in the parameters of thrombin generation between ITP patients before TPO-RA treatment and controls. However, by using this approach, we found an increase in thrombin generation in TPO-RA-treated patients after two weeks (shorter ttPeaak, higher peak and VI) and after six weeks (shorter ttPeaak, higher peak, VI and ETP) of TPO-RA treatment compared with controls. This was paralleled by increased MV-associated PS activity, indicating increased procoagulant PLs (PSpositive MVs) in plasma after TPO-RA treatment. Although some of the parameters of the phospholipid-dependent thrombin generation (peak, VI and ETP) showed an increasing trend after the initiation of TPO-RAs compared with pre-treatment levels, the differences did not attain statistical significance. 
MV-associated thrombin generation

In this approach, a CAT assay was performed using isolated MVs from PPP from ITP patients and controls without the addition of any other trigger. MVs were isolated by high-speed centrifugation and added to PNP to which anti-TFPI was added to enhance the generation of thrombin. The advantage of this approach is that it specifically tests the ability of procoagulant MVs to generate thrombin. Another advantage of this approach is the removal of other plasma factors that may affect thrombin generation. Measuring thrombin generation directly in plasma or by using isolated MVs can be influenced by pre-analytical factors related to blood sampling, plasma preparation and freezing/storing [170]. In addition, some variation could be caused by the method used to pellet the MVs. The commonly used centrifugation speed is in the $10000-$ $20000 \mathrm{~g}$ range [171]. We used $17000 \mathrm{~g}$ for $30 \mathrm{~min}$ to isolate the MVs from all samples. As the pellet from a high-speed spin may contain protein complexes/aggregates and other contaminants, each pellet was resuspended in Tris-buffered saline with $0.5 \% \mathrm{v} / \mathrm{v}$ bovine serum albumin and centrifuged to aid in the removal of these impurities. As all the sequential samples and the samples of the controls were processed by the same procedure at the same time, this method will reduce the effects on the results related to sample preparation.

\section{Statistical methods}

A general weakness of our study is the relatively low number of patients, which affects the possibility of detecting existing significant effects. However, this has to some extent been compensated by having 3-4 repeated measurements for each patient. Small sample size also impedes testing for distributions. In the articles included in the thesis, we used both parametric and non-parametric statistical tests to compare patients with controls and to compare patients before and after treatment. Although non-parametric tests are useful for small sample sizes when their distribution cannot be assessed, they tend to have less power than parametric tests. In article I, comparisons between patients and controls were carried out using the MannWhitney test. When we compared the sequential samples in this article where we had up to 4 time points for each patient, we chose to use a mixed effects model. This is a regression model that takes into account that multiple measurements taken on the same patients will be correlated. The model assumes that different patients respond similarly to the covariates (age, sex, time, etc.) but allows for individual levels of the response. These individual levels are considered random and represent the sample at hand. Patients are, therefore, included as random effects in the model. This model has the advantage that it does not rely on having measurements at all timepoints for all patients but utilizes all available measurements. 
In articles II and III, we did not include the last time point (after 12 weeks of treatment) or patients on treatment for more than one year, either because of a large number of the samples were not available or to reduce the cost of analysis. In these two articles, comparisons of data between ITP patients and controls were carried out using the Kruskal-Wallis test with Dunn's multiple comparisons test. We did not use mixed effects model to compare sequential samples in articles II and III because fewer time points were included (3 time points) and there were few or no missing samples. Non-parametric statistics were carried out for repeated measures (Friedman test) in article II and both parametric (one-way ANOVA) and non-parametric statistical tests (Friedman test) according to the distributions of the data in article III. In both articles II and III, we used correction for multiple comparisons to limit the risk of finding falsely significant results for any of the comparisons performed (risk of type 1 error). Both small sample size and the correction for multiple comparisons cause a loss of power [172]; therefore, some statisticians do not recommend correction for multiple comparisons since such adjustment may also result in a reduced ability to detect true significant differences.

It is important to choose a proper statistical analysis for a given set of data and a given clinical objective. Failure to do so may lead to a misinterpretation of the data and false conclusions. Our choices of statistical methods for the various analyses reflect an aim to utilize the data in an optimal manner and observe their limitations with respect to sample size and what assumptions could be made about their distributions. We consider this a conservative approach. Nevertheless, we found significant and consistent differences of clinical interest.

\section{Discussion of the main findings}

In article I, we found that ITP patients had significantly higher levels of $\mathrm{F}_{1+2}$ and D-dimer prior to the initiation of TPO-RA treatment than controls. $\mathrm{F}_{1+2}$ and D-dimer remained high after treatment with TPO-RAs, but they did not increase further. The levels of $\mathrm{F}_{1+2}$ and D-dimer were also higher in ITP patients who had been treated with TPO-RAs for more than one year than in controls. Prothrombin fragment $1+2$ is released when the prothrombinase complex $(\mathrm{FXa} / \mathrm{FVa})$ converts prothrombin to thrombin [173]; thus, elevated levels of $F_{1+2}$ in ITP patients reflect the presence of coagulation activation. D-dimer is generated when cross-linked fibrin polymers are degraded by plasmin, and thus elevated levels indicate both coagulation activation and fibrinolysis. Since elevated levels of $F_{1+2}$ and D-dimer were found in ITP patients prior to treatment with TPO-RAs as well as in those who had been treated with TPO-RAs for more than one year, we believe that there is ongoing coagulation activation in patients with ITP, regardless 
of the type of treatment, indicating that the disease itself is prothrombotic. This may explain the findings of an increased risk of VTE in the ITP population observed in epidemiological studies compared to the risk in the general population. However, treatment with TPO-RAs did not result in significant elevation of $\mathrm{F}_{1+2}$ and $\mathrm{D}$-dimer, which may indicate that treatment with TPO-RAs does not cause further activation of the coagulation system.

In addition, our study showed that PAI-1 activity was significantly higher in ITP patients before initiating treatment with TPO-RAs and in those who had been on treatment with TPO-RAs for more than one year compared with controls. PAI-1 activity increased after the initiation of TPORA treatment, and then there was a slight decline; however, the levels remained higher in ITP patients than in healthy controls throughout the follow-up period of the study. Reduced fibrinolysis is a risk factor for both venous and arterial thrombosis [174, 175]. PAI-1 has been shown to be the main determinant of increased plasma clot lysis time, which indicates reduced fibrinolysis, and high levels of PAI-1 are associated with venous thrombosis [176] and ischaemic heart disease [177]. Elevated levels of PAI-1 in ITP patients were also observed by Alvarez- Roman et al. The group also showed, by using rotational thromboelastometry (ROTEM), that the clot in ITP patients was more resistant to fibrinolysis, and they attributed this to the increased levels of PAI-1 since no differences were found in other fibrinolysis-related proteins, including tPA, uPA or TAFI activity [55].

Both increased coagulation activation and impaired fibrinolysis before the initiation of treatment with TPO-RAs support the presence of a hypercoagulable state in ITP patients, and the further increase in PAI-1 activity after the initiation of TPO-RA treatment may contribute to the increased thrombotic risk associated with the use of these agents.

The levels of sP-selectin in ITP patients before initiating treatment with TPO-RAs did not differ significantly from those in healthy controls. However, sP-selectin increased significantly two weeks after initiating treatment with a TPO-RA, and the levels remained increased at six and twelve weeks of treatment. In addition, the levels of sP-selectin in ITP patients who had been on TPO-RAs for more than one year were significantly higher than the levels in ITP patients before the initiation of treatment with TPO-RAs as well as the levels in healthy controls. Furthermore, we found increased expression of SELP, which is in line with the increase in sPselectin.

Following platelet stimulation, P-selectin becomes expressed on the platelet surface, where it is rapidly shed into the circulation [76], and this shedding from activated platelets is thought to be the main source of the soluble form of P-selectin found in the circulation [81]. Although it 
was reported that $\mathrm{P}$-selectin expressed on the membrane of activated endothelial cells would be recycled back into the cell, a study showed that part of the soluble P-selectin found in plasma might also be of endothelial origin [83]. Thus, increased sP-selectin in the circulation reflects mainly platelet activation. Studying the effect of eltrombopag on platelets in healthy subjects did not show changes in their function [178].

Data on the function of platelets induced by TPO-RAs in ITP patients have shown some inconsistent results. In a small hypothesis-generating study, Haselboeck et al. monitored platelet activation during eltrombopag treatment in three ITP patients over several weeks and found that the expression of P-selectin, which was already elevated before treatment, and platelet-monocyte aggregation increased further in the first weeks after initiating eltrombopag treatment, indicating ongoing platelet activation during the early period of treatment [179]. Subsequently, the same group investigated the function of platelets in vivo and after the in vitro addition of agonists in a larger study of ITP patients treated with eltrombopag and control ITP patients [167]. They found that the expression of P-selectin decreased after treatment with eltrombopag without agonist stimulation but increased upon activation with thrombin receptor activator peptide-6 (TRAP-6) after eltrombopag treatment compared with baseline. The expression of P-selectin was significantly higher after stimulation with TRAP-6 in eltrombopag-treated patients at a platelet count of $>50 \cdot 10^{9} / \mathrm{L}$ than in control ITP patients not treated with eltrombopag even after adjustment for platelet counts [167]. Psaila et al. showed higher platelet activation in ITP patients before treatment with eltrombopag (higher expression of P-selectin and GPIb) than in healthy controls. In contrast to the previous study, they found a slight increase in the expression of P-selectin after treatment with eltrombopag without agonist stimulation in both responders and non-responders. They also found a slight but non-significant increase in TRAP-induced platelet surface P-selectin expression after treatment with eltrombopag when both responders and non-responders were considered together; however, when comparing responders and non-responders, only responders showed increased expression of P-selectin in response to TRAP-6 stimulation [166].

The expression of P-selectin on the activated platelet surface promotes platelet-leukocyte adhesion and the binding of procoagulant MVs to platelets through the interaction of the PSGL1 ligand and platelet P-selectin at the site of thrombus formation and participates in clot propagation [66]. Furthermore, soluble or membrane-bound P-selectin increases PS expression on monocytes [180]. Higher levels of sP-selectin have been shown to predict thrombosis in cancer patients [181]. 
The increased levels of sP-selectin observed in our study after treatment with TPO-RAs may indicate increased platelet and endothelial cell activation, but since, in article III, we could not show an increase in markers of endothelial cell activation after this treatment, we are more inclined to believe that the increased sP-selectin reflects, most likely, increased platelet activation by TPO-RAs. However, because of the concomitant rise in platelet count, one may suspect that the increase in $\mathrm{SP}$-selectin after the initiation of treatment with TPO-RAs is related to the increase in the platelet count occurring in response to TPO-RA treatment. We therefore studied the effect of platelet count on sP-selectin in the linear mixed model, which showed a significant effect. However, we found no clear association between sP-selectin levels in those with good platelet responses versus those with no or poor platelet responses, indicating that this increase in sP-selectin was due to not only increased platelet count, but also increased in vivo platelet activation.

Nevertheless, since the platelet count in ITP patients reflects the net result of platelet production in the bone marrow and the counteracting platelet destruction in the spleen, it is possible that ITP patients who do not respond to TPO-RAs have extensive turnover due to very high destruction activity resulting in the consumption of all newly produced platelets. This theory can be supported by the fact that the addition of immunosuppressants to TPO-RA therapy can improve the response to TPO-RAs. Hence, one cannot exclude the possibility that the elevated levels of sP-selectin may also reflect increased platelet production and concomitant destruction. In line with other studies, our study showed that a high proportion of ITP patients $(23 \%)$ had positive tests for APAs. Although APAs are common in ITP patients, their role in the occurrence of thrombosis in these patients has been controversial. However, a large metaanalysis including 1574 ITP patients showed that the pooled odds ratios for the risk of all thromboses associated with the presence of LA and aCL were 6 and 2, respectively, compared to those with no APAs [143]. APAs have been implicated in the dysregulation of haemostatic balance, as they may interfere with different haemostatic reactions, including the inhibition of antithrombotic control mechanisms, the inhibition of fibrinolysis and the activation of coagulation factor XI [182]. They have also been shown to activate other cells, such as platelets [183], and are involved in the activation of the complement system [184].

In article I, we did not find significant differences in the parameters of thrombin generation between ITP patients before initiating TPO-RA treatment or those on TPO-RA treatment for more than one year and controls. We also did not observe significant changes in the parameters of thrombin generation at two weeks, six weeks or twelve weeks after the initiation of treatment 
with TPO-RAs. We performed the CAT assay using PPP reagent, which contains TF (5 pM) and relatively high amounts of PLs $(4 \mu \mathrm{M})$. Alvarez-Roman et al. performed CAT assay in a cohort of 13 ITP patients and found that ETP and peak height were higher and ttpeak was shorter in ITP patients prior to the initiation of treatment with TPO-RAs than in healthy controls. However, in line with our results, they did not find significant changes in these parameters after achieving a response to TPO-RA treatment. They performed a CAT assay in platelet-free plasma and used a different reagent (PPP reagent LOW) that contains a much lower TF concentration $(1 \mathrm{pM})$ than the reagent that we used $(5 \mathrm{pM})$ but with the same amounts of PLs $(4 \mu \mathrm{M})$. These differences in the method could, at least partly, contribute to the differences in the results. In addition, the small sample size in both studies and the variations in the preanalytical conditions may further contribute to the differences in the results.

There is an increasing body of evidence showing that MVs are procoagulants and that they, through exposure to PS, provide binding sites for activated coagulation factors and promote subsequent thrombin formation [51]. Some MVs, especially monocyte- and tumour-derived MVs, may also express TF, a primary initiator of coagulation, and could both support and initiate thrombin generation [185]. As previous studies have shown that platelet- and red-cellderived MVs are increased in ITP patients $[55,56]$, we aimed in article II to evaluate the role of MVs in the procoagulant state in ITP patients and to study whether treatment with TPO-RAs increases this procoagulant activity of MVs. To assess the procoagulant activity of MVs in the plasma of ITP patients and the effect of TPO-RA treatment on this activity, we used commercial kits to measure MV-associated TF activity and MV-associated PS activity before and after the initiation of treatment with TPO-RAs. In line with the study by Alvarez-Roman et al., we found no statistically significant difference in MV-associated TF activity between ITP patients before TPO-RA treatment and controls. Treatment with TPO-RAs did not cause significant changes in MV-associated TF activity. Alvarez-Roman et al. explored the cellular origin of MVs in ITP patients using flow cytometry and found increased platelet- and red-cell-derived MVs. They did not find a significant increase in the number of monocyte-derived MVs [55]. It is known that monocytes (and tumour cells) are the main cellular origin of TF-positive MVs [59]. Platelet-derived MVs may express a small amount of TF; however, studies have shown conflicting results depending on the analytical approach used [51]. In addition, the presence of TF on platelets may be due to the binding of monocyte-derived TF-positive MVs to P-selectin expressed on activated platelets [186]. 
Although MV-associated PS activity in our study was slightly higher in ITP patients before TPO-RA treatment than in controls, it did not reach statistical significance. MV-associated PS activity after two weeks and six weeks of TPO-RA treatment was, however, significantly higher than that in controls but not significantly higher than pre-treatment levels. Alvarez-Roman et al. found significantly higher MV-associated PS activity in ITP patients before TPO-RA treatment than in controls, but in accordance with our study, they did not find a significant increase in MV-associated PS activity after achieving a response to TPO-RAs compared with pre-treatment levels [165]. The difference between the two studies in MV-associated PS activity prior to treatment with TPO-RAs could be attributed to the small sample size and pre-analytical variation in the preparation of the samples between the two studies. In 2012, Van der Meijden et al. reported that PS-positive platelet- and erythrocyte-derived MVs can initiate and propagate thrombin in an FXII-dependent manner [62]. Since we found higher MV-associated PS activity in TPO-RA-treated ITP patients than in controls, while MV-associated TF activity during TPORA treatment showed no increase, we believe that MVs with PS activity are the dominant procoagulant MVs in ITP patients after TPO-RA treatment.

To confirm the importance of the procoagulant role of PS and MVs in ITP, we measured thrombin generation using two different CAT assay approaches designed to show the contribution of the procoagulant MVs and PLs in the generation of thrombin: MV-associated thrombin generation and phospholipid-dependent thrombin generation in plasma. The use of theses CAT assay approaches showed significant differences in some of the parameters of thrombin generation after TPO-RA initiation, confirming the importance of PLs and MVs in this procoagulant state.

In MV-associated thrombin generation, isolated MVs from the plasma of ITP patients were used as a trigger for thrombin generation without any additional reagent. In this CAT assay, all types of procoagulant MVs in the plasma contribute to the generation of thrombin, i.e., this assay reflects the total procoagulant activity of all MVs and eventually other procoagulant molecules in the plasma, such as polyphosphates [187]. Here, we found no significant differences between ITP patients before treatment with TPO-RAs and controls. However, MVassociated thrombin generation increased in ITP patients two weeks after the initiation of treatment with TPO-RAs (with shorter ttPeaks, higher peaks and VI) compared with controls and pre-treatment levels indicating that this treatment was associated with increased procoagulant activity of MVs. 
By measuring phospholipid-dependent thrombin generation in plasma, we found no significant differences in the parameters of thrombin generation in this approach between ITP patients before treatment with TPO-RAs and controls. However, phospholipid-dependent thrombin generation in plasma increased in ITP patients treated with TPO-RAs for two and six weeks compared with controls. Of note, some of the parameters of phospholipid-dependent thrombin generation (peak, ETP and VI) increased after the initiation of TPO-RAs; however, the difference between pre-treatment and on-treatment levels did not reach statistical significance (table 2 in article II) [188]. Because of the small sample size, we did not test for significance in responders versus non-responders; however, the two non-responders at both two and six weeks of treatment were among the five patients with the lowest phospholipid-dependent thrombin generation (figure 1 in article II) [188]. Moreover, we found good correlations between MVassociated PS activity and some parameters of thrombin generation (ttPeak, peaks and VI) in both phospholipid-dependent thrombin generation in plasma and MV-associated thrombin generation after treatment with TPO-RAs, which was expected, as these parameters of thrombin generation are phospholipid-dependent.

The findings of article II showed that treatment with TPO-RAs in ITP patients was associated with increased phospholipid-dependent procoagulant activity of MVs resulting in more thrombin generation. In addition to PS-positive MVs, TF in low amounts and other procoagulant molecules, such as polyphosphates [187], may also contribute to the procoagulant capacity of MVs to generate thrombin. This increase in the procoagulant effect of MVs and thrombin generation may lead to the exacerbation of a pre-existing hypercoagulable state and possibly result in an increased thrombotic risk. It has been shown that patients with arterial and venous thrombosis have higher MV-associated thrombin generation [163]. Higher levels of MVs, especially TF-positive MVs, are risk factors for venous thrombosis, and in pancreatic cancer can predict the development of venous thrombosis [59]. This increase in the procoagulant activity of MVs after TPO-RA treatment may be due to increased in vivo platelet activation (although studies have shown contradictory results [166,167]) and/or increased platelet apoptosis leading to the generation of more procoagulant MVs [189]. These two CAT assay approaches, especially phospholipid-dependent thrombin generation in plasma, are relatively easy to perform, and they could help in determining the presence of a procoagulant state before potentially prothrombotic treatment is intended to be used, especially in ITP patients with other risk factors for thrombosis. 
In article III, we studied the role of the vascular endothelium in the procoagulant state in ITP. While the normal vascular endothelium has a thromboresistant phenotype by providing a balance between procoagulant and anticoagulant activity, activated/injured endothelium has procoagulant and pro-adhesive properties. In ITP, there are several potential stimuli that can alter the normal phenotype of endothelial cells to a procoagulant phenotype. The increase in some inflammatory cytokines may interact with endothelial cells and induce a loss of the normal thromboresistant phenotype. It has been shown in cultured endothelial cells that the addition of cytokines results in procoagulant responses [190], including increased expression of TF and PAI-1 and the generation of procoagulant microparticles [191]. Furthermore, antiplatelet antibodies and antiphospholipid antibodies in ITP patients can bind to endothelial cells, leading to their activation $[192,193]$. In addition, activated platelets, platelet-derived MVs and NETs may induce endothelial cell activation/injury in these patients [194, 195].

Therefore, we measured markers of endothelial cell activation/injury, including the endothelial adhesive molecules ICAM-1, VCAM-1, thrombomodulin and E-selectin, and found that ITP patients had elevated levels of ICAM-1 and thrombomodulin prior to the initiation of treatment with TPO-RAs compared with the levels in healthy controls. The levels of VCAM-1 and Eselectin were not found to be increased in our study. ICAM-1 and thrombomodulin remained elevated but did not increase further after the initiation of treatment with TPO-RAs. AlvarezRoman et al. found higher levels of E-selectin in ITP patients than in controls [55]. A possible explanation for not finding elevated levels of VCAM-1 and E-selectin in our study could be that a considerable number of our patients were on treatment with steroids, which has been shown to reduce the levels of soluble VCAM-1, E-selectin and ICAM-1 [196]. However, due to the small sample size, we did not perform statistical testing to explore the possible effect of steroids on our results.

Our findings indicate that there may be ongoing endothelial cell activation/injury in ITP patients, but we could not show that treatment with TPO-RAs exacerbates this endothelial cell activation/injury. Endothelial cell activation/injury induces a shift in the haemostatic balance, and this procoagulant and pro-adhesive endothelium may contribute to the procoagulant state by increasing the recruitment of platelets, monocytes, and neutrophils, all of which are capable of initiating or amplifying coagulation. In addition, activated/damaged endothelium at the site of injury also provides binding sites for the assembly of the prothrombinase complex and supports thrombin formation [7]. 
In recent years, venous thrombosis has been linked to neutrophil activation and the release of NETs. Engelmann and Massberg reviewed NET-mediated microvascular thrombosis and proposed it as a potential mechanism to contain uncontrolled infection, calling this process “immunothrombosis" [197]. Importantly, NETs have been shown to enhance experimental venous and arterial thrombosis, and it has been shown that there is an association between NET formation and thrombosis in humans. Activated neutrophils and increased plasma nucleosomes have been shown in patients with acute venous thrombosis [198], and plasma DNA and myeloperoxidase were increased in both acute venous thrombosis and thrombotic microangiopathies [199, 200]. Furthermore, neutrophils and NETs were found in thrombi isolated from patients with acute myocardial infarction [201].

NETs can contribute to thrombus formation by several mechanisms. Fuchs et al. reported in 2010 that NETs can bind platelets and red blood cells and cause platelet adhesion, activation and aggregation, thus promoting the generation of thrombin [45]. In addition, NETs can provide a surface for the binding and activation of coagulation factors such as FXII [202] and can bind to other proteins important in thrombus formation, such as VWF and fibrinogen. It has also been shown that NETs can induce endothelial cell activation, leading to increased thrombogenicity through the concerted action of IL-1 $\alpha$ and cathepsin G [203].

Therefore, in article III, we wanted to explore whether NET formation is increased in ITP patients as a possible contributor to the hypercoagulable state and whether NET formation could be enhanced by TPO-RA treatment and thus a potential cause of the prothrombotic effect of this treatment. In ITP, there is an imbalance between proinflammatory and anti-inflammatory cytokines, and treatment with TPO-RAs has been shown to cause some changes in the levels of these cytokines to a more balanced steady state of immune activation [204]. Some of the inflammatory cytokines that are increased in ITP, such as IL-8 and IL-17 [205], have been shown to enhance NET formation [206]. Furthermore, activated platelets can provoke the release of NETs through the interaction of the expressed P-selectin on their surface with PSGL1 on neutrophils and via the high mobility group protein B1 (HMGB1) receptor [40]. In addition, circulating P-selectin can also promote NETosis by binding to PSGL-1 on neutrophils [207]. Since the expression of P-selectin on the surface of platelets is increased in ITP patients [166] and as we showed in article I that the levels of sP-selectin were elevated in TPO-RAtreated patients, we anticipated that ITP patients may have increased NET formation and that TPO-RA treatment may cause a further increase in NET formation. As assaying cfDNA alone is probably not sufficient evidence for NET formation since free DNA can be released in other 
forms of lytic cell death [159], we also measured citrullinated histone H3 complexed to DNA (H3Cit-DNA), as H3Cit is neutrophil specific and is considered a marker for NET formation. We found that ITP patients had elevated levels of H3Cit-DNA compared with those in controls, indicating increased NET formation in these patients. However, cfDNA was not significantly increased in our ITP patients compared with controls. The lack of increased cfDNA could be explained by the small sample size of our study, since in a larger study by Lozano et al. with 63 ITP patients, the levels of both H3Cit-DNA and cfDNA were increased in ITP patients compared with controls [208].

Therefore, our findings of increased NET formation in ITP patients may indicate that NETs contribute to the hypercoagulable state in ITP. However, treatment with TPO-RAs did not cause a further increase in markers of NET formation, suggesting that this treatment does not enhance NET formation and that this mechanism is probably not involved in the increased thrombotic risk associated with TPO-RA treatment. 


\section{Conclusion and future perspectives}

\section{Conclusions}

I. Patients with ITP have ongoing increased coagulation activation, impaired fibrinolysis, increased endothelial cell activation and NET formation prior to the initiation of TPO-RAs, reflecting that ITP itself is a hypercoagulable condition. Different mechanisms are likely to be involved in initiating and sustaining this hypercoagulable state in ITP (Figure 9), including platelet and endothelial cell activation. Activated pro-adhesive endothelium leads to the recruitment and activation of neutrophils and platelets. Activated platelets adhere to the damaged endothelium and release various cytokines and chemokines, which lead to platelet aggregation and the recruitment and activation of neutrophils. Activated platelets also provide a surface for the assembly of procoagulant complexes and ultimately the generation of thrombin. Furthermore, neutrophil activation leads to NET formation. NETs can recruit and activate platelets, provide surfaces for the activation of FXII and promote thrombin generation. In addition, procoagulant MVs can bind to activated platelets through the interaction of MV PSGL-1 and platelet P-selectin. MVs can provide surface for the assembly of coagulation factors that initiate and support thrombin generation. In addition to ongoing coagulation activation, there is an impairment/reduction in fibrinolysis, as elevated levels of PAI-1 have been shown in these patients.

II. Treatment with TPO-RAs was associated with a significant increase in the levels of sPselectin, which may indicate that this treatment enhances platelet and endothelial cell activation. An increase in PAI-1 activity was also observed after the initiation of TPO-RA treatment, which could lead to further impairment of fibrinolysis during this treatment. The increase in platelet and endothelial cell activation together with reduced fibrinolysis after the initiation of TPO-RA treatment may contribute to the increased arterial and venous thromboembolic risk associated with the use of these agents in ITP patients. Prospective studies are needed to evaluate whether monitoring sP-selectin and PAI-1 activity may help predict future thromboembolism in ITP patients.

Phospholipids and procoagulant MVs play an important role in the hypercoagulable state in ITP patients during TPO-RA treatment. Although our study could not confirm that ITP patients have higher levels of MV-associated PS activity before initiating treatment with TPO-RAs, the phospholipid-dependent procoagulant activity of MVs increased after this treatment, leading to 
more thrombin generation. Therefore, the increased phospholipid-dependent procoagulant activity of MVs after TPO-RA treatment may contribute to the exacerbation of a pre-existing hypercoagulable state present in some ITP patients and could possibly explain, at least partly, the increased risk of venous thrombosis associated with this treatment that has been observed in clinical studies. Measuring the phospholipid-dependent procoagulant activity of MVs may be a useful tool in the risk assessment of future thromboembolic events; however, this needs to be confirmed in larger studies.

Although ITP patients were shown to have increased endothelial cell activation and NET formation prior to the initiation of TPO-RA treatment, we did not observe any further enhancement after the initiation of TPO-RA treatment, suggesting that these agents do not potentiate endothelial cell activation or NET formation.

Overall, our study shows that ITP patients have increased coagulation activation and impaired fibrinolysis as well as increased endothelial cell activation and NET formation. The results of this thesis support the presence of a hypercoagulable state in ITP patients and demonstrate that the cause of this state is multifactorial, where platelets, endothelial cells, neutrophils and procoagulant MVs play important roles through different mechanisms and therefore lead to increased arterial and venous thrombosis. The work of this thesis also shows that treatment with TPO-RAs may potentiate this hypercoagulable state, as this treatment was associated with increased levels of sP-selectin, which may indicate increased platelet and endothelial cell activation, and increased PAI-1 activity, indicating impaired fibrinolysis, as well as increased phospholipid-dependent procoagulant activity of the MVs. 


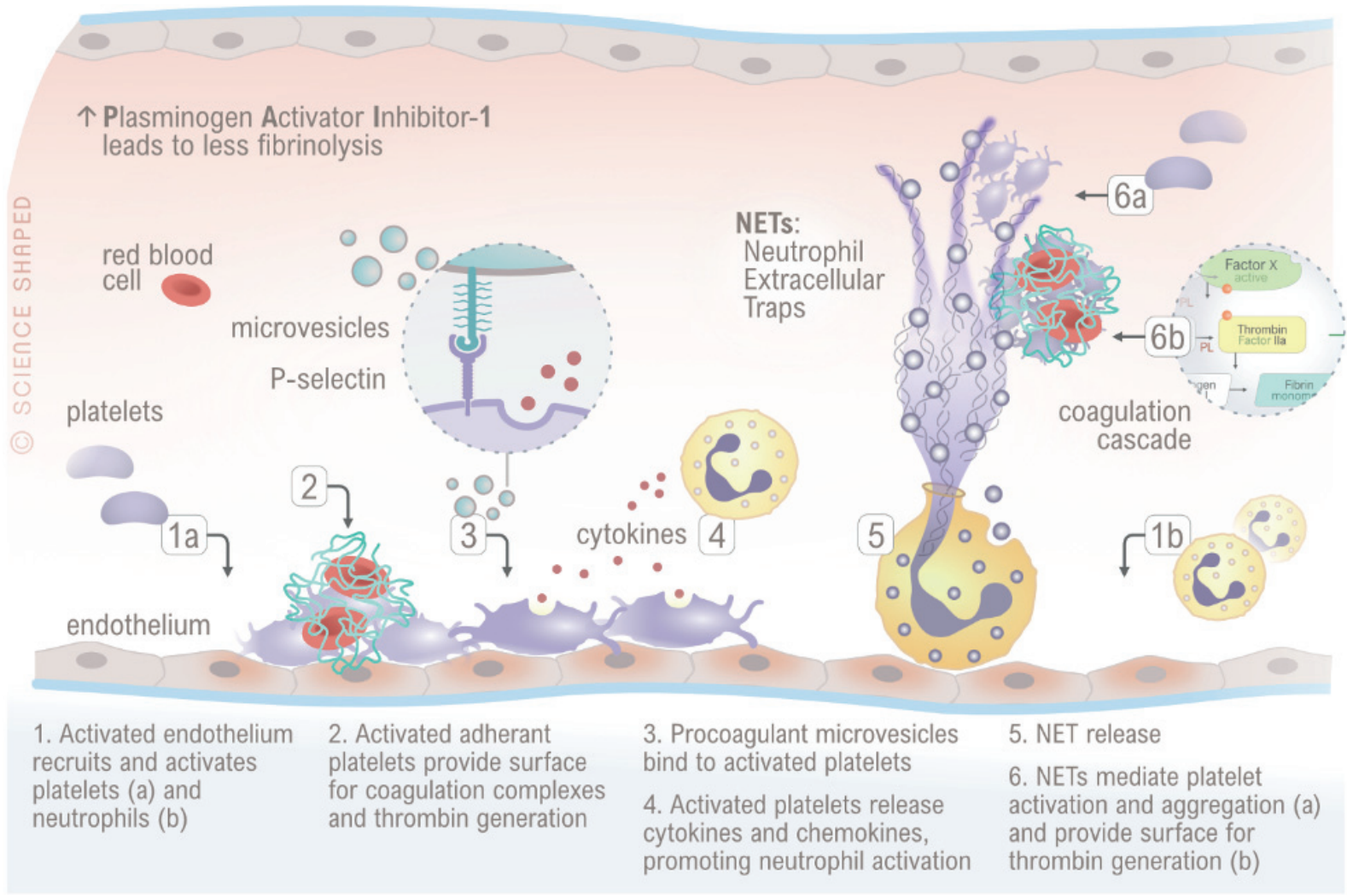

Figure 9: Potential mechanisms promoting thrombosis in ITP

Activated endothelium recruits and activate platelets and neutrophils. Activated platelets release cytokines and chemokines promoting neutrophil activation and the release of neutrophil extracellular traps which promote platelet activation and adhesion and thrombin generation. Procoagulant micovesicles bind to activated platelets and provide surface for assembly of the coagulation factors and thrombin generation.

\section{Future perspectives}

To confirm our findings, one needs to explore the role of sP-selectin and PAI-1 in a larger cohort of ITP patients who are to be treated with TPO-RAs and follow up these patients prospectively to evaluate whether higher levels of sP-selectin and/or PAI-1 can predict future thromboembolic events since no patient developed thrombosis during the follow-up period of our study (12 weeks).

We used different approaches to measure thrombin generation in our ITP patients. Since other studies have shown that ITP patients have increased platelet and red cell MVs and increased MV-associated PS activity, we believe that phospholipid-dependent thrombin generation performed either in plasma or by using isolated MVs could help to evaluate whether these patients have a hypercoagulable state before the initiation of treatment with TPO-RA or another type of treatment that could be potentially prothrombotic and whether this state becomes further 
enhanced after treatment, especially in patients with other risk factors to develop thrombosis. It is also important to assess whether the increased thrombotic risk is specific to TPO-RA treatment or is also associated with other types of treatment for ITP. Therefore, validation studies are needed in a larger cohort of ITP patients after the initiation of treatment with TPORAs; in ITP patients who have been treated with TPO-RAs for more than one year (long-term effect); and in ITP patients on other types of treatment. Of note, in phase III studies of fostamatinib, a spleen tyrosine kinase (Syk) inhibitor that has recently been licenced for ITP treatment, no VTE was observed [209]. It would be interesting to compare fostamatinib-treated patients with TPO-RA-treated ITP patients. On the other hand, avatrombopag, a new TPO-RA, seems to be associated with a substantial risk of thromboembolism, as indicated in the phase III study. Evaluating and comparing the coagulation status of avatrombopag to that of other TPO-RAs would be of interest. These studies will help to evaluate the role of this assay in the risk assessment of future thrombosis in ITP patients for better selection of treatment and to evaluate the need for prophylactic antithrombotic treatment in high-risk patients.

Furthermore, the role of complement activation in the pathophysiology of thrombosis in ITP has not been extensively explored. Platelet-associated complement activation has been shown to correlate with increased arterial thrombotic events in patients with systemic lupus erythematosus and antiphospholipid syndrome. In addition, evidence has shown that complement activation is associated with enhanced platelet clearance from the circulation in patients with ITP [210]. In a preliminary analysis of interim data, sutimlimab, a humanized monoclonal antibody that selectively inhibits $\mathrm{C} 1 \mathrm{~s}$, the proximal mediator of the classical pathway, resulted in a rapid and sustained increase in platelet count in patients with chronic ITP, indicating that the complement classical pathway plays an important role in ITP [211]. It would be interesting to explore the role of complement activation in the hypercoagulable state and thrombosis and to study whether treatment with TPO-RA enhances complement activation in ITP patients. 


\section{References}

[1] G. Lippi, M. Franchini, G. Targher, Arterial thrombus formation in cardiovascular disease, Nat Rev Cardiol 8(9) (2011) 502-12.

[2] G.J. Stewart, W.G. Ritchie, P.R. Lynch, Venous endothelial damage produced by massive sticking and emigration of leukocytes, Am J Pathol 74(3) (1974) 507-32.

[3] C.T. Esmon, Inflammation and thrombosis, J Thromb Haemost 1(7) (2003) 1343-8.

[4] S.J. Shattil, P.J. Newman, Integrins: dynamic scaffolds for adhesion and signaling in platelets, Blood 104(6) (2004) 1606-15.

[5] S.P. Jackson, The growing complexity of platelet aggregation, Blood 109(12) (2007) 508795.

[6] R.K. Andrews, Y. Shen, E.E. Gardiner, J.F. Dong, J.A. Lopez, M.C. Berndt, The glycoprotein Ib-IX-V complex in platelet adhesion and signaling, Thromb Haemost 82(2) (1999) 357-64.

[7] L. Ivanciu, S. Krishnaswamy, R.M. Camire, New insights into the spatiotemporal localization of prothrombinase in vivo, Blood 124(11) (2014) 1705-14.

[8] E.W. Davie, O.D. Ratnoff, Waterfall Sequence for Intrinsic Blood Clotting, Science 145(3638) (1964) 1310-2.

[9] R.G. Macfarlane, An Enzyme Cascade in the Blood Clotting Mechanism, and Its Function as a Biochemical Amplifier, Nature 202 (1964) 498-9.

[10] H. Saito, Contact factors in health and disease, Semin Thromb Hemost 13(1) (1987) 3649.

[11] B. Osterud, S.I. Rapaport, Activation of 125I-factor IX and 125I-factor X: effect of tissue factor and factor VII, factor Xa and thrombin, Scand J Haematol 24(3) (1980) 213-26.

[12] J.A. Oliver, D.M. Monroe, H.R. Roberts, M. Hoffman, Thrombin activates factor XI on activated platelets in the absence of factor XII, Arterioscler Thromb Vasc Biol 19(1) (1999) 170-7.

[13] H.R. Roberts, M. Hoffman, D.M. Monroe, A cell-based model of thrombin generation, Semin Thromb Hemost 32 Suppl 1 (2006) 32-8.

[14] G.J. Broze, Jr., Tissue factor pathway inhibitor and the revised theory of coagulation, Annu Rev Med 46 (1995) 103-12.

[15] D.M. Monroe, M. Hoffman, What does it take to make the perfect clot?, Arterioscler Thromb Vasc Biol 26(1) (2006) 41-8. 
[16] I. Del Conde, C.N. Shrimpton, P. Thiagarajan, J.A. Lopez, Tissue-factor-bearing microvesicles arise from lipid rafts and fuse with activated platelets to initiate coagulation, Blood 106(5) (2005) 1604-11.

[17] H.H. Versteeg, J.W. Heemskerk, M. Levi, P.H. Reitsma, New fundamentals in hemostasis, Physiol Rev 93(1) (2013) 327-58.

[18] J.S. O'Donnell, J.M. O'Sullivan, R.J.S. Preston, Advances in understanding the molecular mechanisms that maintain normal haemostasis, Br J Haematol 186(1) (2019) 24-36.

[19] D. Collen, On the regulation and control of fibrinolysis. Edward Kowalski Memorial Lecture, Thromb Haemost 43(2) (1980) 77-89.

[20] M. Hoylaerts, D.C. Rijken, H.R. Lijnen, D. Collen, Kinetics of the activation of plasminogen by human tissue plasminogen activator. Role of fibrin, J Biol Chem 257(6) (1982) 2912-9.

[21] W.S. Hur, N. Mazinani, X.J. Lu, H.M. Britton, J.R. Byrnes, A.S. Wolberg, C.J. Kastrup, Coagulation factor XIIIa is inactivated by plasmin, Blood 126(20) (2015) 2329-37.

[22] E.D. Sprengers, C. Kluft, Plasminogen activator inhibitors, Blood 69(2) (1987) 381-7.

[23] G. Cesarman-Maus, K.A. Hajjar, Molecular mechanisms of fibrinolysis, Br J Haematol 129(3) (2005) 307-21.

[24] J.C. Chapin, K.A. Hajjar, Fibrinolysis and the control of blood coagulation, Blood Rev 29(1) (2015) 17-24.

[25] R. Favier, N. Aoki, P. de Moerloose, Congenital alpha(2)-plasmin inhibitor deficiencies: a review, Br J Haematol 114(1) (2001) 4-10.

[26] J.M. Edelberg, S.V. Pizzo, Lipoprotein (a) promotes plasmin inhibition by alpha 2antiplasmin, Biochem J 286 ( Pt 1) (1992) 79-84.

[27] D.M. Monroe, M. Hoffman, H.R. Roberts, Platelets and thrombin generation, Arterioscler Thromb Vasc Biol 22(9) (2002) 1381-9.

[28] A. Zarbock, R.K. Polanowska-Grabowska, K. Ley, Platelet-neutrophil-interactions: linking hemostasis and inflammation, Blood Rev 21(2) (2007) 99-111.

[29] P.S. Frenette, C.V. Denis, L. Weiss, K. Jurk, S. Subbarao, B. Kehrel, J.H. Hartwig, D. Vestweber, D.D. Wagner, P-Selectin glycoprotein ligand 1 (PSGL-1) is expressed on platelets and can mediate platelet-endothelial interactions in vivo, J Exp Med 191(8) (2000) 1413-22.

[30] B. Kasper, E. Brandt, M. Ernst, F. Petersen, Neutrophil adhesion to endothelial cells induced by platelet factor 4 requires sequential activation of Ras, Syk, and JNK MAP kinases, Blood 107(5) (2006) 1768-75.

[31] M.R. Thomas, R.F. Storey, The role of platelets in inflammation, Thromb Haemost 114(3) (2015) 449-58. 
[32] E.M. Golebiewska, A.W. Poole, Platelet secretion: From haemostasis to wound healing and beyond, Blood Rev 29(3) (2015) 153-62.

[33] F.A. Ruiz, C.R. Lea, E. Oldfield, R. Docampo, Human platelet dense granules contain polyphosphate and are similar to acidocalcisomes of bacteria and unicellular eukaryotes, J Biol Chem 279(43) (2004) 44250-7.

[34] J.H. Morrissey, S.H. Choi, S.A. Smith, Polyphosphate: an ancient molecule that links platelets, coagulation, and inflammation, Blood 119(25) (2012) 5972-9.

[35] P.L. Gross, W.C. Aird, The endothelium and thrombosis, Semin Thromb Hemost 26(5) (2000) 463-78.

[36] D.D. Wagner, P.S. Frenette, The vessel wall and its interactions, Blood 111(11) (2008) 5271-81.

[37] T. Bombeli, A. Karsan, J.F. Tait, J.M. Harlan, Apoptotic vascular endothelial cells become procoagulant, Blood 89(7) (1997) 2429-42.

[38] E. Vazquez-Garza, C. Jerjes-Sanchez, A. Navarrete, J. Joya-Harrison, D. Rodriguez, Venous thromboembolism: thrombosis, inflammation, and immunothrombosis for clinicians, $\mathrm{J}$ Thromb Thrombolysis 44(3) (2017) 377-385.

[39] V. Brinkmann, U. Reichard, C. Goosmann, B. Fauler, Y. Uhlemann, D.S. Weiss, Y. Weinrauch, A. Zychlinsky, Neutrophil extracellular traps kill bacteria, Science 303(5663) (2004) 1532-5.

[40] V. Papayannopoulos, Neutrophil extracellular traps in immunity and disease, Nat Rev Immunol 18(2) (2018) 134-147.

[41] T.A. Fuchs, U. Abed, C. Goosmann, R. Hurwitz, I. Schulze, V. Wahn, Y. Weinrauch, V. Brinkmann, A. Zychlinsky, Novel cell death program leads to neutrophil extracellular traps, J Cell Biol 176(2) (2007) 231-41.

[42] B.G. Yipp, B. Petri, D. Salina, C.N. Jenne, B.N. Scott, L.D. Zbytnuik, K. Pittman, M. Asaduzzaman, K. Wu, H.C. Meijndert, S.E. Malawista, A. de Boisfleury Chevance, K. Zhang, J. Conly, P. Kubes, Infection-induced NETosis is a dynamic process involving neutrophil multitasking in vivo, Nat Med 18(9) (2012) 1386-93.

[43] F. Semeraro, C.T. Ammollo, J.H. Morrissey, G.L. Dale, P. Friese, N.L. Esmon, C.T. Esmon, Extracellular histones promote thrombin generation through platelet-dependent mechanisms: involvement of platelet TLR2 and TLR4, Blood 118(7) (2011) 1952-61.

[44] Y. Wang, L. Luo, O.O. Braun, J. Westman, R. Madhi, H. Herwald, M. Morgelin, H. Thorlacius, Neutrophil extracellular trap-microparticle complexes enhance thrombin generation via the intrinsic pathway of coagulation in mice, Sci Rep 8(1) (2018) 4020.

[45] T.A. Fuchs, A. Brill, D. Duerschmied, D. Schatzberg, M. Monestier, D.D. Myers, Jr., S.K. Wrobleski, T.W. Wakefield, J.H. Hartwig, D.D. Wagner, Extracellular DNA traps promote thrombosis, Proc Natl Acad Sci U S A 107(36) (2010) 15880-5. 
[46] M. Saffarzadeh, C. Juenemann, M.A. Queisser, G. Lochnit, G. Barreto, S.P. Galuska, J. Lohmeyer, K.T. Preissner, Neutrophil extracellular traps directly induce epithelial and endothelial cell death: a predominant role of histones, PLoS One 7(2) (2012) e32366.

[47] J. Chou, N. Mackman, G. Merrill-Skoloff, B. Pedersen, B.C. Furie, B. Furie, Hematopoietic cell-derived microparticle tissue factor contributes to fibrin formation during thrombus propagation, Blood 104(10) (2004) 3190-7.

[48] G. van Niel, G. D'Angelo, G. Raposo, Shedding light on the cell biology of extracellular vesicles, Nat Rev Mol Cell Biol 19(4) (2018) 213-228.

[49] B. Gyorgy, T.G. Szabo, M. Pasztoi, Z. Pal, P. Misjak, B. Aradi, V. Laszlo, E. Pallinger, E. Pap, A. Kittel, G. Nagy, A. Falus, E.I. Buzas, Membrane vesicles, current state-of-the-art: emerging role of extracellular vesicles, Cell Mol Life Sci 68(16) (2011) 2667-88.

[50] R.J. Berckmans, R. Nieuwland, A.N. Boing, F.P. Romijn, C.E. Hack, A. Sturk, Cellderived microparticles circulate in healthy humans and support low grade thrombin generation, Thromb Haemost 85(4) (2001) 639-46.

[51] A.P. Owens, 3rd, N. Mackman, Microparticles in hemostasis and thrombosis, Circ Res 108(10) (2011) 1284-97.

[52] R. Flaumenhaft, J.R. Dilks, J. Richardson, E. Alden, S.R. Patel-Hett, E. Battinelli, G.L. Klement, M. Sola-Visner, J.E. Italiano, Jr., Megakaryocyte-derived microparticles: direct visualization and distinction from platelet-derived microparticles, Blood 113(5) (2009) 111221.

[53] M.J. Mooberry, N.S. Key, Microparticle analysis in disorders of hemostasis and thrombosis, Cytometry A 89(2) (2016) 111-22.

[54] Y. Yuana, A. Sturk, R. Nieuwland, Extracellular vesicles in physiological and pathological conditions, Blood Rev 27(1) (2013) 31-9.

[55] M.T. Alvarez-Roman, I. Fernandez-Bello, V. Jimenez-Yuste, M. Martin-Salces, E.G. Arias-Salgado, M.I. Rivas Pollmar, R. Justo Sanz, N.V. Butta, Procoagulant profile in patients with immune thrombocytopenia, Br J Haematol 175(5) (2016) 925-934.

[56] E.M. Sewify, D. Sayed, R.F. Abdel Aal, H.M. Ahmad, M.A. Abdou, Increased circulating red cell microparticles (RMP) and platelet microparticles (PMP) in immune thrombocytopenic purpura, Thromb Res 131(2) (2013) e59-63.

[57] A. Tesse, M.C. Martinez, F. Meziani, B. Hugel, M.A. Panaro, V. Mitolo, J.M. Freyssinet, R. Andriantsitohaina, Origin and biological significance of shed-membrane microparticles, Endocr Metab Immune Disord Drug Targets 6(3) (2006) 287-94.

[58] S.I. Rapaport, L.V. Rao, Initiation and regulation of tissue factor-dependent blood coagulation, Arterioscler Thromb 12(10) (1992) 1111-21.

[59] P.E. Rautou, N. Mackman, Microvesicles as risk markers for venous thrombosis, Expert Rev Hematol 6(1) (2013) 91-101. 
[60] J.J. Jimenez, W. Jy, L.M. Mauro, C. Soderland, L.L. Horstman, Y.S. Ahn, Endothelial cells release phenotypically and quantitatively distinct microparticles in activation and apoptosis, Thromb Res 109(4) (2003) 175-80.

[61] N.S. Key, P. Chantrathammachart, P.W. Moody, J.Y. Chang, Membrane microparticles in VTE and cancer, Thromb Res 125 Suppl 2 (2010) S80-3.

[62] P.E. Van Der Meijden, M. Van Schilfgaarde, R. Van Oerle, T. Renne, H. ten Cate, H.M. Spronk, Platelet- and erythrocyte-derived microparticles trigger thrombin generation via factor XIIa, J Thromb Haemost 10(7) (2012) 1355-62.

[63] E.J. van Beers, M.C. Schaap, R.J. Berckmans, R. Nieuwland, A. Sturk, F.F. van Doormaal, J.C. Meijers, B.J. Biemond, C.s. group, Circulating erythrocyte-derived microparticles are associated with coagulation activation in sickle cell disease, Haematologica 94(11) (2009) 1513-9.

[64] O. Rubin, J. Delobel, M. Prudent, N. Lion, K. Kohl, E.I. Tucker, J.D. Tissot, A. AngelilloScherrer, Red blood cell-derived microparticles isolated from blood units initiate and propagate thrombin generation, Transfusion 53(8) (2013) 1744-54.

[65] M. Camera, M. Brambilla, V. Toschi, E. Tremoli, Tissue factor expression on platelets is a dynamic event, Blood 116(23) (2010) 5076-7.

[66] B.A. Bouchard, K.G. Mann, S. Butenas, No evidence for tissue factor on platelets, Blood 116(5) (2010) 854-5.

[67] E.I. Sinauridze, D.A. Kireev, N.Y. Popenko, A.V. Pichugin, M.A. Panteleev, O.V. Krymskaya, F.I. Ataullakhanov, Platelet microparticle membranes have 50- to 100-fold higher specific procoagulant activity than activated platelets, Thromb Haemost 97(3) (2007) 425-34.

[68] B. Steppich, C. Mattisek, D. Sobczyk, A. Kastrati, A. Schomig, I. Ott, Tissue factor pathway inhibitor on circulating microparticles in acute myocardial infarction, Thromb Haemost 93(1) (2005) 35-9.

[69] R.L. Koshiar, S. Somajo, E. Norstrom, B. Dahlback, Erythrocyte-derived microparticles supporting activated protein C-mediated regulation of blood coagulation, PLoS One 9(8) (2014) e104200.

[70] S. Somajo, R.L. Koshiar, E. Norstrom, B. Dahlback, Protein S and factor V in regulation of coagulation on platelet microparticles by activated protein C, Thromb Res 134(1) (2014) 144-52.

[71] R. Lacroix, L. Plawinski, S. Robert, L. Doeuvre, F. Sabatier, S. Martinez de Lizarrondo, A. Mezzapesa, F. Anfosso, A.S. Leroyer, P. Poullin, N. Jourde, M.S. Njock, C.M. Boulanger, E. Angles-Cano, F. Dignat-George, Leukocyte- and endothelial-derived microparticles: a circulating source for fibrinolysis, Haematologica 97(12) (2012) 1864-72.

[72] R. Lacroix, S. Robert, P. Poncelet, F. Dignat-George, Overcoming limitations of microparticle measurement by flow cytometry, Semin Thromb Hemost 36(8) (2010) 807-18. 
[73] J. Stagnara, F. Garnache Ottou, F. Angelot, G. Mourey, E. Seilles, S. Biichle, P. Saas, E. Racadot, Correlation between platelet-derived microparticle enumeration by flow cytometry and phospholipid-dependent procoagulant activity in microparticles: the centrifugation step matters!, Thromb Haemost 107(6) (2012) 1185-7.

[74] V. Ollivier, J. Wang, D. Manly, K.R. Machlus, A.S. Wolberg, M. Jandrot-Perrus, N. Mackman, Detection of endogenous tissue factor levels in plasma using the calibrated automated thrombogram assay, Thromb Res 125(1) (2010) 90-6.

[75] M. Gawaz, F.J. Neumann, T. Dickfeld, W. Koch, K.L. Laugwitz, H. Adelsberger, K. Langenbrink, S. Page, D. Neumeier, A. Schomig, K. Brand, Activated platelets induce monocyte chemotactic protein-1 secretion and surface expression of intercellular adhesion molecule-1 on endothelial cells, Circulation 98(12) (1998) 1164-71.

[76] P. Andre, P-selectin in haemostasis, Br J Haematol 126(3) (2004) 298-306.

[77] E.R. Vandendries, B.C. Furie, B. Furie, Role of P-selectin and PSGL-1 in coagulation and thrombosis, Thromb Haemost 92(3) (2004) 459-66.

[78] M. Silva, P.A. Videira, R. Sackstein, E-Selectin Ligands in the Human Mononuclear Phagocyte System: Implications for Infection, Inflammation, and Immunotherapy, Frontiers in immunology 8 (2017) 1878.

[79] P.E. Stenberg, R.P. McEver, M.A. Shuman, Y.V. Jacques, D.F. Bainton, A platelet alphagranule membrane protein (GMP-140) is expressed on the plasma membrane after activation, J Cell Biol 101(3) (1985) 880-6.

[80] T.N. Mayadas, R.C. Johnson, H. Rayburn, R.O. Hynes, D.D. Wagner, Leukocyte rolling and extravasation are severely compromised in P selectin-deficient mice, Cell 74(3) (1993) 541-54.

[81] L.C. Dunlop, M.P. Skinner, L.J. Bendall, E.J. Favaloro, P.A. Castaldi, J.J. Gorman, J.R. Gamble, M.A. Vadas, M.C. Berndt, Characterization of GMP-140 (P-selectin) as a circulating plasma protein, J Exp Med 175(4) (1992) 1147-50.

[82] A.D. Michelson, M.R. Barnard, H.B. Hechtman, H. MacGregor, R.J. Connolly, J. Loscalzo, C.R. Valeri, In vivo tracking of platelets: circulating degranulated platelets rapidly lose surface P-selectin but continue to circulate and function, Proc Natl Acad Sci U S A 93(21) (1996) 11877-82.

[83] P.C. Burger, D.D. Wagner, Platelet P-selectin facilitates atherosclerotic lesion development, Blood 101(7) (2003) 2661-6.

[84] A. Stadtmann, G. Germena, H. Block, M. Boras, J. Rossaint, P. Sundd, C. Lefort, C.I. Fisher, K. Buscher, B. Gelschefarth, A. Urzainqui, V. Gerke, K. Ley, A. Zarbock, The PSGL1-L-selectin signaling complex regulates neutrophil adhesion under flow, J Exp Med 210(11) (2013) 2171-80. 
[85] T. Palabrica, R. Lobb, B.C. Furie, M. Aronovitz, C. Benjamin, Y.M. Hsu, S.A. Sajer, B. Furie, Leukocyte accumulation promoting fibrin deposition is mediated in vivo by P-selectin on adherent platelets, Nature 359(6398) (1992) 848-51.

[86] S. Falati, Q. Liu, P. Gross, G. Merrill-Skoloff, J. Chou, E. Vandendries, A. Celi, K. Croce, B.C. Furie, B. Furie, Accumulation of tissue factor into developing thrombi in vivo is dependent upon microparticle P-selectin glycoprotein ligand 1 and platelet P-selectin, J Exp Med 197(11) (2003) 1585-98.

[87] I. Muller, A. Klocke, M. Alex, M. Kotzsch, T. Luther, E. Morgenstern, S. Zieseniss, S. Zahler, K. Preissner, B. Engelmann, Intravascular tissue factor initiates coagulation via circulating microvesicles and platelets, FASEB journal : official publication of the Federation of American Societies for Experimental Biology 17(3) (2003) 476-8.

[88] A.J. Horrevoets, Plasminogen activator inhibitor 1 (PAI-1): in vitro activities and clinical relevance, Br J Haematol 125(1) (2004) 12-23.

[89] D.J. Loskutoff, T. Ny, M. Sawdey, D. Lawrence, Fibrinolytic system of cultured endothelial cells: regulation by plasminogen activator inhibitor, J Cell Biochem 32(4) (1986) 273-80.

[90] P. Declerck, [Plasminogen activator-inhibitor 1: biochemical, structural and functional studies], Verh K Acad Geneeskd Belg 55(5) (1993) 457-73.

[91] H. Brogren, L. Karlsson, M. Andersson, L. Wang, D. Erlinge, S. Jern, Platelets synthesize large amounts of active plasminogen activator inhibitor 1, Blood 104(13) (2004) 3943-8.

[92] G. Rega, C. Kaun, T.W. Weiss, S. Demyanets, G. Zorn, S.P. Kastl, S. Steiner, D. Seidinger, C.W. Kopp, M. Frey, R. Roehle, G. Maurer, K. Huber, J. Wojta, Inflammatory cytokines interleukin-6 and oncostatin $\mathrm{m}$ induce plasminogen activator inhibitor-1 in human adipose tissue, Circulation 111(15) (2005) 1938-45.

[93] I.M. Nilsson, H. Ljungner, L. Tengborn, Two different mechanisms in patients with venous thrombosis and defective fibrinolysis: low concentration of plasminogen activator or increased concentration of plasminogen activator inhibitor, Br Med J (Clin Res Ed) 290(6480) (1985) 1453-6.

[94] D.E. Vaughan, PAI-1 and atherothrombosis, J Thromb Haemost 3(8) (2005) 1879-83.

[95] A. Sanchez Miralles, R. Reig Saenz, P. Marco Vera, F. Munoz Perez, B. Alvarez Sanchez, I. Sebastian Munoz, [Abnormalities in coagulation and fibrinolysis in septic shock with purpura], An Esp Pediatr 56(2) (2002) 99-103.

[96] T. Hoekstra, J.M. Geleijnse, E.G. Schouten, C. Kluft, Plasminogen activator inhibitor-type 1: its plasma determinants and relation with cardiovascular risk, Thromb Haemost 91(5) (2004) 861-72.

[97] T. Baglin, The measurement and application of thrombin generation, Br J Haematol 130(5) (2005) 653-61. 
[98] H.C. Hemker, P. Giesen, R. AlDieri, V. Regnault, E. de Smed, R. Wagenvoord, T. Lecompte, S. Beguin, The calibrated automated thrombogram (CAT): a universal routine test for hyper- and hypocoagulability, Pathophysiol Haemost Thromb 32(5-6) (2002) 249-53.

[99] A. Tripodi, Thrombin Generation Assay and Its Application in the Clinical Laboratory, Clin Chem 62(5) (2016) 699-707.

[100] F. Rodeghiero, R. Stasi, T. Gernsheimer, M. Michel, D. Provan, D.M. Arnold, J.B. Bussel, D.B. Cines, B.H. Chong, N. Cooper, B. Godeau, K. Lechner, M.G. Mazzucconi, R. McMillan, M.A. Sanz, P. Imbach, V. Blanchette, T. Kuhne, M. Ruggeri, J.N. George, Standardization of terminology, definitions and outcome criteria in immune thrombocytopenic purpura of adults and children: report from an international working group, Blood 113(11) (2009) 2386-93.

[101] D.B. Cines, J.B. Bussel, H.A. Liebman, E.T. Luning Prak, The ITP syndrome: pathogenic and clinical diversity, Blood 113(26) (2009) 6511-21.

[102] D.R. Terrell, L.A. Beebe, S.K. Vesely, B.R. Neas, J.B. Segal, J.N. George, The incidence of immune thrombocytopenic purpura in children and adults: A critical review of published reports, Am J Hematol 85(3) (2010) 174-80.

[103] C.F. Christiansen, S. Bahmanyar, W. Ghanima, N. Risbo, C. Ekstrand, S. Stryker, J. Acquavella, K. Kilpatrick, H. Frederiksen, M. Norgaard, H.T. Sorensen, Chronic immune thrombocytopenia in Denmark, Sweden and Norway: The Nordic Country Patient Registry for Romiplostim, EClinicalMedicine 14 (2019) 80-87.

[104] J.W. Semple, J.E. Italiano, Jr., J. Freedman, Platelets and the immune continuum, Nat Rev Immunol 11(4) (2011) 264-74.

[105] K. Adelborg, N.R. Kristensen, M. Norgaard, S. Bahmanyar, W. Ghanima, K. Kilpatrick, H. Frederiksen, C. Ekstrand, H.T. Sorensen, C. Fynbo Christiansen, Cardiovascular and bleeding outcomes in a population-based cohort of patients with chronic immune thrombocytopenia, J Thromb Haemost 17(6) (2019) 912-924.

[106] M.L. Piel-Julian, M. Mahevas, J. Germain, L. Languille, T. Comont, M. Lapeyre-Mestre, B. Payrastre, O. Beyne-Rauzy, M. Michel, B. Godeau, D. Adoue, G. Moulis, C.i. group, Risk factors for bleeding, including platelet count threshold, in newly diagnosed immune thrombocytopenia adults, J Thromb Haemost 16(9) (2018) 1830-1842.

[107] C. Neunert, N. Noroozi, G. Norman, G.R. Buchanan, J. Goy, I. Nazi, J.G. Kelton, D.M. Arnold, Severe bleeding events in adults and children with primary immune thrombocytopenia: a systematic review, J Thromb Haemost 13(3) (2015) 457-64.

[108] M. Perera, T. Garrido, Advances in the pathophysiology of primary immune thrombocytopenia, Hematology 22(1) (2017) 41-53.

[109] J.L. Newton, J.A. Reese, S.I. Watson, S.K. Vesely, P.H. Bolton-Maggs, J.N. George, D.R. Terrell, Fatigue in adult patients with primary immune thrombocytopenia, Eur J Haematol 86(5) (2011) 420-9. 
[110] A. Cuker, E.T. Prak, D.B. Cines, Can immune thrombocytopenia be cured with medical therapy?, Semin Thromb Hemost 41(4) (2015) 395-404.

[111] P.J. Ballem, G.M. Segal, J.R. Stratton, T. Gernsheimer, J.W. Adamson, S.J. Slichter, Mechanisms of thrombocytopenia in chronic autoimmune thrombocytopenic purpura. Evidence of both impaired platelet production and increased platelet clearance, J Clin Invest 80(1) (1987) 33-40.

[112] N. Cooper, W. Ghanima, Immune Thrombocytopenia, N Engl J Med 381(10) (2019) $945-$ 955.

[113] B. Olsson, P.O. Andersson, M. Jernas, S. Jacobsson, B. Carlsson, L.M. Carlsson, H. Wadenvik, T-cell-mediated cytotoxicity toward platelets in chronic idiopathic thrombocytopenic purpura, Nat Med 9(9) (2003) 1123-4.

[114] D.B. Cines, A. Cuker, J.W. Semple, Pathogenesis of immune thrombocytopenia, Presse Med 43(4 Pt 2) (2014) e49-59.

[115] A. Zufferey, R. Kapur, J.W. Semple, Pathogenesis and Therapeutic Mechanisms in Immune Thrombocytopenia (ITP), J Clin Med 6(2) (2017).

[116] J. Zhang, D. Ma, X. Zhu, X. Qu, C. Ji, M. Hou, Elevated profile of Th17, Th1 and Tc1 cells in patients with immune thrombocytopenic purpura, Haematologica 94(9) (2009) 1326-9.

[117] T. Nishimoto, M. Kuwana, CD4+CD25+Foxp3+ regulatory $T$ cells in the pathophysiology of immune thrombocytopenia, Semin Hematol 50 Suppl 1 (2013) S43-9.

[118] X. Li, H. Zhong, W. Bao, N. Boulad, J. Evangelista, M.A. Haider, J. Bussel, K. Yazdanbakhsh, Defective regulatory B-cell compartment in patients with immune thrombocytopenia, Blood 120(16) (2012) 3318-25.

[119] C. Zhao, X. Li, F. Zhang, L. Wang, J. Peng, M. Hou, Increased cytotoxic T-lymphocytemediated cytotoxicity predominant in patients with idiopathic thrombocytopenic purpura without platelet autoantibodies, Haematologica 93(9) (2008) 1428-30.

[120] B. Olsson, B. Ridell, L. Carlsson, S. Jacobsson, H. Wadenvik, Recruitment of T cells into bone marrow of ITP patients possibly due to elevated expression of VLA-4 and CX3CR1, Blood 112(4) (2008) 1078-84.

[121] D. Provan, D.M. Arnold, J.B. Bussel, B.H. Chong, N. Cooper, T. Gernsheimer, W. Ghanima, B. Godeau, T.J. Gonzalez-Lopez, J. Grainger, M. Hou, C. Kruse, V. McDonald, M. Michel, A.C. Newland, S. Pavord, F. Rodeghiero, M. Scully, Y. Tomiyama, R.S. Wong, F. Zaja, D.J. Kuter, Updated international consensus report on the investigation and management of primary immune thrombocytopenia, Blood Adv 3(22) (2019) 3780-3817.

[122] C. Neunert, D.R. Terrell, D.M. Arnold, G. Buchanan, D.B. Cines, N. Cooper, A. Cuker, J.M. Despotovic, J.N. George, R.F. Grace, T. Kuhne, D.J. Kuter, W. Lim, K.R. McCrae, B. Pruitt, H. Shimanek, S.K. Vesely, American Society of Hematology 2019 guidelines for immune thrombocytopenia, Blood Adv 3(23) (2019) 3829-3866. 
[123] F. Rodeghiero, M. Ruggeri, Is splenectomy still the gold standard for the treatment of chronic ITP?, Am J Hematol 83(2) (2008) 91.

[124] K. Kojouri, S.K. Vesely, D.R. Terrell, J.N. George, Splenectomy for adult patients with idiopathic thrombocytopenic purpura: a systematic review to assess long-term platelet count responses, prediction of response, and surgical complications, Blood 104(9) (2004) 2623-34.

[125] S. Boyle, R.H. White, A. Brunson, T. Wun, Splenectomy and the incidence of venous thromboembolism and sepsis in patients with immune thrombocytopenia, Blood 121(23) (2013) 4782-90.

[126] V.L. Patel, M. Mahevas, S.Y. Lee, R. Stasi, S. Cunningham-Rundles, B. Godeau, J. Kanter, E. Neufeld, T. Taube, U. Ramenghi, S. Shenoy, M.J. Ward, N. Mihatov, V.L. Patel, P. Bierling, M. Lesser, N. Cooper, J.B. Bussel, Outcomes 5 years after response to rituximab therapy in children and adults with immune thrombocytopenia, Blood 119(25) (2012) 5989-95.

[127] E. Lucchini, F. Zaja, J. Bussel, Rituximab in the treatment of immune thrombocytopenia: what is the role of this agent in 2019?, Haematologica 104(6) (2019) 1124-1135.

[128] S. Deshayes, M. Khellaf, A. Zarour, R. Layese, O. Fain, L. Terriou, J.F. Viallard, S. Cheze, J. Graveleau, B. Slama, S. Audia, M. Cliquennois, M. Ebbo, G. Le Guenno, G. Salles, C. Bonmati, F. Teillet, L. Galicier, O. Lambotte, A. Hot, F. Lefrere, M. Mahevas, F. CanouiPoitrine, M. Michel, B. Godeau, Long-term safety and efficacy of rituximab in 248 adults with immune thrombocytopenia: Results at 5 years from the French prospective registry ITP-ritux, Am J Hematol (2019).

[129] A. Newland, B. Godeau, V. Priego, J.F. Viallard, M.F. Lopez Fernandez, A. Orejudos, M. Eisen, Remission and platelet responses with romiplostim in primary immune thrombocytopenia: final results from a phase 2 study, Br J Haematol 172(2) (2016) 262-73.

[130] T.J. Gonzalez-Lopez, C. Pascual, M.T. Alvarez-Roman, F. Fernandez-Fuertes, B. Sanchez-Gonzalez, I. Caparros, I. Jarque, M.E. Mingot-Castellano, J.A. Hernandez-Rivas, M. Martin-Salces, L. Solan, P. Beneit, R. Jimenez, S. Bernat, M.M. Andrade, M. Cortes, M.J. Cortti, S. Perez-Crespo, M. Gomez-Nunez, P.E. Olivera, G. Perez-Rus, V. Martinez-Robles, R. Alonso, A. Fernandez-Rodriguez, M.C. Arratibel, M. Perera, C. Fernandez-Minano, M.A. Fuertes-Palacio, J.A. Vazquez-Paganini, I. Gutierrez-Jomarron, I. Valcarce, E. de Cabo, A. Sainz, R. Fisac, C. Aguilar, M. Paz Martinez-Badas, M.J. Penarrubia, M. Calbacho, C. de Cos, M. Gonzalez-Silva, E. Coria, A. Alonso, A. Casaus, A. Luana, P. Galan, C. Fernandez-Canal, J. Garcia-Frade, J.R. Gonzalez-Porras, Successful discontinuation of eltrombopag after complete remission in patients with primary immune thrombocytopenia, Am J Hematol 90(3) (2015) E40-3.

[131] D.J. Kuter, J.B. Bussel, R.M. Lyons, V. Pullarkat, T.B. Gernsheimer, F.M. Senecal, L.M. Aledort, J.N. George, C.M. Kessler, M.A. Sanz, H.A. Liebman, F.T. Slovick, J.T. de Wolf, E. Bourgeois, T.H. Guthrie, Jr., A. Newland, J.S. Wasser, S.I. Hamburg, C. Grande, F. Lefrere, A.E. Lichtin, M.D. Tarantino, H.R. Terebelo, J.F. Viallard, F.J. Cuevas, R.S. Go, D.H. Henry, R.L. Redner, L. Rice, M.R. Schipperus, D.M. Guo, J.L. Nichol, Efficacy of romiplostim in patients with chronic immune thrombocytopenic purpura: a double-blind randomised controlled trial, Lancet 371(9610) (2008) 395-403. 
[132] D.J. Kuter, M. Rummel, R. Boccia, B.G. Macik, I. Pabinger, D. Selleslag, F. Rodeghiero, B.H. Chong, X. Wang, D.P. Berger, Romiplostim or standard of care in patients with immune thrombocytopenia, N Engl J Med 363(20) (2010) 1889-99.

[133] G. Cheng, M.N. Saleh, C. Marcher, S. Vasey, B. Mayer, M. Aivado, M. Arning, N.L. Stone, J.B. Bussel, Eltrombopag for management of chronic immune thrombocytopenia (RAISE): a 6-month, randomised, phase 3 study, Lancet 377(9763) (2011) 393-402.

[134] F. Rodeghiero, Is ITP a thrombophilic disorder?, Am J Hematol 91(1) (2016) 39-45.

[135] A. Sarpatwari, D. Bennett, J.W. Logie, A. Shukla, K.J. Beach, A.C. Newland, S. Sanderson, D. Provan, Thromboembolic events among adult patients with primary immune thrombocytopenia in the United Kingdom General Practice Research Database, Haematologica 95(7) (2010) 1167-75.

[136] M.T. Severinsen, M.C. Engebjerg, D.K. Farkas, A.O. Jensen, M. Norgaard, S. Zhao, H.T. Sorensen, Risk of venous thromboembolism in patients with primary chronic immune thrombocytopenia: a Danish population-based cohort study, Br J Haematol 152(3) (2011) 3602 .

[137] M. Norgaard, K. Cetin, M.L. Maegbaek, N.R. Kristensen, W. Ghanima, S. Bahmanyar, S. Stryker, C.F. Christiansen, Risk of arterial thrombotic and venous thromboembolic events in patients with primary chronic immune thrombocytopenia: a Scandinavian population-based cohort study, Br J Haematol 174(4) (2016) 639-42.

[138] C. Enger, D. Bennett, U. Forssen, P.F. Fogarty, A.T. McAfee, Comorbidities in patients with persistent or chronic immune thrombocytopenia, Int J Hematol 92(2) (2010) 289-95.

[139] M. Norgaard, Thrombosis in patients with primary chronic immune thrombocytopenia, Thromb Res 130 Suppl 1 (2012) S74-5.

[140] J.S. Chandan, T. Thomas, S. Lee, T. Marshall, B. Willis, K. Nirantharakumar, P. Gill, The association between idiopathic thrombocytopenic purpura and cardiovascular disease: a retrospective cohort study, J Thromb Haemost 16(3) (2018) 474-480.

[141] D.J. Kuter, The biology of thrombopoietin and thrombopoietin receptor agonists, Int J Hematol 98(1) (2013) 10-23.

[142] C. Ekstrand, M. Linder, B. Baricault, M. Lafaurie, L. Sailler, M. Lapeyre-Mestre, H. Kieler, G. Moulis, S. Bahmanyar, Impact of risk factors on the occurrence of arterial thrombosis and venous thromboembolism in adults with primary immune thrombocytopenia - Results from two nationwide cohorts, Thromb Res 178 (2019) 124-131.

[143] G. Moulis, A. Audemard-Verger, L. Arnaud, C. Luxembourger, F. Montastruc, A.M. Gaman, E. Svenungsson, M. Ruggeri, M. Mahevas, M. Gerfaud-Valentin, A. Brainsky, M. Michel, B. Godeau, M. Lapeyre-Mestre, L. Sailler, Risk of thrombosis in patients with primary immune thrombocytopenia and antiphospholipid antibodies: A systematic review and metaanalysis, Autoimmunity reviews 15(3) (2016) 203-9.

[144] M. Ruggeri, A. Tosetto, F. Palandri, N. Polverelli, M.G. Mazzucconi, C. Santoro, G. Gaidano, M. Lunghi, F. Zaja, V. De Stefano, R. Sartori, P. Fazi, F. Rodeghiero, E.d.A.A. 
Gruppo Italiano Malattie, G.S.I.T.P. Thrombocytopenias Working Party, Thrombotic risk in patients with primary immune thrombocytopenia is only mildly increased and explained by personal and treatment-related risk factors, J Thromb Haemost 12(8) (2014) 1266-73.

[145] A.Z. Cheloff, H. Al-Samkari, Avatrombopag for the treatment of immune thrombocytopenia and thrombocytopenia of chronic liver disease, J Blood Med 10 (2019) 313321.

[146] L. Wang, Z. Gao, X.P. Chen, H.Y. Zhang, N. Yang, F.Y. Wang, L.X. Guan, Z.Y. Gu, S.S. Zhao, L. Luo, H.P. Wei, C.J. Gao, Efficacy and safety of thrombopoietin receptor agonists in patients with primary immune thrombocytopenia: A systematic review and meta-analysis, Sci Rep 6 (2016) 39003.

[147] J.B. Bussel, D. Provan, T. Shamsi, G. Cheng, B. Psaila, L. Kovaleva, A. Salama, J.M. Jenkins, D. Roychowdhury, B. Mayer, N. Stone, M. Arning, Effect of eltrombopag on platelet counts and bleeding during treatment of chronic idiopathic thrombocytopenic purpura: a randomised, double-blind, placebo-controlled trial, Lancet 373(9664) (2009) 641-8.

[148] J.B. Bussel, D.J. Kuter, J.N. George, R. McMillan, L.M. Aledort, G.T. Conklin, A.E. Lichtin, R.M. Lyons, J. Nieva, J.S. Wasser, I. Wiznitzer, R. Kelly, C.F. Chen, J.L. Nichol, AMG 531, a thrombopoiesis-stimulating protein, for chronic ITP, N Engl J Med 355(16) (2006) 167281.

[149] J.B. Bussel, G. Cheng, M.N. Saleh, B. Psaila, L. Kovaleva, B. Meddeb, J. Kloczko, H. Hassani, B. Mayer, N.L. Stone, M. Arning, D. Provan, J.M. Jenkins, Eltrombopag for the treatment of chronic idiopathic thrombocytopenic purpura, N Engl J Med 357(22) (2007) 223747.

[150] W. Ghanima, N. Cooper, F. Rodeghiero, B. Godeau, J.B. Bussel, Thrombopoietin receptor agonists: ten years later, Haematologica 104(6) (2019) 1112-1123.

[151] S. Birocchi, G.M. Podda, M. Manzoni, G. Casazza, M. Cattaneo, Thrombopoietin receptor agonists for the treatment of primary immune thrombocytopenia: a meta-analysis and systematic review, Platelets (2020) 1-11.

[152] D.J. Kuter, J.B. Bussel, A. Newland, R.I. Baker, R.M. Lyons, J. Wasser, J.F. Viallard, G. Macik, M. Rummel, K. Nie, S. Jun, Long-term treatment with romiplostim in patients with chronic immune thrombocytopenia: safety and efficacy, Br J Haematol 161(3) (2013) 411-23.

[153] F. Rodeghiero, R. Stasi, A. Giagounidis, J.F. Viallard, B. Godeau, I. Pabinger, D. Cines, H. Liebman, X. Wang, P. Woodard, Long-term safety and tolerability of romiplostim in patients with primary immune thrombocytopenia: a pooled analysis of 13 clinical trials, Eur J Haematol 91(5) (2013) 423-36.

[154] R.S.M. Wong, M.N. Saleh, A. Khelif, A. Salama, M.S.O. Portella, P. Burgess, J.B. Bussel, Safety and efficacy of long-term treatment of chronic/persistent ITP with eltrombopag: final results of the EXTEND study, Blood 130(23) (2017) 2527-2536. 
[155] W. Jurczak, K. Chojnowski, J. Mayer, K. Krawczyk, B.D. Jamieson, W. Tian, L.F. Allen, Phase 3 randomised study of avatrombopag, a novel thrombopoietin receptor agonist for the treatment of chronic immune thrombocytopenia, Br J Haematol 183(3) (2018) 479-490.

[156] C. Neunert, J. Despotovic, K. Haley, M.P. Lambert, K. Nottage, K. Shimano, C. Bennett, R. Klaassen, K. Stine, A. Thompson, Y. Pastore, T. Brown, P.W. Forbes, R.F. Grace, I.T.P.C.o.N.A. Pediatric, Thrombopoietin Receptor Agonist Use in Children: Data From the Pediatric ITP Consortium of North America ICON2 Study, Pediatr Blood Cancer 63(8) (2016) 1407-13.

[157] K. Ramaswamy, L. Hsieh, E. Leven, M.V. Thompson, D. Nugent, J.B. Bussel, Thrombopoietic agents for the treatment of persistent and chronic immune thrombocytopenia in children, J Pediatr 165(3) (2014) 600-5 e4.

[158] H.C. Hemker, P. Giesen, R. Al Dieri, V. Regnault, E. de Smedt, R. Wagenvoord, T. Lecompte, S. Beguin, Calibrated automated thrombin generation measurement in clotting plasma, Pathophysiol Haemost Thromb 33(1) (2003) 4-15.

[159] B.G. Yipp, P. Kubes, NETosis: how vital is it?, Blood 122(16) (2013) 2784-94.

[160] E. Lefrancais, B. Mallavia, H. Zhuo, C.S. Calfee, M.R. Looney, Maladaptive role of neutrophil extracellular traps in pathogen-induced lung injury, JCI Insight 3(3) (2018).

[161] R.A. Irizarry, B. Hobbs, F. Collin, Y.D. Beazer-Barclay, K.J. Antonellis, U. Scherf, T.P. Speed, Exploration, normalization, and summaries of high density oligonucleotide array probe level data, Biostatistics 4(2) (2003) 249-64.

[162] G.K. Smyth, Linear models and empirical bayes methods for assessing differential expression in microarray experiments, Statistical applications in genetics and molecular biology 3 (2004) Article3.

[163] L. Bidot, W. Jy, C. Bidot, Jr., J.J. Jimenez, V. Fontana, L.L. Horstman, Y.S. Ahn, Microparticle-mediated thrombin generation assay: increased activity in patients with recurrent thrombosis, J Thromb Haemost 6(6) (2008) 913-9.

[164] K.J. Kim, I.W. Baek, C.H. Yoon, W.U. Kim, C.S. Cho, Thrombotic risk in patients with immune thrombocytopenia and its association with antiphospholipid antibodies, Br J Haematol 161(5) (2013) 706-14.

[165] M.T. Alvarez Roman, I. Fernandez Bello, E.G. Arias-Salgado, M.I. Rivas Pollmar, V. Jimenez Yuste, M. Martin Salces, N.V. Butta, Effects of thrombopoietin receptor agonists on procoagulant state in patients with immune thrombocytopenia, Thromb Haemost 112(1) (2014) $65-72$.

[166] B. Psaila, J.B. Bussel, M.D. Linden, B. Babula, Y. Li, M.R. Barnard, C. Tate, K. Mathur, A.L. Frelinger, A.D. Michelson, In vivo effects of eltrombopag on platelet function in immune thrombocytopenia: no evidence of platelet activation, Blood 119(17) (2012) 4066-72. 
[167] J. Haselboeck, A. Kaider, I. Pabinger, S. Panzer, Function of eltrombopag-induced platelets compared to platelets from control patients with immune thrombocytopenia, Thromb Haemost 109(4) (2013) 676-83.

[168] H.C. Hemker, G.M. Willems, S. Beguin, A computer assisted method to obtain the prothrombin activation velocity in whole plasma independent of thrombin decay processes, Thromb Haemost 56(1) (1986) 9-17.

[169] R. Altman, A. Scazziota, J. Rouvier, C. Gonzalez, Effect of sodium arachidonate on thrombin generation through platelet activation--inhibitory effect of aspirin, Thromb Haemost 84(6) (2000) 1109-12.

[170] R. Lacroix, C. Judicone, M. Mooberry, M. Boucekine, N.S. Key, F. Dignat-George, I.S.S.C.W. The, Standardization of pre-analytical variables in plasma microparticle determination: results of the International Society on Thrombosis and Haemostasis SSC Collaborative workshop, J Thromb Haemost (2013).

[171] K.W. Witwer, E.I. Buzas, L.T. Bemis, A. Bora, C. Lasser, J. Lotvall, E.N. Nolte-'t Hoen, M.G. Piper, S. Sivaraman, J. Skog, C. Thery, M.H. Wauben, F. Hochberg, Standardization of sample collection, isolation and analysis methods in extracellular vesicle research, J Extracell Vesicles 2 (2013).

[172] C.H. Olsen, Review of the use of statistics in infection and immunity, Infect Immun 71(12) (2003) 6689-92.

[173] P.B. Tracy, L.L. Eide, K.G. Mann, Human prothrombinase complex assembly and function on isolated peripheral blood cell populations, J Biol Chem 260(4) (1985) 2119-24.

[174] T. Lisman, P.G. de Groot, J.C. Meijers, F.R. Rosendaal, Reduced plasma fibrinolytic potential is a risk factor for venous thrombosis, Blood 105(3) (2005) 1102-5.

[175] A.H. Guimaraes, E.L. de Bruijne, T. Lisman, D.W. Dippel, J.W. Deckers, D. Poldermans, D.C. Rijken, F.W. Leebeek, Hypofibrinolysis is a risk factor for arterial thrombosis at young age, Br J Haematol 145(1) (2009) 115-20.

[176] M.E. Meltzer, T. Lisman, P.G. de Groot, J.C. Meijers, S. le Cessie, C.J. Doggen, F.R. Rosendaal, Venous thrombosis risk associated with plasma hypofibrinolysis is explained by elevated plasma levels of TAFI and PAI-1, Blood 116(1) (2010) 113-21.

[177] A.M. Thogersen, J.H. Jansson, K. Boman, T.K. Nilsson, L. Weinehall, F. Huhtasaari, G. Hallmans, High plasminogen activator inhibitor and tissue plasminogen activator levels in plasma precede a first acute myocardial infarction in both men and women: evidence for the fibrinolytic system as an independent primary risk factor, Circulation 98(21) (1998) 2241-7.

[178] J.M. Jenkins, D. Williams, Y. Deng, J. Uhl, V. Kitchen, D. Collins, C.L. Erickson-Miller, Phase 1 clinical study of eltrombopag, an oral, nonpeptide thrombopoietin receptor agonist, Blood 109(11) (2007) 4739-41. 
[179] J. Haselboeck, I. Pabinger, C. Ay, S. Koder, S. Panzer, Platelet activation and function during eltrombopag treatment in immune thrombocytopenia, Ann Hematol 91(1) (2012) 10913.

[180] I. del Conde, F. Nabi, R. Tonda, P. Thiagarajan, J.A. Lopez, N.S. Kleiman, Effect of Pselectin on phosphatidylserine exposure and surface-dependent thrombin generation on monocytes, Arterioscler Thromb Vasc Biol 25(5) (2005) 1065-70.

[181] C. Ay, R. Simanek, R. Vormittag, D. Dunkler, G. Alguel, S. Koder, G. Kornek, C. Marosi, O. Wagner, C. Zielinski, I. Pabinger, High plasma levels of soluble P-selectin are predictive of venous thromboembolism in cancer patients: results from the Vienna Cancer and Thrombosis Study (CATS), Blood 112(7) (2008) 2703-8.

[182] C.G. Mackworth-Young, Antiphospholipid syndrome: multiple mechanisms, Clin Exp Immunol 136(3) (2004) 393-401.

[183] M. Jankowski, I. Vreys, C. Wittevrongel, D. Boon, J. Vermylen, M.F. Hoylaerts, J. Arnout, Thrombogenicity of beta 2-glycoprotein I-dependent antiphospholipid antibodies in a photochemically induced thrombosis model in the hamster, Blood 101(1) (2003) 157-62.

[184] J.E. Salmon, P.G. de Groot, Pathogenic role of antiphospholipid antibodies, Lupus 17(5) (2008) 405-11.

[185] M.M. Aleman, C. Gardiner, P. Harrison, A.S. Wolberg, Differential contributions of monocyte- and platelet-derived microparticles towards thrombin generation and fibrin formation and stability, J Thromb Haemost 9(11) (2011) 2251-61.

[186] A. Zillmann, T. Luther, I. Muller, M. Kotzsch, M. Spannagl, T. Kauke, U. Oelschlagel, S. Zahler, B. Engelmann, Platelet-associated tissue factor contributes to the collagen-triggered activation of blood coagulation, Biochem Biophys Res Commun 281(2) (2001) 603-9.

[187] K.F. Nickel, G. Ronquist, F. Langer, L. Labberton, T.A. Fuchs, C. Bokemeyer, G. Sauter, M. Graefen, N. Mackman, E.X. Stavrou, G. Ronquist, T. Renne, The polyphosphate-factor XII pathway drives coagulation in prostate cancer-associated thrombosis, Blood 126(11) (2015) 1379-89.

[188] L. Garabet, W. Ghanima, M. Hellum, P.M. Sandset, J.B. Bussel, H. Tran, C.E. Henriksson, Increased microvesicle-associated thrombin generation in patients with immune thrombocytopenia after initiation of thrombopoietin receptor agonists, Platelets 31(3) (2020) 322-328.

[189] R. Justo Sanz, E. Monzon Manzano, I. Fernandez Bello, M. Teresa Alvarez Roman, M. Martin Salces, M.I. Rivas Pollmar, V. Jimenez Yuste, N.V. Butta, Platelet Apoptosis and PAI1 are Involved in the Pro-Coagulant State of Immune Thrombocytopaenia Patients Treated with Thrombopoietin Receptor Agonists, Thromb Haemost 119(4) (2019) 645-659.

[190] W.C. Aird, The role of the endothelium in severe sepsis and multiple organ dysfunction syndrome, Blood 101(10) (2003) 3765-77. 
[191] R. Lacroix, F. Sabatier, A. Mialhe, A. Basire, R. Pannell, H. Borghi, S. Robert, E. Lamy, L. Plawinski, L. Camoin-Jau, V. Gurewich, E. Angles-Cano, F. Dignat-George, Activation of plasminogen into plasmin at the surface of endothelial microparticles: a mechanism that modulates angiogenic properties of endothelial progenitor cells in vitro, Blood 110(7) (2007) $2432-9$

[192] P. Thiagarajan, S.S. Shapiro, E. Levine, L. DeMarco, A. Yalcin, A monoclonal antibody to human platelet glycoprotein IIIa detects a related protein in cultured human endothelial cells, J Clin Invest 75(3) (1985) 896-901.

[193] N. Del Papa, L. Guidali, A. Sala, C. Buccellati, M.A. Khamashta, K. Ichikawa, T. Koike, G. Balestrieri, A. Tincani, G.R. Hughes, P.L. Meroni, Endothelial cells as target for antiphospholipid antibodies. Human polyclonal and monoclonal anti-beta 2-glycoprotein I antibodies react in vitro with endothelial cells through adherent beta 2-glycoprotein I and induce endothelial activation, Arthritis Rheum 40(3) (1997) 551-61.

[194] O.P. Barry, D. Pratico, R.C. Savani, G.A. FitzGerald, Modulation of monocyteendothelial cell interactions by platelet microparticles, J Clin Invest 102(1) (1998) 136-44.

[195] C. Carmona-Rivera, W. Zhao, S. Yalavarthi, M.J. Kaplan, Neutrophil extracellular traps induce endothelial dysfunction in systemic lupus erythematosus through the activation of matrix metalloproteinase-2, Ann Rheum Dis 74(7) (2015) 1417-24.

[196] K.A. Zielinska, L. Van Moortel, G. Opdenakker, K. De Bosscher, P.E. Van den Steen, Endothelial Response to Glucocorticoids in Inflammatory Diseases, Frontiers in immunology 7 (2016) 592.

[197] B. Engelmann, S. Massberg, Thrombosis as an intravascular effector of innate immunity, Nat Rev Immunol 13(1) (2013) 34-45.

[198] M.L. van Montfoort, F. Stephan, M.N. Lauw, B.A. Hutten, G.J. Van Mierlo, S. Solati, S. Middeldorp, J.C. Meijers, S. Zeerleder, Circulating nucleosomes and neutrophil activation as risk factors for deep vein thrombosis, Arterioscler Thromb Vasc Biol 33(1) (2013) 147-51.

[199] T.A. Fuchs, J.A. Kremer Hovinga, D. Schatzberg, D.D. Wagner, B. Lammle, Circulating DNA and myeloperoxidase indicate disease activity in patients with thrombotic microangiopathies, Blood 120(6) (2012) 1157-64.

[200] J.A. Diaz, T.A. Fuchs, T.O. Jackson, J.A. Kremer Hovinga, B. Lammle, P.K. Henke, D.D. Myers, Jr., D.D. Wagner, T.W. Wakefield, G. for the Michigan Research Venous, Plasma DNA is Elevated in Patients with Deep Vein Thrombosis, J Vasc Surg Venous Lymphat Disord 1(4) (2013).

[201] O.J. de Boer, X. Li, P. Teeling, C. Mackaay, H.J. Ploegmakers, C.M. van der Loos, M.J. Daemen, R.J. de Winter, A.C. van der Wal, Neutrophils, neutrophil extracellular traps and interleukin-17 associate with the organisation of thrombi in acute myocardial infarction, Thromb Haemost 109(2) (2013) 290-7.

[202] M.L. von Bruhl, K. Stark, A. Steinhart, S. Chandraratne, I. Konrad, M. Lorenz, A. Khandoga, A. Tirniceriu, R. Coletti, M. Kollnberger, R.A. Byrne, I. Laitinen, A. Walch, A. 
Brill, S. Pfeiler, D. Manukyan, S. Braun, P. Lange, J. Riegger, J. Ware, A. Eckart, S. Haidari, M. Rudelius, C. Schulz, K. Echtler, V. Brinkmann, M. Schwaiger, K.T. Preissner, D.D. Wagner, N. Mackman, B. Engelmann, S. Massberg, Monocytes, neutrophils, and platelets cooperate to initiate and propagate venous thrombosis in mice in vivo, J Exp Med 209(4) (2012) 819-35.

[203] E.J. Folco, T.L. Mawson, A. Vromman, B. Bernardes-Souza, G. Franck, O. Persson, M. Nakamura, G. Newton, F.W. Luscinskas, P. Libby, Neutrophil Extracellular Traps Induce Endothelial Cell Activation and Tissue Factor Production Through Interleukin-1alpha and Cathepsin G, Arterioscler Thromb Vasc Biol 38(8) (2018) 1901-1912.

[204] S. Gudbrandsdottir, W. Ghanima, C.H. Nielsen, X. Feng, H.C. Hasselbalch, J. Bussel, Effect of thrombopoietin-receptor agonists on circulating cytokine and chemokine levels in patients with primary immune thrombocytopenia (ITP), Platelets 28(5) (2017) 478-483.

[205] M.J. Wang, Y.G. Xu, X.Q. Ding, R.C. Quan, H.Y. Chen, Z.Y. Deng, P. Zhao, T. Fan, S.R. Zhu, X.M. Hu, [Secretory Imbalance between Pro-inflammatory and Anti-inflammatory Cytokines in the Patients with Immune Thrombocytopenia], Zhongguo shi yan xue ye xue za zhi / Zhongguo bing li sheng li xue hui $=$ Journal of experimental hematology / Chinese Association of Pathophysiology 26(2) (2018) 522-527.

[206] E. Frangou, A. Chrysanthopoulou, A. Mitsios, K. Kambas, S. Arelaki, I. Angelidou, A. Arampatzioglou, H. Gakiopoulou, G.K. Bertsias, P. Verginis, K. Ritis, D.T. Boumpas, REDD1/autophagy pathway promotes thromboinflammation and fibrosis in human systemic lupus erythematosus (SLE) through NETs decorated with tissue factor (TF) and interleukin17A (IL-17A), Ann Rheum Dis 78(2) (2019) 238-248.

[207] J. Etulain, K. Martinod, S.L. Wong, S.M. Cifuni, M. Schattner, D.D. Wagner, P-selectin promotes neutrophil extracellular trap formation in mice, Blood 126(2) (2015) 242-6.

[208] M.L. Lozano, L. Garabet, M.P. Fernandez-Perez, A.M. De Los Reyes-Garcia, P. DiazLozano, N. Garcia-Barbera, S. Aguila, V. Vicente, W. Ghanima, C. Martinez, R. GonzalezConejero, Platelet activation and neutrophil extracellular trap (NET) formation in immune thrombocytopenia: is there an association?, Platelets (2019) 1-7.

[209] J. Bussel, D.M. Arnold, E. Grossbard, J. Mayer, J. Trelinski, W. Homenda, A. Hellmann, J. Windyga, L. Sivcheva, A.A. Khalafallah, F. Zaja, N. Cooper, V. Markovtsov, H. Zayed, A.M. Duliege, Fostamatinib for the treatment of adult persistent and chronic immune thrombocytopenia: Results of two phase 3, randomized, placebo-controlled trials, Am J Hematol 93(7) (2018) 921-930.

[210] E.I. Peerschke, W. Yin, B. Ghebrehiwet, Complement activation on platelets: implications for vascular inflammation and thrombosis, Mol Immunol 47(13) (2010) 2170-5.

[211] C.M. Broome, A. Röth, D.J. Kuter, M. Scully, R. Smith, J. Wang, C. Reuter, W. Hobbs, Inhibition of the Classical Pathway of Complement with Sutimlimab in Chronic Immune Thrombocytopenic Purpura Patients without Adequate Response to Two or More Prior Therapies, in: Blood (Ed.) American Society of Hematology, Blood, Orlando, USA, 2019, p. 898. 


\section{Errata list}

\begin{tabular}{|l|l|l|l|l|}
\hline Page & Line & Original text & $\begin{array}{l}\text { Type of } \\
\text { correction }\end{array}$ & Corrected text \\
\hline 9 & 32 & $\begin{array}{l}\ldots \text { plasminogen } \\
\text { PAI-1 activity }\end{array}$ & Typo & .. PAI-1 activity \\
\hline 11 & 14 & $\begin{array}{l}\text {. Thrombopoietin } \\
\text { Receptor Rgonists }\end{array}$ & Typo & $\begin{array}{l}\text {.. Thrombopoietin } \\
\text { Receptor Agonists }\end{array}$ \\
\hline 19 & 27 & $\begin{array}{l}\text { Another important } \\
\text { inhibitor of plasmin } \\
\text { is alpha-2- } \\
\text { antiplasmin }\end{array}$ & Typo & $\begin{array}{l}\text { Another important } \\
\text { inhibitor of plasmin } \\
\text { is } \alpha 2 \text {-antiplasmin.. }\end{array}$ \\
\hline
\end{tabular}


Original articles 



Full Length Article

\title{
Markers of endothelial cell activation and neutrophil extracellular traps are elevated in immune thrombocytopenia but are not enhanced by thrombopoietin receptor agonists
}

\author{
Lamya Garabet $^{\mathrm{a}, \mathrm{b}, \mathrm{c}, *}$, Carola E. Henriksson ${ }^{\mathrm{c}, \mathrm{d}}$, María Luisa Lozano ${ }^{\mathrm{e}, \mathrm{f}}$, Waleed Ghanima ${ }^{\mathrm{b}, \mathrm{c}}$, \\ James Bussel $^{\mathrm{g}}$, Ellen Brodin ${ }^{\mathrm{h}}$, María Piedad Fernández-Pérez ${ }^{\mathrm{e}}$, Constantino Martínez ${ }^{\mathrm{e}}$, \\ Rocío González-Conejero ${ }^{\mathrm{e}}$, Marie-Christine Mowinckel ${ }^{\mathrm{i}, \mathrm{j}}$, Per Morten Sandset ${ }^{\mathrm{c}, \mathrm{i}, \mathrm{j}}$ \\ ${ }^{a}$ Multidisciplinary Laboratory Medicine and Medical Biochemistry, Akershus University Hospital, Norway \\ ${ }^{\mathrm{b}}$ Department of Research, Østfold Hospital Trust, Norway \\ ${ }^{\mathrm{c}}$ Institute of Clinical Medicine, University of Oslo, Norway \\ ${ }^{\mathrm{d}}$ Department of Medical Biochemistry, Oslo University Hospital, Norway \\ ${ }^{\mathrm{e}}$ Hospital JM Morales Meseguer, Centro Regional de Hemodonacion, IMIB-Arrixaca, Murcia, Spain \\ ${ }^{\mathrm{f}}$ Grupo de investigación CB15/00055 del Centro de Investigacion Biomedica en Red de Enfermedades Raras (CIBERER), Instituto de Salud Carlos III (ISCIII), Madrid, \\ Spain \\ ${ }^{8}$ New York Presbyterian Hospital, Weill Cornell, United States \\ ${ }^{\mathrm{h}}$ Department of Haematology, Akershus University Hospital, Norway \\ ${ }^{\mathrm{i}}$ Research Institute of Internal Medicine, Oslo University Hospital, Norway \\ j Department of Haematology, Oslo University Hospital, Norway
}

\section{A R T I C L E I N F O}

\section{Keywords:}

Endothelial cells

NETs

ITP

TPO-RAs

ICAM-1

\begin{abstract}
A B S T R A C T
Introduction: Patients with immune thrombocytopenia (ITP) are at increased risk of thrombosis, which seems to be further enhanced by treatment with thrombopoietin-receptor-agonists (TPO-RAs). The underlying mechanisms of thrombosis in ITP are not fully understood. Endothelial cell activation and neutrophil extracellular traps (NETs) play important roles in thrombosis, however, their roles in ITP itself, or in TPO-RA-treatment, have not yet been fully explored. We aimed to investigate whether endothelial cell activation and NETs are involved in the hypercoagulable state of ITP, and whether TPO-RA-treatment enhances endothelial cell activation and NET formation.

Material and methods: We measured markers of endothelial cell activation including intercellular adhesion molecule-1 (ICAM-1), vascular adhesion molecule-1 (VCAM-1) and thrombomodulin in 21 ITP patients, and Eselectin in 18 ITP patients. Markers of NET formation, citrullinated histone H3-DNA (H3Cit-DNA) and cell-free DNA (cfDNA), were measured in 15 ITP patients. All markers were measured before, and 2 and 6 weeks after initiation of TPO-RA-treatment in ITP patients, and in matched controls.

Results: Higher levels of ICAM-1, thrombomodulin, and H3Cit-DNA were found in ITP patients, both before and after TPO-RA-treatment, compared with controls. No differences were found for VCAM-1, E-selectin or cfDNA. TPO-RA-treatment did not further increase markers of endothelial cell activation or NET formation.

Conclusions: This study showed that ITP patients have increased endothelial cell activation and NET formation, both of which may contribute to the intrinsic hypercoagulable state of ITP. TPO-RA-treatment, however, did not further increase endothelial cell activation or NET formation indicating that other drug-associated prothrombotic mechanisms are involved.
\end{abstract}

\section{Introduction}

Studies have shown that patients with primary immune thrombocytopenia (ITP), despite having low platelet counts, are at slightly higher risk of venous and arterial thrombosis as compared to the general population [1-3]. Older age, splenectomy, and the presence of other thrombotic risk factors put ITP patients at higher risk of thrombosis $[3,4]$. Previous reports have shown that different ITP therapies,

\footnotetext{
* Corresponding author at: Multidisciplinary Laboratory Medicine and Medical Biochemistry, Akershus University Hospital, Lørenskog, Norway.

E-mail address: lamyagarabet@hotmail.com (L. Garabet).
} 
including corticosteroids, intravenous immunoglobulins, and especially thrombopoietin receptor agonists (TPO-RAs), may contribute to an additional increase in the risk of thrombosis [3-6]. In long-term studies of the two TPO-RA agents, eltrombopag and romiplostim, $6 \%$ of the patients encountered thromboembolic events during a five year follow up $[7,8]$. The underlying mechanisms of increased thrombosis in ITP or the potential prothrombotic effects of TPO-RAs are not fully understood. Several mechanisms have been proposed to contribute to the hypercoagulable state in ITP including increased number of young, reticulated platelets; presence of antiphospholipid antibodies; and increased number and procoagulant activity of microvesicles (MVs) [9-13].

The vascular endothelium plays an important role in maintaining local haemostasis as it produces factors that regulate cellular trafficking and contribute to the local balance between procoagulant and anticoagulant activity, thus providing defense against thrombus formation [14]. However, activated/injured endothelial cells have procoagulant and pro-adhesive properties and contribute to hypercoagulability as observed in critical illnesses such as severe sepsis [15]. The role of endothelial cell activation/injury in the hypercoagulable state of ITP has not been well explored. Our group has previously shown that plasma levels of plasminogen activator inhibitor-1 (PAI-1) were increased in patients with ITP compared with controls [16]. Alvarez et al. have also shown that plasma levels of PAI-1 and E-selectin were higher in ITP patients than in controls [17]. E-selectin and PAI-1 are synthesized by the vascular endothelium; thus, increased levels of these markers in ITP patients may suggest endothelial cell activation/injury. PAI-1 is also secreted by other types of cells including activated platelets and smooth muscle cells [18]. We have also demonstrated that both PAI-1 and P-selectin increased further after the initiation of treatment with TPO-RAs [16] suggesting that treatment with these agents may lead to endothelial cell activation/injury and platelet activation.

Activated/injured endothelium expresses adhesive molecules that contribute to the recruitment of platelets and neutrophils, both of which are recognized to be crucial for thrombus initiation and progression [19]. Neutrophil extracellular traps (NETs) are extracellular DNA fibers comprising histones and neutrophil granular proteins released via a cell death program called NETosis [20], and can entrap and kill bacteria [21]. NETs are also shown to contribute to venous thrombosis in mice [22,23], and found to be present in human thrombi [24]. They can promote thrombosis through platelet activation/aggregation $[25,26]$, or by enhancing thrombin generation via factor XII (FXII) activation [27]. In addition, NETs have several immune-modulatory functions and have been implicated in disease to induce inflammation and potentiate autoimmunity [28]. To our knowledge, the effect of TPO-RAs on endothelial cell activation/injury and NET formation in ITP patients has not yet been studied.

Here we studied markers of endothelial cell activation/injury and NET formation in patients with ITP and investigated the effect of treatment with TPO-RAs on these markers.

\section{Material and methods}

\subsection{Patients and study design}

Patients from Norway and USA with chronic ITP who were planned to start with a TPO-RA, either eltrombopag (Revolade ${ }^{\circledR}$, Promacta ${ }^{\circledR}$, Novartis, Basel, Switzerland) or romiplostim (Nplate ${ }^{\circledast}$, Amgen, Thousand Oaks, CA, USA) were recruited into the study, as well as healthy controls. The indication for treatment with TPO-RAs was according to current guidelines, but at the discretion of the treating hematologist. Blood samples were obtained before the initiation of treatment with TPO-RAs, then at two and six weeks after initiation of treatment. Two cohorts of ITP patients were included.

Cohort 1 comprised 29 ITP patients and 22 matched controls for the measurement of markers of endothelial cell activation/injury. However, because of the lack of full sets of samples at the three time-points, or the lack of appropriate type of samples needed for the different assays (plasma or serum), ICAM-1, VCAM-1 and thrombomodulin were measured in plasma from 21 patients, and E-selectin in serum from 18 patients. Cohort 2 comprised 15 ITP patients and 15 matched controls for measurement of markers of NET formation.

Informed consent was obtained from all patients and controls before obtaining the blood samples. The study was approved by the Institutional Review Board at Weill Medical College of Cornell University and the South-Eastern Norway Regional Committee for Medical and Health Research Ethics (2011/1747a).

\subsection{Blood sampling}

In patients, blood samples were collected prior to the initiation of TPO-RAs (day - 15 to day 0) (T1), and at two (T2) and six weeks (T3) ( \pm 2 days) after the initiation of treatment. One single blood sample was drawn from the controls. Venous blood samples were collected in serum tubes and in tubes containing ethylene-diamine-tetra-acetic acid (EDTA). After resting for $30 \mathrm{~min}$ (min.), serum tubes were centrifuged at $2000 \mathrm{~g}$ for $10 \mathrm{~min}$. EDTA whole blood tubes were immediately centrifuged at $2000 \mathrm{~g}$ for $15 \mathrm{~min}$, and plasma was obtained from the top supernatant. Aliquots of EDTA plasma and serum were stored at $-80{ }^{\circ} \mathrm{C}$ until analysed.

\subsection{Markers of endothelial cell activation}

Intercellular adhesion molecule-1 (ICAM-1), vascular cell adhesion molecule-1 (VCAM-1), and thrombomodulin were measured in plasma samples, and E-selectin in serum using commercial kits (Quantikine ELISA assay kits from R\&D Systems, Minneapolis, MI, USA) according to the manufacturer's instructions.

\subsection{Markers of neutrophil extracellular trap formation}

Citrullinated histone H3-DNA (H3Cit-DNA) was quantified in EDTAplasma using a sandwich ELISA according to the method proposed by other authors [29]. Using 96 microwell plates (Nunc Maxi Sorp, Thermo Scientific, Waltham, MA, USA), $50 \mu \mathrm{L}$ of the anti-H3Cit antibody (ab-5103, Abcam, Cambridge, MA, USA) (diluted 1:250 in carbonate-bicarbonate buffer ( $\mathrm{pH}$ 9.6)) was added to each well (overnight at $4{ }^{\circ} \mathrm{C}$ ). After washing the wells with phosphate-buffered saline (PBS) and blocking them with $5 \%$ bovine albumin, $50 \mu \mathrm{L}$ of EDTA plasma or PBS, was added to the wells and incubated for $2 \mathrm{~h}$ at room temperature (RT) on an orbital shaker. Then, the wells were washed again with PBS and $50 \mu \mathrm{L}$ of anti-DNA-peroxidase (POD) antibody (diluted 1:100 in incubation buffer (Cell Death Detection ELISA Kit, Roche Applied Science, Indianapolis, IN, USA)) was added and the plate incubated for $2 \mathrm{~h}$ at RT. After washing, $100 \mu \mathrm{L}$ of ABTS (2,2'-azinobis 3-ethylbenzthiazoline-6-sulfonic acid) peroxidase substrate (ThermoFisher Scientific, Madrid, Spain) was added to each well, and the plate was incubated for $2 \mathrm{~h}$ at RT in the dark. Finally, the optical density (OD) of the sample was measured at $405 \mathrm{~nm}$ wavelength using a microplate reader (BiotekSinergyHt, Izasa, Barcelona, Spain). The absorbance in the wells where only PBS was added was subtracted.

Cell free DNA (cfDNA) was quantified by using cell-impermeant SYTOX dye (ThermoFisher), that after binding to the free DNA emits fluorescence. EDTA-plasma from controls or patients was diluted 1:3 in Tris buffered buffer (TBS) and mixed 1:1 with $1 \mu \mathrm{M}$ of SYTOX dye in a 96-well plate, and the plate was incubated for $15 \mathrm{~min}$. in the dark. The fluorescence was measured (excitation $488 \mathrm{~nm}$, emission $528 \mathrm{~nm}$ ) in a plate reader (Biotek Sinergy $\mathrm{Ht}$ ), and the autofluorescence was subtracted. The DNA concentration in the samples was calculated by extrapolating to a standard line $(0-2.5 \mu \mathrm{g} / \mathrm{mL})$ of known concentrations of salmon sperm DNA (Sigma-Aldrich, Madrid, Spain). 


\subsection{Statistics}

Values were expressed either as medians and interquartile ranges (IQRs), or mean and standard deviations for non-normally and normally distributed parameters, respectively. Comparisons of data between ITP patients (with and without treatment with TPO-RAs) and healthy controls were carried out using the Kruskal-Wallis test with Dunn's multiple comparisons test. To compare data from ITP patients before and after initiation of treatment with TPO-RAs, the Friedman test with Dunn's multiple comparisons test was performed for the non-parametric data (ICAM-1, VCAM-1, H3Cit-DNA and cfDNA), and one-way ANOVA with Dunn's multiple comparisons for the parametric data (thrombomodulin and E-selectin). Statistical analyses were performed using GraphPad, Prism 7.0, and $p<0.05$ was considered as statistically significant.

\section{Results}

\subsection{Patients' demographics}

In cohort $1(n=29)$, the median age for ITP patients was 59 years (IQR 42-67) and for controls $(n=22) 55$ years (IQR $41-63)$; $52 \%$ of ITP patients and $55 \%$ of controls were females. In cohort $2(n=15)$, the median age for ITP patients was 61 years (IQR 44-66) and for controls ( $n=15) 59$ years (IQR 47-67); 53\% of ITP patients and controls were females (Table 1). The number of patients treated with each of the two TPO-RAs (Romiplostim, Eltrombopag), concomitant ITP therapy at inclusion of the study, and the number of splenectomized patients are also presented in Table 1. Platelet count in ITP patients before initiation of treatment with TPO-RAs, and in healthy controls, are also shown

Table 1

Characteristics of the study populations.

\begin{tabular}{lll}
\hline Cohort 1 & $\begin{array}{l}\text { Patients } \\
(n=29)\end{array}$ & Controls $(n=2$ \\
\hline Markers of endothelial cell activation/injury & & \\
Age in years, median (IQR) & $59(42-67)$ & $55(41-63)$ \\
Females, $n$ & 15 & 12 \\
Splenectomy, $n(\%)$ & $7(24)$ & 0 \\
Platelet count $\left(\cdot 10^{9} / \mathrm{L}\right)$, mean $(\mathrm{SD})^{\mathrm{a}}$ & $38(46)$ & $230(52)$ \\
Romiplostim, $n(\%)$ & $14(48)$ & \\
Eltrombopag, $n(\%)$ & $15(52)$ & \\
Concomitant ITP therapy at inclusion, $(n)$ & & \\
-Steroids & 13 & \\
-Intravenous immunoglobulins & 4 & \\
$\quad$-Immunosuppressants & 3 & \\
Other medications & & \\
$\quad$-Antihypertensives & 11 & \\
-Statins & 4 & \\
-Antidiabetics & 4 &
\end{tabular}

\begin{tabular}{lll}
\hline Cohort 2 & $\begin{array}{l}\text { Patients } \\
(n=15)\end{array}$ & Controls $(n=15)$ \\
\hline
\end{tabular}

Markers of NET formation

Age in years, mean (IQR)

Females, $n$

Splenectomy, $n(\%)$

Platelet count $\left(10^{9} / \mathrm{L}\right)$, mean $(\mathrm{SD})^{\mathrm{a}}$

Romiplostim, $n(\%)$

Eltrombopag, $n(\%)$

Concomitant ITP Therapy at inclusion $(n)$

-Steroids

-Intravenous immunoglobulins

-Immunosuppressants

Other medications

-Antihypertensives 8

-Statins 3

-Antidiabetics

\begin{tabular}{ll}
$61(44-66)$ & $59(47-67)$ \\
8 & 8 \\
$5(33)$ & 0 \\
$18(11)$ & $245(50)$ \\
$8(53)$ & \\
$7(47)$ & \\
8 & \\
1 & \\
1 & \\
8 & \\
3 & \\
4 & \\
\hline
\end{tabular}

${ }^{\text {a }}$ Platelet count in ITP patients before initiation of TPO-RA-treatment (T1) and in healthy controls.
(Table 1).

\subsection{ICAM-1, VCAM-1, E-selectin and thrombomodulin}

Compared with healthy controls, ITP patients had significantly higher baseline levels of ICAM-1 (351 ng/mL vs. $260 \mathrm{ng} / \mathrm{mL} ; p=0.02)$ and thrombomodulin $(5631 \mathrm{pg} / \mathrm{mL}$ vs. $4147 \mathrm{pg} / \mathrm{mL} ; p=0.002)$. The levels of ICAM-1 and thrombomodulin were higher at two weeks after the initiation of TPO-RA treatment $(321 \mathrm{ng} / \mathrm{mL}$ vs. $260 \mathrm{ng} / \mathrm{mL}$; $p=0.04$, and $5815 \mathrm{pg} / \mathrm{mL}$ vs. $4147 \mathrm{pg} / \mathrm{mL} ; p=0.0005$, respectively), and at six weeks after the initiation of TPO-RA treatment $(350 \mathrm{ng} / \mathrm{mL}$ vs. $260 \mathrm{ng} / \mathrm{mL} ; p=0.01$, and $5804 \mathrm{pg} / \mathrm{mL}$ vs. $4147 \mathrm{pg} / \mathrm{mL} ; p=0.0005$, respectively) compared with controls (Fig. 1). No significant differences in the levels of VCAM- 1 or E-selectin were found in ITP patients, neither before initiation of TPO-RA-treatment nor after two or six weeks of TPO-RA treatment, compared with controls. Furthermore, we did not find any significant changes in the levels of ICAM-1, VCAM-1, thrombomodulin or E-selectin at two weeks or six weeks after initiation of TPO-RAs, compared with pre-treatment levels.

\subsection{H3Cit-DNA and cfDNA}

The levels of H3Cit-DNA were significantly higher in ITP patients before initiating treatment with TPO-RAs, compared with controls ( 0.145 vs. $0.124 ; p=0.003)$. The levels of H3Cit-DNA were significantly higher in ITP patients also after two (0.182 vs. 0.124; $p=0.004)$ and six weeks ( 0.164 vs. $0.124 ; p=0.003)$ of TPO-RAtreatment, compared with controls (Fig. 2). There was no statistically significant difference in cfDNA between healthy controls and ITP patients before and after initiation of treatment with TPO-RAs. Furthermore, there were no significant changes in the levels of H3Cit-DNA or cfDNA after two and six weeks of treatment with TPO-RAs as compared with pre-treatment levels. No statistically significant correlations were found between H3Cit-DNA and ICAM-1/thrombomodulin.

\section{Discussion}

This study continued our group's exploration of the hypercoagulable state in ITP patients and the potential additive prothrombotic effect of TPO-RA-treatment. The ultimate goal was to find biomarkers that could identify ITP patients at increased risk of treatment-related thrombosis. This study showed that ITP patients, both before and after the initiation of TPO-RA-treatment, had elevated levels of markers of endothelial cell activation/injury (ICAM-1 and soluble thrombomodulin) and increased marker of NET formation (H3Cit-DNA), compared with controls. Our study also showed that treatment with TPO-RAs did not cause further increase in these markers. The lack of significant differences in the levels of the other measured markers VCAM-1, E-selectin and cfDNA between ITP patients and controls could be explained by the small sample size in this study. This is supported by another unpublished study by our group with larger sample size from another cohort of patients where both H3Cit-DNA and cfDNA were increased in ITP patients compared with controls [30].

Elevated plasma levels of ICAM-1 and thrombomodulin in ITP patients, both before and after treatment with TPO-RAs, suggest that there is ongoing endothelial cell activation/injury [31]. ICAM-1 is constitutively expressed at low levels on endothelial cells and its expression is upregulated upon stimulation. ICAM-1 plays a key role in leukocyte migration and activation [32]. Thrombomodulin is expressed by the endothelial cells and is an important component of the anticoagulation system, but it also regulates cellular adhesion to the endothelium [33]. Soluble thrombomodulin is shown to retain anticoagulant effect [34]. Activated/injured endothelium loses its thrombo-protective phenotype, promotes the recruitment and activation of platelets and neutrophils, and provides binding sites for coagulation factors [35]. The increased soluble thrombomodulin may therefore provide an anticoagulant effect 

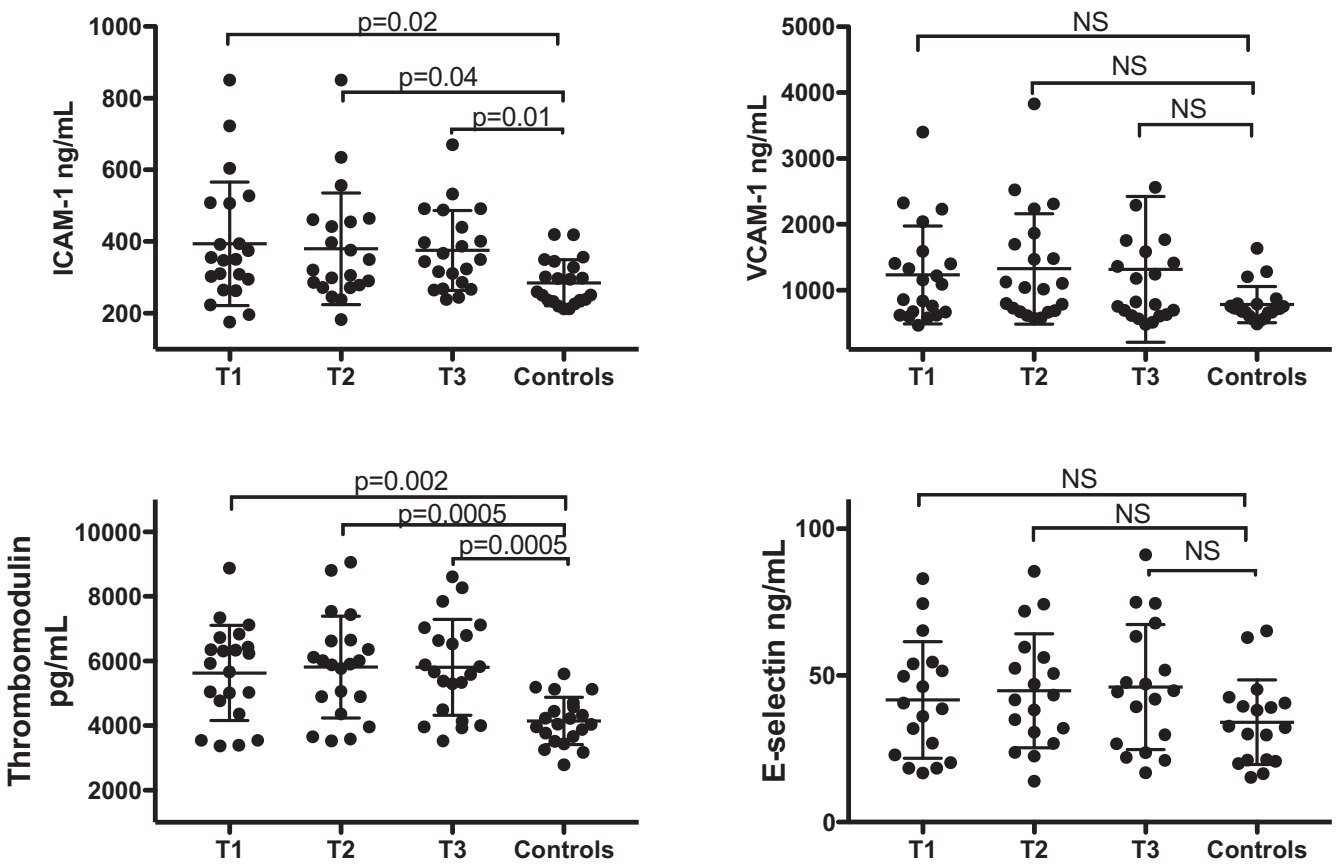

Fig. 1. Markers of endothelial cell activation/injury.

Measurements of ICAM-1, VCAM-1, thrombomodulin and E-selectin before (T1), two weeks (T2) and six weeks (T3) after initiation of TPO-RA treatment in ITP patients, and in controls. Kruskal-Wallis test with Dunn's multiple comparisons test was performed for comparisons between ITP patients (with and without treatment with TPORAs) and controls. NS (not significant; $p \geq 0.05$ ). to counterbalance the procoagulant property of activated endothelium.

A possible mechanism for the endothelial cell activation/injury in ITP is the cross reactivity of the autoantibodies against platelet membrane glycoprotein (GP)IIIa that are present in ITP patients to an immunologically related protein present on endothelial cell surfaces [36]. Moreover, platelet-derived microvesicles (MVs), that are shown to be increased in ITP [10,12], may also induce endothelial cell activation/ injury through potentiating the adhesion of monocytes to the endothelial cells [37]. In addition, patients with ITP have increased platelet activation [38]. Activated platelets secrete proinflammatory mediators that activate neutrophils and mediate platelet-neutrophil adhesion via P-selectin/P-selectin glycoprotein ligand-1 which in turn facilitates the adhesion of neutrophils to the endothelium and induces the expression of adhesion molecules by the endothelium [39]. Furthermore, NETs can also induce endothelial cell damage [40,41].

Increased proinflammatory cytokines including IL-8 [42], IL-1 $\beta$ [43], and IL-17 [44], as well as platelet activation in ITP can provoke the release of NETs [42,45]. The citrullinated histone H3 (H3Cit) is neutrophil specific and is considered as marker for NET formation [46]. Finding elevated levels of H3Cit-DNA in our ITP patients indicates increased NET formation. Studies have shown that NETs play a role in the initiation and propagation of venous thrombosis [22,23]. Extracellular histones, a component of NETs, can activate platelets promoting more thrombin generation mediated by platelet toll-like receptors- 2 and 4 [47]. In addition, NETs can bind plasma protein von Willebrand factor and fibrinogen [26], and provide surface for the activation of FXII leading to thrombin generation [27].
Treatment with TPO-RAs was not associated with further increase in markers of endothelial cell activation or NET formation. This may imply that the increased thrombotic risk in ITP patients treated with TPO-RAs is not mediated through increased endothelial cell activation or increased NET formation and that other mechanisms could be involved. In addition to increased soluble P-selectin, our group has previously shown that treatment with TPO-RAs was associated with increased phospholipid-dependent procoagulant activity of MVs leading to more thrombin generation [48]. Justo Sanz et al. has shown that TPO-RAtreatment increased platelet apoptosis, and increased plasma and platelet PAI-1 levels leading to a more fibrinolysis-resistant clot [49].

The main limitation of the study is the small sample size. However, repetitive measurements, before and after treatment with TPO-RAs, showed that these markers were consistently higher in ITP patients than in controls, thus strengthening our findings. We chose to follow up our patients and measure the markers reported at two and six weeks after initiating treatment with TPO-RAs. This timing could have led to missing changes in these markers occurring before the first sampling at two weeks and after the last sampling at six weeks. Another limitation is that a considerable proportion of our patients were on steroids. It has been shown that steroids reduce the levels of soluble ICAM-1, VCAM-1, and E-selectin [50]. Despite that, ICAM-1 was significantly higher in ITP patients. However, we cannot exclude that treatment with steroids may have reduced E-selectin and VCAM-1 levels in our patients. In addition, the presence of comorbidities, such as diabetes and hypertension and the use of medications such as statins, could also have an effect on the results.
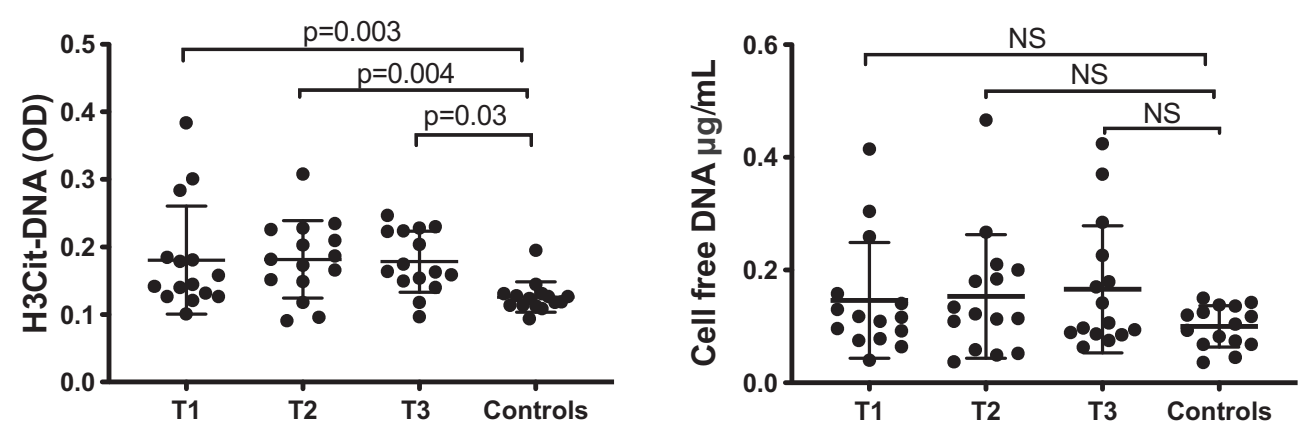

Fig. 2. Neutrophil Extracellular Trap (NET) formation.

H3Cit-DNA and cell free DNA before (T1), two weeks (T2) and six weeks (T3) after initiation of TPO-RA treatment in ITP patients, and in controls. Kruskal-Wallis test with Dunn's multiple comparisons test performed for comparisons between ITP patients (with and without treatment with TPO-RAs) and controls. NS (not significant; $p \geq 0.05$ ); OD (optical density). 
In conclusion, our study showed that ITP patients have increased ongoing endothelial cell activation and NET formation suggesting that these two mechanisms may contribute to the increased thrombotic propensity in ITP patients. However, treatment with TPO-RAs was not associated with further increase in endothelial cell activation or NET formation. This may imply that the prothrombotic characteristics of TPO-RAs treatment seen in ITP patients are through other mechanisms.

\section{Declaration of competing interest}

ML.L. has received research support from Amgen, and lecture honoraria from Amgen and Novartis. W.G. has received research support from Novartis, and lecture honoraria from Amgen and Novartis. J.B.B. has received research support from Amgen and Novartis, has been a consultant at Novartis, and has participated in advisory board for Amgen and Novartis.

\section{References}

[1] M. Norgaard, K. Cetin, M.L. Maegbaek, N.R. Kristensen, W. Ghanima, S. Bahmanyar, S. Stryker, C.F. Christiansen, Risk of arterial thrombotic and venous thromboembolic events in patients with primary chronic immune thrombocytopenia: a Scandinavian population-based cohort study, Br. J. Haematol. 174 (4) (2016) 639-642.

[2] A. Sarpatwari, D. Bennett, J.W. Logie, A. Shukla, K.J. Beach, A.C. Newland, S. Sanderson, D. Provan, Thromboembolic events among adult patients with primary immune thrombocytopenia in the United Kingdom General Practice Research Database, Haematologica 95 (7) (2010) 1167-1175.

[3] M. Ruggeri, A. Tosetto, F. Palandri, N. Polverelli, M.G. Mazzucconi, C. Santoro, G. Gaidano, M. Lunghi, F. Zaja, V. De Stefano, R. Sartori, P. Fazi, F. Rodeghiero, E.d.A.A. Gruppo Italiano Malattie, G.S.I.T.P. Thrombocytopenias Working Party, Thrombotic risk in patients with primary immune thrombocytopenia is only mildly increased and explained by personal and treatment-related risk factors, J. Thromb. Haemost. 12 (8) (2014) 1266-1273.

[4] M. Wittstock, R. Benecke, U.K. Zettl, Therapy with intravenous immunoglobulins: complications and side-effects, Eur. Neurol. 50 (3) (2003) 172-175.

[5] F. Catala-Lopez, I. Corrales, C. de la Fuente-Honrubia, D. Gonzalez-Bermejo, G. Martin-Serrano, D. Montero, D.M. Saint-Gerons, Risk of thromboembolism with thrombopoietin receptor agonists in adult patients with thrombocytopenia: systematic review and meta-analysis of randomized controlled trials, Med. Clin. (Barc.) 145 (12) (2015) 511-519.

[6] F. Rodeghiero, Is ITP a thrombophilic disorder? Am. J. Hematol. 91 (1) (2016) $39-45$.

[7] M.N. Saleh, J.B. Bussel, G. Cheng, O. Meyer, C.K. Bailey, M. Arning, A. Brainsky, E.S. Group, Safety and efficacy of eltrombopag for treatment of chronic immune thrombocytopenia: results of the long-term, open-label EXTEND study, Blood 121 (3) (2013) 537-545.

[8] D.J. Kuter, J.B. Bussel, A. Newland, R.I. Baker, R.M. Lyons, J. Wasser, J.F. Viallard, G. Macik, M. Rummel, K. Nie, S. Jun, Long-term treatment with romiplostim in patients with chronic immune thrombocytopenia: safety and efficacy, Br. J Haematol. 161 (3) (2013) 411-423.

[9] S. Karpatkin, Heterogeneity of human platelets. II. Functional evidence suggestive of young and old platelets, J. Clin. Invest. 48 (6) (1969) 1083-1087.

[10] E.M. Sewify, D. Sayed, R.F. Abdel Aal, H.M. Ahmad, M.A. Abdou, Increased circulating red cell microparticles (RMP) and platelet microparticles (PMP) in immune thrombocytopenic purpura, Thromb. Res. 131 (2) (2013) e59-e63.

[11] K.J. Kim, I.W. Baek, C.H. Yoon, W.U. Kim, C.S. Cho, Thrombotic risk in patients with immune thrombocytopenia and its association with antiphospholipid antibodies, Br. J. Haematol. 161 (5) (2013) 706-714.

[12] M.T. Alvarez Roman, I. Fernandez Bello, E.G. Arias-Salgado, M.I. Rivas Pollmar, V. Jimenez Yuste, M. Martin Salces, N.V. Butta, Effects of thrombopoietin receptor agonists on procoagulant state in patients with immune thrombocytopenia, Thromb. Haemost. 112 (1) (2014) 65-72.

[13] M.T. Alvarez-Roman, I. Fernandez-Bello, V. Jimenez-Yuste, M. Martin-Salces, E.G. Arias-Salgado, M.I. Rivas Pollmar, R. Justo Sanz, N.V. Butta, Procoagulant profile in patients with immune thrombocytopenia, Br. J. Haematol. 175 (5) (2016) 925-934.

[14] P. Verhamme, M.F. Hoylaerts, The pivotal role of the endothelium in haemostasis and thrombosis, Acta Clin. Belg. 61 (5) (2006) 213-219.

[15] S.R. Ostrowski, N. Haase, R.B. Muller, M.H. Moller, F.C. Pott, A. Perner, P.I. Johansson, Association between biomarkers of endothelial injury and hypocoagulability in patients with severe sepsis: a prospective study, Crit. Care 19 (2015) 191.

[16] L. Garabet, W. Ghanima, C. Monceyron Jonassen, V. Skov, R. Holst, M.C. Mowinckel, C.H. H, A.K. T, M. Thomassen, H. Liebman, J.B. Bussel, P.M. Sandset, Effect of thrombopoietin receptor agonists on markers of coagulation and P-selectin in patients with immune thrombocytopenia, Platelets 30 (2) (2019) 206-212

[17] Guidelines for the investigation and management of idiopathic thrombocytopenic purpura in adults, children and in pregnancy, Br. J. Haematol. 120 (4) (2003)
574-596.

18] K. Yamamoto, K. Takeshita, T. Kojima, J. Takamatsu, H. Saito, Aging and plasminogen activator inhibitor-1 (PAI-1) regulation: implication in the pathogenesis of thrombotic disorders in the elderly, Cardiovasc. Res. 66 (2) (2005) 276-285.

[19] K. Martinod, D.D. Wagner, Thrombosis: tangled up in NETs, Blood 123 (18) (2014) 2768-2776.

[20] T.A. Fuchs, U. Abed, C. Goosmann, R. Hurwitz, I. Schulze, V. Wahn, Y. Weinrauch, V. Brinkmann, A. Zychlinsky, Novel cell death program leads to neutrophil extracellular traps, J. Cell Biol. 176 (2) (2007) 231-241.

[21] V. Brinkmann, U. Reichard, C. Goosmann, B. Fauler, Y. Uhlemann, D.S. Weiss, Y. Weinrauch, A. Zychlinsky, Neutrophil extracellular traps kill bacteria, Science 303 (5663) (2004) 1532-1535.

[22] A. Brill, T.A. Fuchs, A.S. Savchenko, G.M. Thomas, K. Martinod, S.F. De Meyer, A.A. Bhandari, D.D. Wagner, Neutrophil extracellular traps promote deep vein thrombosis in mice, J. Thromb. Haemost. 10 (1) (2012) 136-144.

[23] M.L. von Bruhl, K. Stark, A. Steinhart, S. Chandraratne, I. Konrad, M. Lorenz, A. Khandoga, A. Tirniceriu, R. Coletti, M. Kollnberger, R.A. Byrne, I. Laitinen, A. Walch, A. Brill, S. Pfeiler, D. Manukyan, S. Braun, P. Lange, J. Riegger, J. Ware, A. Eckart, S. Haidari, M. Rudelius, C. Schulz, K. Echtler, V. Brinkmann, M. Schwaiger, K.T. Preissner, D.D. Wagner, N. Mackman, B. Engelmann, S. Massberg, Monocytes, neutrophils, and platelets cooperate to initiate and propagate venous thrombosis in mice in vivo, J. Exp. Med. 209 (4) (2012) 819-835.

[24] O.J. de Boer, X. Li, P. Teeling, C. Mackaay, H.J. Ploegmakers, C.M. van der Loos, M.J. Daemen, R.J. de Winter, A.C. van der Wal, Neutrophils, neutrophil extracellular traps and interleukin-17 associate with the organisation of thrombi in acute myocardial infarction, Thromb. Haemost. 109 (2) (2013) 290-297.

[25] O. Elaskalani, N.B. Abdol Razak, P. Metharom, Neutrophil extracellular traps induce aggregation of washed human platelets independently of extracellular DNA and histones, Cell. Commun. Signal. 16 (1) (2018) 24.

[26] T.A. Fuchs, A. Brill, D. Duerschmied, D. Schatzberg, M. Monestier, D.D. Myers Jr., S.K. Wrobleski, T.W. Wakefield, J.H. Hartwig, D.D. Wagner, Extracellular DNA traps promote thrombosis, Proc. Natl. Acad. Sci. U. S. A. 107 (36) (2010) $15880-15885$

[27] Y. Wang, L. Luo, O.O. Braun, J. Westman, R. Madhi, H. Herwald, M. Morgelin, H. Thorlacius, Neutrophil extracellular trap-microparticle complexes enhance thrombin generation via the intrinsic pathway of coagulation in mice, Sci. Rep. \& (1) (2018) 4020

[28] V. Papayannopoulos, Neutrophil extracellular traps in immunity and disease, Nat. Rev. Immunol. 18 (2) (2018) 134-147.

[29] E. Lefrancais, B. Mallavia, H. Zhuo, C.S. Calfee, M.R. Looney, Maladaptive role of neutrophil extracellular traps in pathogen-induced lung injury, JCI Insight 3 (3) (2018).

[30] M.L. Lozano, M.P. Fernandez-Perez, A.M. De Los Reyes-Garcia, P. Diaz-Lozano, N. Garcia-Barbera, L. Garabet, W. Ghanima, C. Martinez, R. Gonzalez-Conejero, Neutrophil extracellular traps (NETs), blood cell counts and thrombotic risk in ITP patients, European Haematology Association, HemaSphere, Amsterdam (2019) 689-690.

[31] J. Constans, C. Conri, Circulating markers of endothelial function in cardiovascular disease, Clin. Chim. Acta 368 (1-2) (2006) 33-47.

[32] N. Hogg, P.A. Bates, J. Harvey, Structure and function of intercellular adhesion molecule-1, Chem. Immunol. 50 (1991) 98-115.

[33] H.C. Huang, G.Y. Shi, S.J. Jiang, C.S. Shi, C.M. Wu, H.Y. Yang, H.L. Wu, Thrombomodulin-mediated cell adhesion: involvement of its lectin-like domain, J. Biol. Chem. 278 (47) (2003) 46750-46759.

[34] A.K. Ohlin, K. Larsson, M. Hansson, Soluble thrombomodulin activity and soluble thrombomodulin antigen in plasma, J. Thromb. Haemost. 3 (5) (2005) 976-982.

[35] L. Ivanciu, S. Krishnaswamy, R.M. Camire, New insights into the spatiotemporal localization of prothrombinase in vivo, Blood 124 (11) (2014) 1705-1714.

[36] P. Thiagarajan, S.S. Shapiro, E. Levine, L. DeMarco, A. Yalcin, A monoclonal antibody to human platelet glycoprotein IIIa detects a related protein in cultured human endothelial cells, J. Clin. Invest. 75 (3) (1985) 896-901.

[37] O.P. Barry, D. Pratico, R.C. Savani, G.A. FitzGerald, Modulation of monocyte-endothelial cell interactions by platelet microparticles, J. Clin. Invest. 102 (1) (1998) 136-144.

[38] B. Psaila, J.B. Bussel, M.D. Linden, B. Babula, Y. Li, M.R. Barnard, C. Tate, K. Mathur, A.L. Frelinger, A.D. Michelson, In vivo effects of eltrombopag on platelet function in immune thrombocytopenia: no evidence of platelet activation, Blood 119 (17) (2012) 4066-4072.

[39] S.J. Kim, C.N. Jenne, Role of platelets in neutrophil extracellular trap (NET) production and tissue injury, Semin. Immunol. 28 (6) (2016) 546-554.

[40] M. Saffarzadeh, C. Juenemann, M.A. Queisser, G. Lochnit, G. Barreto, S.P. Galuska, J. Lohmeyer, K.T. Preissner, Neutrophil extracellular traps directly induce epithelial and endothelial cell death: a predominant role of histones, PLoS One 7 (2) (2012) e32366.

[41] C. Carmona-Rivera, W. Zhao, S. Yalavarthi, M.J. Kaplan, Neutrophil extracellular traps induce endothelial dysfunction in systemic lupus erythematosus through the activation of matrix metalloproteinase-2, Ann. Rheum. Dis. 74 (7) (2015) $1417-1424$.

[42] M.J. Wang, Y.G. Xu, X.Q. Ding, R.C. Quan, H.Y. Chen, Z.Y. Deng, P. Zhao, T. Fan, S.R. Zhu, X.M. Hu, [Secretory Imbalance between Pro-inflammatory and Anti-inflammatory Cytokines in the Patients with Immune Thrombocytopenia], Zhongguo Shi Yan Xue Ye Xue Za Zhi/Zhongguo Bing Li Sheng Li Xue Hui = Journal of Experimental Hematology/Chinese Association of Pathophysiology 26 (2) (2018) 522-527.

[43] P. Sil, H. Wicklum, C. Surell, B. Rada, Macrophage-derived IL-1beta enhances monosodium urate crystal-triggered NET formation, Inflamm. Res. 66 (3) (2017) 
$227-237$

44] E. Frangou, A. Chrysanthopoulou, A. Mitsios, K. Kambas, S. Arelaki, I. Angelidou, A. Arampatzioglou, H. Gakiopoulou, G.K. Bertsias, P. Verginis, K. Ritis,

D.T. Boumpas, REDD1/autophagy pathway promotes thromboinflammation and fibrosis in human systemic lupus erythematosus (SLE) through NETs decorated with tissue factor (TF) and interleukin-17A (IL-17A), Ann. Rheum. Dis. 78 (2) (2019) 238-248.

[45] S.R. Clark, A.C. Ma, S.A. Tavener, B. McDonald, Z. Goodarzi, M.M. Kelly, K.D. Patel, S. Chakrabarti, E. McAvoy, G.D. Sinclair, E.M. Keys, E. Allen-Vercoe, R. Devinney, C.J. Doig, F.H. Green, P. Kubes, Platelet TLR4 activates neutrophil extracellular traps to ensnare bacteria in septic blood, Nat. Med. 13 (4) (2007) 463-469.

[46] L.M. Mauracher, F. Posch, K. Martinod, E. Grilz, T. Daullary, L. Hell, C. Brostjan, C. Zielinski, C. Ay, D.D. Wagner, I. Pabinger, J. Thaler, Citrullinated histone H3, a biomarker of neutrophil extracellular trap formation, predicts the risk of venous thromboembolism in cancer patients, J. Thromb. Haemost. 16 (3) (2018) 508-518.

[47] F. Semeraro, C.T. Ammollo, J.H. Morrissey, G.L. Dale, P. Friese, N.L. Esmon,
C.T. Esmon, Extracellular histones promote thrombin generation through plateletdependent mechanisms: involvement of platelet TLR2 and TLR4, Blood 118 (7) (2011) 1952-1961.

[48] L. Garabet, W. Ghanima, M. Hellum, P.M. Sandset, J.B. Bussel, H. Tran, C.E. Henriksson, Increased microvesicle-associated thrombin generation in patients with immune thrombocytopenia after initiation of thrombopoietin receptor agonists, Platelets (2019) 1-7.

[49] R. Justo Sanz, E. Monzon Manzano, I. Fernandez Bello, M. Teresa Alvarez Roman, M. Martin Salces, M.I. Rivas Pollmar, V. Jimenez Yuste, N.V. Butta, Platelet apoptosis and PAI-1 are involved in the pro-coagulant state of immune thrombocytopaenia patients treated with thrombopoietin receptor agonists, Thromb. Haemost. 119 (4) (2019) 645-659.

[50] K.A. Zielinska, L. Van Moortel, G. Opdenakker, K. De Bosscher, P.E. Van den Steen, Endothelial response to glucocorticoids in inflammatory diseases, Front. Immunol. 7 (2016) 592. 